\title{
Glutamine, an essential nutrient for the gut
}

Citation for published version (APA):

van der Hulst, R. R. W. J. (1996). Glutamine, an essential nutrient for the gut. [Doctoral Thesis, Maastricht University]. Rijksuniversiteit Limburg. https://doi.org/10.26481/dis.19960606rh

Document status and date:

Published: 01/01/1996

DOI:

10.26481/dis.19960606rh

Document Version:

Publisher's PDF, also known as Version of record

\section{Please check the document version of this publication:}

- A submitted manuscript is the version of the article upon submission and before peer-review. There can be important differences between the submitted version and the official published version of record.

People interested in the research are advised to contact the author for the final version of the publication, or visit the DOI to the publisher's website.

- The final author version and the galley proof are versions of the publication after peer review.

- The final published version features the final layout of the paper including the volume, issue and page numbers.

Link to publication

\footnotetext{
General rights rights.

- You may freely distribute the URL identifying the publication in the public portal. please follow below link for the End User Agreement:

www.umlib.nl/taverne-license

Take down policy

If you believe that this document breaches copyright please contact us at:

repository@maastrichtuniversity.nl

providing details and we will investigate your claim.
}

Copyright and moral rights for the publications made accessible in the public portal are retained by the authors and/or other copyright owners and it is a condition of accessing publications that users recognise and abide by the legal requirements associated with these

- Users may download and print one copy of any publication from the public portal for the purpose of private study or research.

- You may not further distribute the material or use it for any profit-making activity or commercial gain

If the publication is distributed under the terms of Article $25 \mathrm{fa}$ of the Dutch Copyright Act, indicated by the "Taverne" license above, 
Glutamine, an essential nutrient for the gut 
Glutamine, an essential nutrient for the gut 
Glutamine, an essential nutrient for the gut

\section{Proefschrift}

ter verkrijging van de graad van doctor, aan de Rijksuniversiteit Limburg te Maastricht, op gezag van de Rector Magnificus, Prof. mr. M.J. Cohen, volgens het besluit van het College van Dekanen, in het openbaar te verdedigen op donderdag 6 juni 1996 om 14.00 uur door

René Remmelt Willie Johan van der Hulst geboren te Heerlen op 3 juni 1966 
Promotores:

Prof.dr. M.F. von Meyenfeldt

Prof.dr. P.B. Soeters

Beoordelingscommissie:

Prof. Dr. R.W. Stockbrügger (voorzitter)

Prof. Dr. J.W. Arends

Dr. K.C.H. Fearon (University of Edinburgh)

Prof. Dr. H.S.A. Heymans (Universiteit van Amsterdam)

Prof. Dr. H.P. Sauerwein (Universiteit van Amsterdam)

De publicatie van dit proefschrift werd financieel mogelijk gemaakt door

Pharmacia-Upjohn

Grafische vormgeving: Guus Vrencken 960506

Drukwerk: Datawyse I Universitaire Pers Maastricht

ISBN: 90-900-9518-7 
...Anaesthesia was given entirely by alcoholic intoxication, which is curious since the Hindus were otherwise forbidden to drink liquor. The ban against eating beef, too, could be suspended by a surgeon: it was said that the sick and weak should fortify themselves with an animal diet.....

(Surgery in the time of Susruta, 800 BC - 400 $A C$. In: The illustrated history of surgery) 
....Anaesthesia was given entirely by a/coholic intoxication, which is curious since the Hindus were otherwise forbidden to drink liquor. The ban against eating beef, too, could be suspended by a surgeon: it was said that the sick and weak should fortify themselves with an animal diet....

(Surgery in the time of Susruta, 800 BC - 400 $A C$. In: The illustrated history of surgery) 
1 Introduction

2 Glutamine extraction by the gut and the effect of nutritional depletion

3 Nutritional depletion and mucosal glutamine concentration

4 Nutritional depletion and gut permeability

5 The role of parenteral glutamine administration in preserving mucosal glutamine concentration

6 The role of parenteral glutamine administration in preserving gut integrity

7 The role of parenteral glutamine administration in gut immune function

8 General discussion

9 Summary and conclusions

Samenvatting en conclusies

Dankwoord

Curriculum vitae 
Chapter 1

2

3

4

5

6

7

8

9 


\section{Introduction}


Studley was the first in 1936 to describe a relationship between nutritional depletion and postoperative mortality and morbidity (1). Subsequently, numerous papers have been published confirming the association between nutritional status and postoperative outcome (2-4). However, many parameters used to assess nutritional depletion are not only affected by nutritional status but also by disease activity $(5,6)$. The effect of nutritional depletion on the postoperative course therefore must be studied in relation to the presence of disease and other risk factors for postoperative complications. In a recently performed study an independent effect of nutritional status on postoperative outcome was confirmed (7). Although already 60 years ago the association between nutritional status and postoperative course was reported, the pathophysiological mechanism underlying this association remains largely unknown. The cause of nutritional depletion has been studied extensively. Depending on the type of disease, decreased food intake or changes in protein and energy metabolism, or a combination of both results in loss of body weight and more importantly of body cell mass (8). In the healthy person starvation evokes mechanisms preserving body protein stores. There is a switch towards increased usage of fatty acids as an energy source, thereby reducing the need for gluconeogenesis and subsequently reducing protein catabolism. In disease, however, despite decreased nutrient intake, there is an ongoing loss of body protein sources. In mild disease protein synthesis is decreased whereas protein degradation is unaltered. With increased metabolic stress protein synthesis and degradation are both increased although protein degradation is accelerated to a higher degree. In both situations this results in net protein loss, resulting in loss of fat-free mass and specifically body cell mass (9-11).

The exact reason for an increased protein turnover in severe metabolic stress is not known. An explanation may be that the increased fluxes of amino acids provide substrate, essential for the immune system and the gut. The ongoing negative protein balance will eventually result in a depletion of body protein and consequently a decreased availability of essential substrates. A very important substrate in this context is the amino acid glutamine.

Glutamine is a classical non-essential amino acid, implying that it is produced at a sufficient rate to adequately supply glutamine consuming tissues. Of all the amino acids that are incorporated into protein glutamine is the most abundant in the human body. Its blood concentration varies between 0.4 and $0.9 \mathrm{mmol} / \mathrm{l}(12)$, which is the highest of all amino acids. Excluding taurine, which is a non-proteinogenic amino acid, $50 \%$ of the total free amino acid pool consists of glutamine. In addition, glutamine is the amino acid with the most versatile function of all amino acids (13) (table 1). Glutamine has two nitrogen residues (an amino and an amide group), making it quantitatively the most important non-toxic nitrogen "transporter", accounting for $35 \%$ of all amino acid nitrogen transported in the blood. Glutamine also serves as a non-toxic carrier for ammonia. The first step in the degradation of glutamine is a deamidation step, yielding ammonia. Degradation of glutamine mainly takes place in tissues that are anatomically situated in such a way that the subsequent release of ammonia is without risk because the ammonia is either excreted (kidney) or converted to urea (liver). Consequently, glutamine is the most important substrate for ammoniagenesis allowing it to play a role in the regulation of acid/base homeostasis in the 
Transport of nitrogen and carbon

Provides substrate for protein synthesis

Regulator of protein synthesis and degradation

Determinator of life span of specific proteins

Stimulates hepatic glycogen synthesis

Precursor for gluconeogenesis in liver

Metabolic fuel for rapidly replicating cells (enterocytes, lymphocytes, tubular cells)

Provides precursors for nucleic acid biosynthesis

Ammoniagenesis (acid-base regulation)

Table 1. Major functions of L-glutamine metabolism in man.

In italics: these functions are suggested.

kidney $(14,15)$. Glutamine may be involved in the regulation of protein synthesis and provides precursors for nucleotide and protein synthesis (13). Most importantly, however, glutamine is the major fuel for rapidly replicating cells, such as immune cells, enterocytes and renal tubular cells (16-18). The main site of production of glutamine in the post-absorptive state is muscle tissue $(19,20)$. Because the extent of glutamine production capacity greatly exceeds the amount of glutamine incorporated in protein and present in the intracellular pool, glutamine must be largely derived from de novo synthesis. It has been demonstrated that the most important nitrogen donors for this de novo synthesis are the branched chain amino acids released by protein breakdown (21). Glutamine may also be released from the brain, heart, lungs and adipose tissue although these organs are probably quantitatively less important (22-27). Uptake of glutamine largely takes place in the splanchnic area (gut, spleen, pancreas)(28), kidney (29) and by the immune system $(20,30,31)$. The liver is capable of both synthesizing and degrading glutamine, depending on several factors like ammonia concentration, $\mathrm{pH}$ and degree of metabolic stress. Under normal non-stressed physiological conditions, however, the breakdown and the synthesis of glutamine in the liver are similar resulting in a close to zero liver glutamine balance in non-stressed conditions (32) (figure 1).

From work carried out over the past two decades it is now clear that glutamine is involved in multiple biochemical cell reactions and has important roles in tissue-specific and inter-tissue physiology. It was recognized that free glutamine concentrations in muscle are markedly reduced during conditions involving metabolic stress $(13,33)$. From these observations the non-essential character of glutamine was questioned, and exogenous supply was considered of potential benefit during metabolic stress. A decline of the glutamine "pool " was thought to have especially consequences for tissues consuming glutamine at high rates such as the gut and the immune tissues. In addition to the obligatory physiological role in digestion and absorption of nutrients, the gut has an important function in providing a highly effective barrier against the entry of microorganisms and toxins from the gut to the systemic circulation (3438). The factors that enhance and preserve this gut barrier are not completely understood. An important factor, however, appears to be the adequate delivery of glutamine to the gut as a fuel for enterocytes as well as for the numerous immune cells 


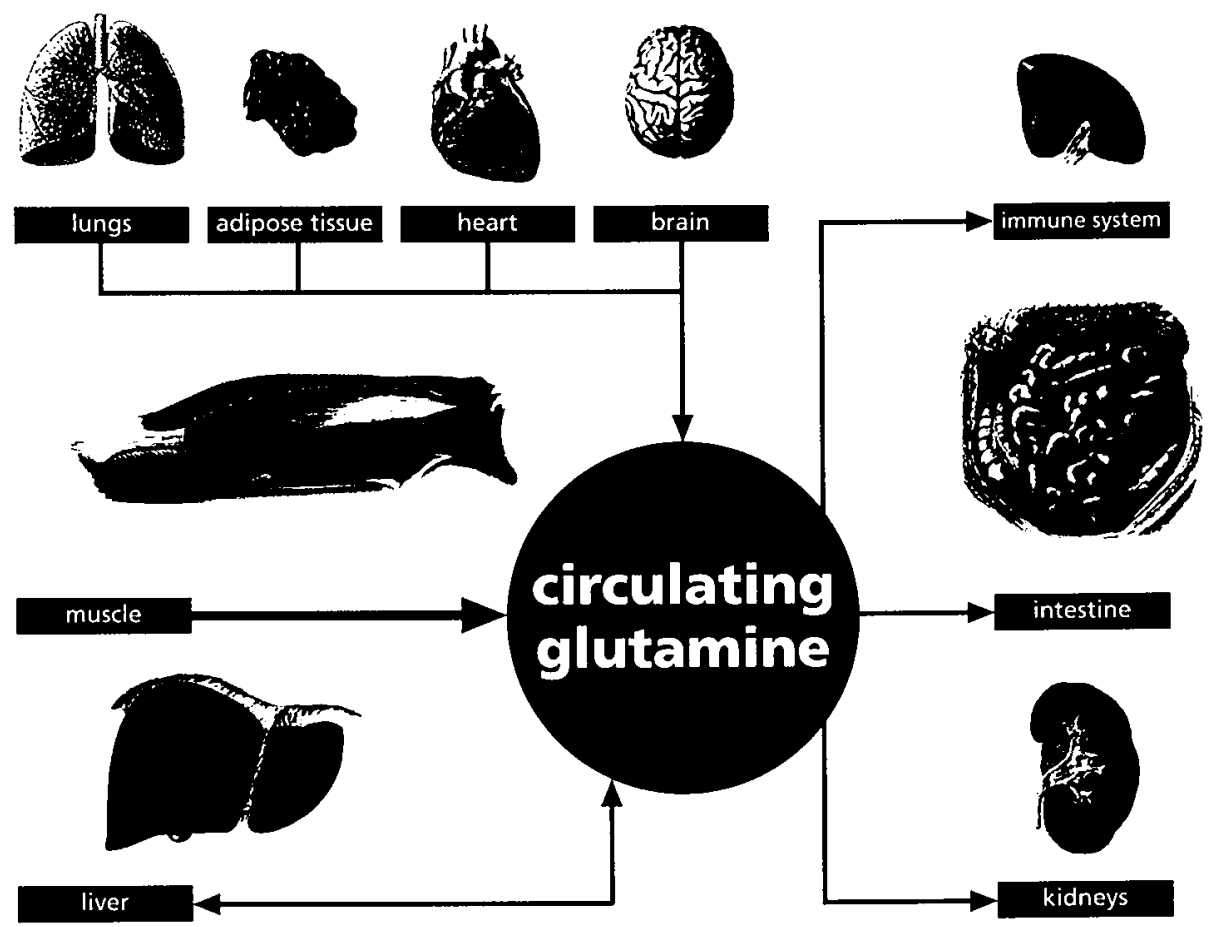

Figure 1. Interorgan fluxes of glutamine

situated in the gut.

In the stressed and diseased state patients often do not receive enteral nutrition. These patients are either starved or receive parenteral nutrition. Parenteral nutrition does not contain glutamine because of the relative instability of this amino acid during prolonged storage and heat sterilization. The consequence is that stressed patients often do not receive exogenous glutamine in situations where there is an increased glutamine demand by tissues involved in the immune response to surgical stress as can be concluded from the increased efflux of glutamine from muscle tissue and increased uptake by the liver and spleen (39). In addition, it is possible that an impaired capacity to produce glutamine is present in nutritionally depleted patients, due to loss of body protein stores and hypothetically as a consequence due to a diminution of the machinery to produce glutamine. A decreased capacity to produce glutamine on the one hand and an increase in demand on the other hand may result in impaired immune function as well as in breakdown of the intestinal barrier, potentially leading to cholestasis (40) and infections.

Based on these observations the general hypothesis of this thesis is that nutritional depletion results in decreased muscle tissue and/or changes in intermediary metabolism leading to a diminished glutamine producing capacity. This results in a decrease in the plasma glutamine concentration resulting in a decreased availability and uptake 
of glutamine by the gut. Experiments in our own laboratory have demonstrated that parts of the immune system (liver and spleen) switch from release of glutamine to uptake after trauma. Although this is not the specific object of this thesis, we hypothesize that in the depleted state (loss of muscle mass) the capacity to produce glutamine to provide the immune system with essential substrate is diminished. As a consequence of diminished availability of glutamine a deterioration of the gut mucosa barrier is expected. The process is amplified by factors such as decreased exogenous supply of glutamine and increased glutamine demand by the immune system. Exogenous supply of glutamine may attenuate deterioration of the gut barrier and restore immune function. The several steps of the hypothesis are depicted in figure 2 . The following steps are studied in this thesis:

1) Nutritional depletion results in a diminished plasma glutamine concentration (chapter 2 and 3).

2) Gut glutamine uptake depends on the plasma glutamine concentration (chapter 2).

3) Diminished gut glutamine uptake results in decreased mucosa glutamine concentration (chapter 3).

4) Diminished mucosa glutamine supply results in changes in gut morphology, immune status and intestinal permeability (chapter 4).

5) Exogenous parenteral glutamine supply increases glutamine concentrations in the mucosa (chapter 5).

6) Increased mucosa glutamine supply is beneficial for the intestinal morphology and intestinal permeability (chapter 6).

7) Increased mucosa glutamine supply is beneficial for the gut immune status (chapter 7)

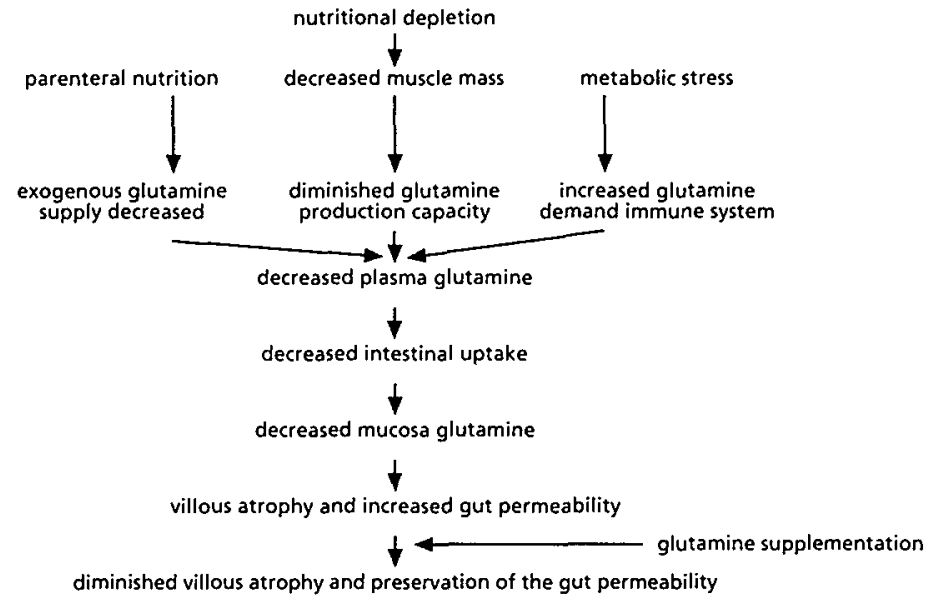

Figure 2. Hypothesis of this thesis. 


\subsection{Summary of background data}

Glutamine metabolism in disease

Catabolism is characterized by a negative nitrogen balance across muscle tissue. Alanine and glutamine together make up $50 \%$ of the amino acids released from peripheral tissues (e.g. muscle) during metabolic stress. This is associated with an increased uptake of alanine by the liver and glutamine by the liver and spleen. The increased efflux of amino acids allows an increase in gluconeogenesis and synthesis of essential proteins in the liver. Glutamine release specifically is thought to, at least partially, reflect increased demand by immune tissue in liver and spleen (39). In addition, glutamine utilization and as a consequence ammonia production by the kidney is increased which facilitates the excretion of acid equivalents by buffering with ammonia. The nitrogen residue liberated in the liver as a result of breakdown of amino acids is converted to urea and excreted in the urine. Increased urinary nitrogen loss is thus a hallmark of the metabolic stress response. The ongoing negative nitrogen balance causes loss of functional proteins and an approximatively $50 \%$ fall of muscle glutamine concentration (41). Glutamine plasma concentrations fall with $10 \%$ to $30 \%$ and only slowly return to normal values (42) indicating convalescence (43).

The causes of the ongoing release of glutamine by skeletal muscle tissue during metabolic stress is not exactly known. It has been hypothesized that glutamine demand by the splanchnic area directly regulates the release of glutamine from skeletal muscle tissue (44-46). Recently this hypothesis was questioned because enterectomy in rats was shown to have no effect on skeletal muscle glutamine release (47). Complex interactions between the effects of starvation and enterectomy may explain the differences in the results of such studies. Furthermore, some studies in which glutamine uptake by the gut was investigated were performed in splenectomized animals (48). As the spleen is an important glutamine consuming organ, studies in splenectomized animals may not adequately reflect physiological interorgan regulation of glutamine flux. The possibility of the immune system being a regulator of changes in glutamine flux appears to be a challenge for future research. This process may be mediated by the production of cytokines such as II- 1 and II-6 $(42,49,50)$. The degree of reduction of circulating glutamine is mainly determined by the degree of stress and is correlated with levels of the cytokine interleukin- 6 (IL-6) (42). Increased II-6 levels are associated with decreased glutamine levels. II-6 is one of the cytokines involved in the regulation of the acute-phase response and reflects the degree of injury (51). In addition, IL-6 predicts the risk of a complicated postoperative outcome (42). It is hypothesized that IL- 6 may regulate uptake of glutamine by immune cells thus enabling the immune system to respond to a challenge e.g. major surgery (42).

Until recently skeletal muscle was considered to be the principal site of glutamine release. Animal experiments have suggested that the lungs also may play a role in glutamine production $(22,23,52-54)$. The lungs are suggested to play a role in the increased release of glutamine after surgical stress (23). However, it seems unlikely that the lung, being a small organ containing relatively little protein and little glycogen allowing delivery of carbon skeletons, is of significance in whole body glutamine homeostasis. In man glutamine production by the lung was not observed in patients 
undergoing celiotomy (55). In addition, in patients undergoing coronary bypass surgery no glutamine production was observed after surgery (56) (figure 3). Despite the fact that the high bloodflow through the lungs in contribution with very low transorgan concentration differences of glutamine, would still lead to significant glutamine fluxes we nevertheless on the basis of the above considerations propose that the lungs do not seem to have a significant contribution to whole body glutamine production in man.

Although the changes in glutamine metabolism in the different types of metabolic stress share similarities, specific alterations depending on the kind of stress are also observed. The changes in interorgan glutamine fluxes during surgical stress (surgery, trauma) are thought to be principally mediated by glucocorticoids. Glucocorticoids are shown to increase efflux of glutamine from muscle tissue. In addition, glucocorticoids increase gut glutamine consumption (34). This process seems to be mediated by an in increased glutaminase activity and glutaminase gene expression in lymphoid tissue and the gut (57-59). If surgery is uncomplicated the reduction in circulating glutamine is temporary but lasts for at least several weeks (60). This coincides with the depressing effect of elective surgery on muscle protein synthesis and the feeling of well-being of the patient (61).

In severe metabolic stress such as sepsis the changes in amino acid fluxes are more extensive compared to the changes after surgical stress. Muscle glutamine levels may decrease with $95 \%$ of the normal concentration $(62,63)$. Plasma amino acids decrease with about $50 \%(62-64)$. In addition, glutamine consumption by the portal drained viscera is decreased (65). This is different in the postoperative situation where an increase in glutamine consumption by the portal drained viscera is reported (48), although this is controversial (39). The liver becomes a quantitatively more important consumer of glutamine in the septic state compared to the postsurgical state (60).

Nutritional depletion, often present in patients with metabolic stress, has its own effects on the interorgan fluxes and circulating levels of glutamine. The interpretation of changes in glutamine metabolism during metabolic stress can only be complete when changes caused by starvation are taken into account. Starvation in rats results initially in an increase of glutamine efflux from muscle tissue reaching a maximum after 3 days, after which a decline is observed (66). The portal drained viscera demonstrate a diminished uptake of glutamine beginning after 3 days of starvation. The liver switches from release to uptake $(66,67)$; however, others have reported the opposite (68). The decreased release of glutamine (and alanine) after a 4 day period of starvation may reflect an adaptive host response to starvation and serves to conserve protein and muscle glutamine concentrations (66). In fact in these animal experiments starvation increased glutamine content per $\mathrm{kg}$ nitrogen in muscle (47), whereas plasma levels remained unaltered. Others have shown a gradual decrease in muscle glutamine levels after prolonged starvation in dogs (69). Weightlosing cancer patients were shown to have decreased levels of gluconeogenic amino acids compared to weight stable cancer patients (70). Using plethysmographic flow measurements and arteriovenous concentration differences the flux of amino acids across the leg was measured. There was no difference in efflux of amino acids from 
3

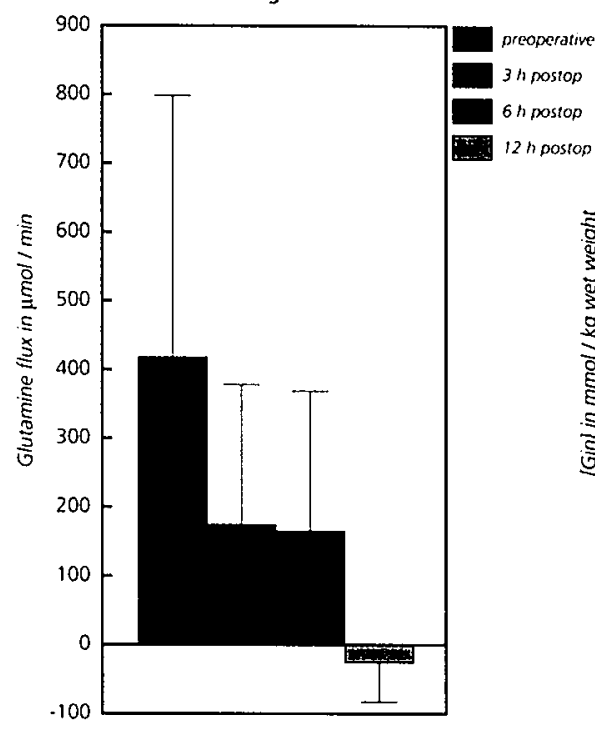

4

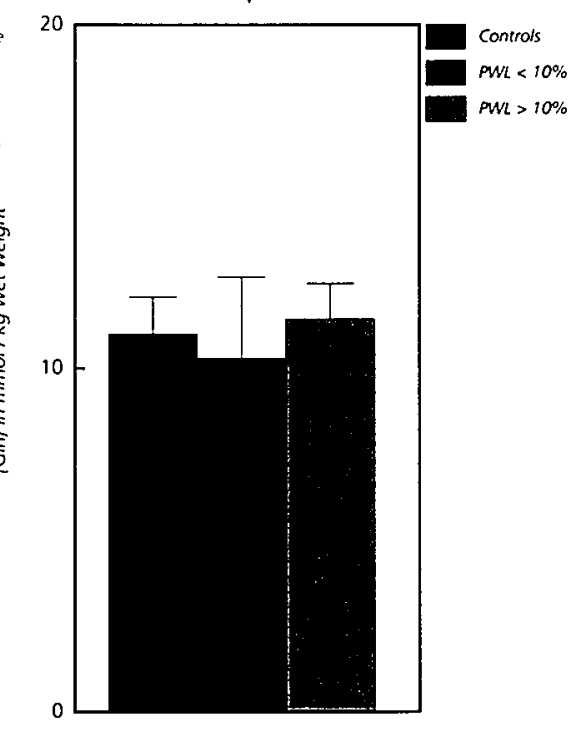

Figure 3.(l) Glutamine flux across the lungs.

Figure 4.(r) Muscle glutamine content in controls and depleted patients. PWL=percentage of weightloss.

skeletal muscle tissue between malnourished and well-nourished patients. However, due to analytical limitations glutamine and glutamic acid were determined together, making it impossible to study specific changes in glutamine efflux, whereas the sum of plasma glutamine and glutamic acid levels were decreased in malnourished cancer patients. This probably reflects a decrease of plasma glutamine concentration, as plasma glutamic acid concentration is less than $10 \%$ of the circulating glutamine level. The different observations made in different studies are not necessarily in contrast with each other but may merely reflect the severity or duration of nutritional depletion. Increased muscle and unaltered plasma concentrations may reflect a relatively early stage of nutritional depletion. In this stage the glutamine production in the remaining diminished total muscle tissue of the depleted host may be upregulated to satisfy (increased) demands. This is in line with observations in depleted cancer patients, where patients with recent weight loss of more than $10 \%(n=5)$, did not have lower muscle glutamine concentrations compared to cancer patients without excessive weight loss ( $n=6$ ) or healthy controls (van Doorn et al, unpublished data, figure 4). Eventually however, we hypothesize that the production of glutamine will be exhausted because muscle mass decreases and the remaining muscle tissue is unable to compensate for this loss. Furthermore, due to derangements in intermediary metabolism of the depleted patient, it may be impossible for the muscle tissue to upregulate or even maintain glutamine production at a normal level. A decrease in muscle mass and/or derangement of intermediary metabolism will therefore cause a decline in glutamine availability.

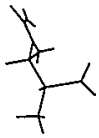


In conclusion, we propose that prolonged metabolic stress causes an ongoing efflux of glutamine from skeletal muscle tissue resulting in depletion of muscle and eventually circulating glutamine. The degree and duration of stress is probably an important determinant of the severity and speed of the glutamine decline. In addition, the degree of nutritional depletion is important because it determines the total glutamine production capacity which is reduced as a result of decreased muscle mass. The factors modulating the efflux of glutamine from muscle tissue are largely unknown. The so called gut-muscle axis hypothesis, in which the gut was thought to play a central role in the regulation of glutamine release, was recently refuted. It seems unlikely that the gut, exhibiting decreased glutamine uptake during metabolic stress, would induce the release of glutamine from muscle. The immune system seems a more plausible regulator of glutamine release, because increased demands by the immune system correspond with increasing glutamine efflux. In addition, the immune system has the tools, e.g. cytokines, to induce efflux of amino acids from muscle tissue. Ongoing efflux, however, will cause a depletion of glutamine which eventually will lead to diminished supply for the immune system possibly resulting in diminished immune function. Furthermore, the gut itself may suffer from diminished glutamine supply.

\section{Glutamine and the gut}

Neptune was one of the first who observed the oxidation of glutamine in the ileum (71). Reports observing utilization of glutamine by the gut were published in the 1960 s $(72,73)$. Enterocytes were shown to utilize glutamine to a greater extent than any other fuel source, even glucose. In vivo perfusion studies revealed that glutamine accounted for $55 \%$ of the respired $\mathrm{CO}_{2}$, whereas acetoacetate and glucose together accounted for only $20 \%(17,74,75)$. Approximately $15 \%$ of the glutamine carbon is incorporated into protein (76). Another $30 \%$ was discovered in lactate, citrate, citrulline, alanine, proline and several other quantitatively less important amino acids. Glutamine nitrogen appears for $97 \%$ in ammonia, alanine, citrulline and proline. A small amount appears in glutamate and ornithine (17). The importance of glutamine as a fuel for the gut has been suggested in several species including man (35). It is, however, important to realize that most of the in vivo studies concerned the metabolism of all portal drained viscera (including spleen and pancreas) rather than the gut alone. In addition, a substantial part of the gut (about $25 \%$ ) consists of immune cells also consuming glutamine at a high rate. Thus, it is likely that at least part of the glutamine consumption by the gut is caused by consumption of immune cells. A distinction can be made by the fact that in vitro studies showed that aspartate is a main product of glutamine metabolism in lymphocytes whereas almost no aspartate is produced by enterocytes. Aspartate not being an important end product in the in vivo studies suggests that most of the glutamine is consumed by enterocytes (77). The question arose whether glutamine was essential for normal functioning of the intestine. The effect of glutamine restriction on intestinal mucosa was studied by Baskerville (78). In their experiment circulating glutamine was depressed using parenteral administration of glutaminase in various species. This proces was associated with edema and ulcerations of the intestinal mucosa. Subsequently the villous atro- 
phy frequently observed during parenteral nutrition was ascribed to the absence of glutamine in commercially available amino acid solutions (13). Standard amino acid solutions do not contain glutamine because of the relative instability of this amino acid during prolonged storage and heat sterilization (13). Studies in animals in which the effect on gut mucosa of standard parenteral nutrition was compared with glutamine containing parenteral nutrition solutions demonstrated that glutamine supplementation attenuated mucosa atrophy (79-88), preserved gut immune status $(89,90)$, preserved gut integrity (91-93) and prevented bacterial translocation (90). Also, exocrine pancreas function was preserved (93) and hepatic steatosis was prevented (95). In addition, glutamine was shown to have a protective effect on the gut in rats challenged with toxic doses of chemotherapeutic agents $(96,97)$ or irradiation (98-100). A significant reduction in mortality was observed, mucosal morphology was preserved and the incidence of bacterial translocation was lowered if glutamine was given in rats with methotrexate-induced enterocolitis (96). Although publication bias cannot be excluded, only a few studies failed to demonstrate a positive effect of glutamine $(101,102)$. Differences in these studies may be explained by the route by which glutamine was given (enteral versus parenteral) or the degree of metabolic stress and depletion in the animals. It seems logical that the beneficial effect of glutamine is limited to experiments in which a glutamine deficiency is likely to develop. The exact mechanism by which glutamine exerts this effect is largely unknown. Several potential mechanisms may be involved. First, the effect of glutamine may be via stimulation of protein synthesis in the gut mucosa $(79,103,104)$. The exact contribution to the increase in protein synthesis by enterocytes on the one side and intestinal immune cells on the other side is not known. A second pathway by which glutamine may have its effect is by the attenuation of immune cellularity in the intestinal mucosa thus preserving gut barrier function (79). Thirdly, glutamine may exert its protective effect by preserving intestinal blood flow by dilatation of submucosal and premucosal arteries (105). In addition, glutamine may have a beneficial effect on the production of radical scavengers necessary to protect the intestinal mucosa from reactive oxygen intermediates (106). Finally glutamine could serve as a secretagogue, stimulating the elaboration of peptide hormones such as glucagon, exerting stimulatory effects on the mucosa. This is indicated by the observation that the glucagon concentration is increased in the portal circulation during glutamine administration (95)

The relevance of glutamine for the gut originated after the awareness that the gut has an important barrier function, preventing translocation of bacteria and toxins to the portal and the systemic circulation (35). Malnutrition as well as parenteral nutrition increase the risk of bacterial translocation (107). It is hypothesized that lack of glutamine may have a pivotal role in this process (90). Although bacterial translocation has been described in animal experiments $(36,37,108-115)$ as well as in humans (116), the clinical relevance in man is still controversial (117). Maintenance of the gut barrier against bacteria and their products is provided by the gastric $\mathrm{pH}$ of the stomach, proteolytic activity by the pancreas enzymes, motility, mucin production, and epithelial membrane and gut associated lymphoid tissue $(37,118)$. Experimental studies have demonstrated bacterial translocation by culturing bacteria from mesen-

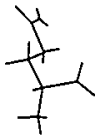


teric lymph nodes, liver and spleen. These studies show a relation between bacterial translocation and mortality $(119,120)$. Evidence from human studies with regard to the clinical relevance of preservation of the intestinal barrier is more indirect. Most studies are performed with dual sugar probe tests and assess intestinal permeability (121-130). Permeability measured in this manner only gives an impression regarding the epithelial part of the gut barrier. Increased intestinal permeability may precede increased bacterial translocation but it is not its equivalent, although this has been suggested in the literature (130). This explains why studies in patients investigating the relationship between increased intestinal permeability and septic morbidity were unable to demonstrate such a relationship (117). Increased intestinal permeability, however, does give information about the condition of the gut. Increased intestinal permeability is associated with morphological deterioration of the gut (123), is present in critically ill patients (124), predicts the risk of relapse in patients with inflammatory bowel disease (131), and has been demonstrated to be a sensitive indicator of relapse of coeliac disease (132).

In conclusion, glutamine is an essential substrate for the intestine. Breakdown of the intestinal barrier may adversely influence the course of the disease and outcome in patients. Preservation of the intestinal barrier appears to be an important therapeutic goal in the metabolically stressed patient. Exogenous supply of glutamine may therefore be an important aspect of the treatment of patients with a diminished glutamine production capacity.

\section{Glutamine in clinical trials}

Clinical trials designed to investigate glutamine effects initially focused on safety of the intravenous administration of glutamine. On the one hand studies were performed to investigate the safety of the administration of intravenous L-glutamine (133-136) whereas on the other hand studies mainly described the alternative form of glutamine administration in the form of a dipeptide (glycyl-glutamine, alanyl-glutamine) (137-140). The potential toxicity of glutamine administration resides in the fact that glutamine deamidates to form ammonia and potentially toxic L-pyrrolidone carboxylic acid (pyroglutamic acid) during prolonged storage or heat sterilization $(133,135,136)$. In addition, it can be metabolized to ammonia and glutamic acid in the body.

The effect of storage on the stability of L-glutamine containing solutions is minimal. The breakdown of L-glutamine containing solutions stored at $4^{\circ} \mathrm{C}$ is less than $2 \%$ over a period of two weeks (135). Studies investigating the safety of intravenous L-glutamine administration in control subjects and patients did not show any clinical or biochemical side effects if glutamine was given in a dosage of $0.57 \mathrm{~g} / \mathrm{kg} /$ day $(133,134)$. From these studies it was concluded that glutamine can be given in its free form (133). It is important, however, to notice that during shelf storage breakdown of glutamine may become relevant. In addition, even heating for short periods (sterilization) may cause a substantial breakdown of glutamine. Therefore, the preparation of Lglutamine containing solutions requires special care in the pharmacy. An alternative may be the use of glutamine containing stable dipeptides. These dipeptides (alanylglutamine and glycyl-glutamine) are hydrolyzed and cleared rapidly from plasma 
(137). Metabolism is efficient in healthy controls as well as in critically ill and postoperative patients $(137,141)$. However, renal insufficiency may decrease clearance of peptides and the use in renal failure may be limited (141). An additional disadvantage of the use of dipeptides is that they are more expensive than free glutamine (142).

Several studies have been performed investigating the potential benefit of glutamine in patients. These studies can be divided into three groups. The first group of studies investigated muscle protein kinetics. Administration of glutamine or glutamine analogues (143-148) counteracted the fall in muscle glutamine and were shown to inhibit obligatory postoperative nitrogen loss, suggesting a positive effect on muscle protein turnover $(146,148)$. Although part of the effect on nitrogen balance may be explained by the increase in the free glutamine pool (149), this cannot account completely for the differences in nitrogen balances observed (150). In addition, in a recent study, using stable isotopes, an increase in muscle protein synthesis in healthy subjects and postoperative patients receiving glutamine supplemented parenteral nutrition was observed (151). In this study however, protein degradation was not measured. In this context it is important to mention that the increased degradation of protein after trauma may be beneficial to yield glutamine for peripheral tissues. Therefore, an inhibitory effect of glutamine supplementation on protein degradation may not be as beneficial as generally thought. From the studies mentioned and experimental work $(79,151)$ support is derived for the conclusion that glutamine indeed has an anabolic effect on muscle protein economy.

The second type of studies investigates potential effects of glutamine on the organs where glutamine is thought to exert its main effects: the gut and the immune system. In one study (152, this thesis) a beneficial effect of glutamine on gut permeability and morphology was observed. The beneficial effect of glutamine on the intestinal mucosa was also shown in a study performed in critically ill patients. Patients receiving glutamine supplemented parenteral nutrition had a better absorptive capacity compared to those who received parenteral nutrition without glutamine (153). A beneficial effect on human gut mucosa proliferation was recently confirmed in an ex vivo study (154). Post-surgical patients receiving glutamine showed an increase in in vitro T-cell DNA synthesis (155). From these studies it is suggested that in man glutamine indeed has beneficial effects on the gut and immune function.

The last type of studies evaluates a clinical benefit of glutamine. These studies theoretically require large study groups. It is therefore remarkable that two studies performed in a relatively small group of bone marrow transplanted patients observed a reduction in hospital stay $(156,157)$, bacterial colonization, and incidence of clinical infections in patients receiving glutamine supplementation (156). The clinical benefit was associated with a reduction in nitrogen loss and attenuated fluid retention $(156,158)$. In addition, patients receiving glutamine supplementation reported an improvement in mood compared to patients receiving standard parenteral nutrition (159).

From these studies it can be concluded that parenteral administration of glutamine in humans is safe. Glutamine can be given in free form or as a dipeptide. It is suggested that glutamine has an anabolic effect on muscle. In addition, the gut and 
immune system seem to benefit from glutamine. Although small groups have been studied, clinical benefit in terms of a decreased number of clinical infections and a shortened hospital stay have been suggested. These results concerning clinical outcome require confirmation, in different diseases. In performing these studies one has to define clearcut end points taking into account that improvements in treatment are not automatically associated with shortened hospital stay or decreased complication rates, because more severely diseased patients survive only after prolonged periods of treatment. Finally, further studies have to be performed investigating the mechanisms by which glutamine exerts its effects. 
1. Studley H.O. Percentage of weight loss. A basic indicator fo surgical risk in patients with chronic peptic ulcer. Journal of the American Medical Association $1936 ; 106: 458-460$.

2. Windsor J.A., and G.L. Hill. Weight loss with physiologic impairment. A basic indicator of surgical risk Annals of Surgery 1987;207:290-296.

3. Campos A.C., and M.M. Meguid. A critical appraisal of the usefulness of perioperative nutritional support. American Journal of Clinical Nutrition 1992:55:117. 130.

4. Mullen J.L. Consequences of malnutition in the surgical patient. Surgical Clinics of North America $1981 ; 61: 465-487$

5. Editorial: Indicators of surgical risk. Lancet 1986;1:14221423.

6. O'Keefe A.J. and J. Dicker. Is plasma albumin concentration useful in the assessment of nutritional status of hospital patients? European Journal of Clinical Nutrition 1988:42:41-45.

7. Meijerink W.J. Perioperative nutrition in gi cancer patients. Thesis. University of Limburg. The Netherlands, 1992.

8. Benedict F.G. A study of prolonged fasting. Carnegie Institution of Washington. 1915.

9. Crane C.W., D. Picou, R. Smith, and J.C. Waterlow. Protein turnover in patients before and after elective orthopaedic operation. British Journal of Surgery 1977;64:165-175.

10. Rennie M.J., and R. Harrison. Effects of injury, disease and malnutrition on protein metabolism in man. Lancet 1984:1:323-325.

11. Shaw J.H., M. Wildbore, and R.R. Wolfe. Whole body protein kinetics in severely septic patients. The response to glucose infusion and total parenteral nutrition. Annals of Surgery 1987;205:288-294.

12. Van Eijk H.M., C.H. Dejong., N.E. Deutz, and P.B. Soeters. Influence of storage conditions on normal plasma amino-acid concentrations. Clinical nutrition 1994:13:374-380

13. Lacey J.M., and D.W. Wilmore. is glutamine a conditionally essential amino acid? Nutrition Reviews 1990:48:297-309.

14. Hatperin M.L., J.H. Ethier, and K.S. Kamel. The excretion of ammonium ions and acid base balance. Clinical Biochemistry 1990;23:185-188.

15. Halperin M.L., K.S. Kamel, J.H. Ethier, B.J. Stinebaugh, and R.L. Jungas. Biochemistry and physiology of ammonium excretion. In: The kidney: physiology and pathophysiology. D.W. Seldin, and G. Giebisch (ed). Raven Press Lid. New York, 1992.
16. Ardawi M.S., and E.A. Newsholme. Glutamine metabolism in lymphocytes of the rat. Biochemical Journal 1983;212:835-842

17. Windmueller H.G. Glutamine utilization by the small intestine. Advances in Enzymology 1982:53:201-237.

18. Welbourne T.C. Interorgan glutamine flow in metabolic acidosis. American Journal of Physiology 1987;235:F1069-F1076

19. Souba W.W. Interorgan ammonia metabolism in health and disease: a surgeon's view. Journal of Parenteral and Enteral Nutrition 1987:11:569-579.

20. Newsholme E.A., and M. Parry-Billings. Properties of glutamine release from muscle and its importance for the immune system. Journal of Parenteral and Enteral Nutrition 1990;14:635-675

21. Darmaun D., and P. Déchelotte. Role of leucine as a precursor of glutamine a-amino nitrogen in vivo in humans. American Journal of Physiology 1991;260:E326-E329

22. Welbourne T.C. Role of the lung in glutamine homeostasis. Contributions in Nephrology 1988;63:178-182.

23. Plumley D.A., T.R. Austgen, R.M. Salloum, and W.W. Souba. Role of the lungs in maintaining amino acid homeostasis. Journal of Parenteral and Enteral Nutrition 1990;14:569-573.

24. Coulson R.A., and T. Hernandez. Site of synthesis of amino acids in the intact cayman. American Journal of Physiology 1987:213:411-417.

25. Cooper A.1., and F. Plum. Biochemistry and physiology of brain ammonia. Physiology Review 1987;67:440519.

26. Dejong C.H., M.T. Kampman, N.E. Deutz, and P.B. Soeters. Cerebral cortex ammonia and glutamine metabolism during liver insufficiency-induced hyperammonia in the rat. Journal of Neurochemistry 1992:59:1071-1079.

27. Elia M. Glutamine metabolism in human adipose tissue in vivo. Clinical Nutrition 1993:12:51-53.

28. Dudrick P.S., and W.W. Souba. The role of glutamine in nutrition. Current Opinion in Gastroenterology 1991:7:299-305

29. Welbourne T.C., and S. Joshi. Interorgan glutamine metabolism during acidosis. Journal of Parenteral and Enteral Nutrition. 1990;14:775-88S

30. Parry-Billings M., J. Evans, P.C. Calder, and E.A Newsholme. Does glutamine contribute to immunosuppresion after major burns? Lancet 1990;336:523525 
31. Calder P.C. Glutamine and the immune system. Clinical Nutrition 1994:13:2-8.

32. Häussınger $D$. Liver glutamine metabolism. Journal of Parenteral and Enteral Nutrition 1990;14:56S-62S.

33. Grimble G.K. Essential and conditionally-essential nutrients in clinical nutrition. Nutrition Research Reviews 1993:6:97-119.

34. Souba W.W., S. Klimberg, D.A. Plumley, et al. The role of glutamine in maintaining a healthy gut and supporting the metabolic response to injury and infection. Journal of Surgical Research 1990;48:383-391.

35. Whimore D.W., R.J. Smith, S.T. O'Dwyer, D.O. Jacobs, T.R. Ziegler, and X.-D. Wang. The gut: a central organ after surgical stress. Surgery 1988:104:917-923.

36. Alexander J.W., S.T. Boyce, G.F. Babcock, et al. The process of microbial translocation. Annals of Surgery 1990:212:496-512.

37. Wells C.L., M.A. Maddaus, and R.L. Simmons. Proposed mechanisms for the translocation of intestinal bacteria. Reviews of Infectious Diseases 1988; 10:958-979.

38. Van Leeuwen P.A., M.A. Boermeester, A.P. Houdijk, et al. Clinical significance of translocation. Gut 1994:51:\$28-\$34.

39. Deutz N.E., P.L. Reijven, G. Athanasas, and P.B. Soeters. Post-operative changes in hepatic, intestinal, splenic and muscle fluxes of amino acids and ammonia in pigs. Clinical Science 1992;83:607-614.

40. Rinsema W., G.J. Gouma, M.F. von Meyenfeldt, and P.B. Soeters. Reinfusions of secretions from high-output stomas or fistulas. Surgery. Gynecology and Obstetrics 1988:167:372-376

41. Fürst P., S. Albers, and P. Stehle. Stress-induced intracellar glutamine depletion. The potential use of glutamine-containing peptides in parenteral nutrition. In: Contributions 10 "infusion therapy and clinical nutrition" Pp 117-136. Bässler K.H., A. Grünert, G. Kleinberger, and $H$. Reissigl (ed). Karger München, 1987.

42. Parry-Billings M., R.J. Baigrie, P.M. Lamont, P.J. Morris, and E.A. Newsholme. Effects of major and minor surgery on plasma glutamine and cytokine levels. Archives of Surgery 1992;127:1237-1240.

43. Askanazi J., Y.A. Carpentier, C.B. Michelsen, et al. Muscle and plasma amino acids following injury. Influence of intercurrent infection. Annals of Surgery $1980 ; 192: 78-85$.

44. Souba W.W., P.T. Roughneen, O.L. Goldwater, J.C Williams, and B.J. Rowlands. Postoperative alterations in interorgan glutamine exchange in enterectomized dogs. Journal of Surgical Research 1980;42:117-125.
45. Fong Y., K.J. Tracey, D.G. Hesse, J.D. Albert, P.S. Barie, and S.F.Lowry. Influence of entereciomy on peripheral tissue glutamine efflux in critically ill patients. Surgery 1990:107:321-326.

46. Darmaun D., B. Messing, B. Just, M. Rongier, and J.-F Desjeux. Glutamine metabolism after small intestinal resection in humans. Metabolism 1991:40:42-44.

47. Deutz N.E., C.H. Dejong, G. Athanasas, and P.B Soeters. Partial enterectomy in the rat does not diminish muscle glutamine production. Metabolism 1992:41:1343-1350.

48. Souba W.W., and D.W. Wilmore. Postoperative alter. ation of arteriovenous exchange of amino acids across the gastrointestinal tract. Surgery 1983;94:342-350.

49. Fischer J.E., and P.-O. Hasselgren. Cytokines and giucocorticoids in the regulation of the "hepato-skeletal muscle axis" in sepsis. The American Journal of Surgery 1991:161:266-271

50. Austgen T.R., M.K. Chen, P.S. Dudrick, E.M. Copeland and W.W. Souba. Cytokine regulation of intestinal glutamine utilization. The American Journal of Surgery 1992:163:174-180.

51. Cruickshank A.M., W.D. Fraser, H.J. Burns, J. Van Dame, and A. Shenkin. Response of serum interleukin6 in patients undergoing elective surgeny of varying intensity. Clinical Science 1990;79:161-165.

52. Souba W.W., D.A. Plumley, R.M. Salloum, and E.M. Copeland. Effects of glucocorticoids on lung glutamine and alanine metabolism. Surgery 1990;108:213-219.

53. Ardawi M.S. Glutamine-synthesizing activity in lungs of fed, starved, acidotic, diabetic, injured and septic rats. Biochemical Journal 1990:270:829-832.

54. Souba W.W., K. Herskowitz, and D.A. Plumley. Lung glutamine metabolism. Journal of Parenteral and Enteral Nutrition 1990;14:S68-S70.

55. Plumley D.A., W.W. Souba, R.D. Hautamaki, et al. Accerated lung amino acid release in hyperdynamic septic surgical patients. Archives of Surgery 1990:125:57-61.

56. van Berlo C.L., R.R. van der Hulst, J.G. Maessen, et al. Lung glutamine metabolism: effects of starvation, parenteral and enteral nutrition. A study in man. Clinical Nutrition in press.

57. Duorick P.S. P. Sarantos, K. Ockert, R. Chakrabarti, E.M. Copeland, and W.W. Souba. Dexamethasone stimulation of glutamine expression in mesenteric lymph nodes. The American Journal of Surgery 1993; $165: 34-39$

58. Sarantos P., A. Abouhamze, and W.W. Souba. Glucocorticoids regulate intestinal glutaminase expression. Surgery 1992;1 12:278-283. 
59. Sarantos P., Z. Abouhamze, E.M. Copeland, and W.W Souba. Glucocorticoids regulate glutaminase gene expression in human intestinal epithelial cells. Journal of Surgical Research 1994;57:227-231.

60. Souba W.W., and T.R. Austgen. Interorgan glutamine flow following surgery and infection. Journal of Parenteral and Enteral Nutrition 1990;14:90S-935.

61. Peterson B., J. Wernerman, S.-O. Waller, A. von der Decken, and $\mathrm{E}$. Vinnars. Elective abdominal surgery depresses muscle protein synthesis and increases subjective fatigue: effects lasting more than 30 days. British Journal of Surgery 1990:77:796-800.

62. Roth E., J. Funovics, F. Mühlbacher, et al. Metabolic disorders in severe abdominal sepsis: glutamine deficiency in skeletal muscle. Clinical Nutrition 1982;1:2541.

63. Roth E., G. Zöch, F. Schulz, et al. Amino acid concentrations in plasma and skeletal muscle of patients with acute hemorrhagic necrotizing pancreatitis. Clinical Chemistry 1985;31:1305-1309.

64. Vente J.P., M.F. von Meyenfeidt, C.L. van Berlo, et al. Plasma amino acid profiles in sepsis and stress. Annals of Surgery 1989;209:57-62

65. Souba W.W., K. Herskowitz, S. Klimberg, et al. The effects of sepsis and endotoxaemia on gut glutamine metabolism. Annals of Surgery 1990;211:543-551.

66. Dejong C.H., N.E. Deutz, and P.B. Soeters. Inter-organ nitrogen exchange during prolonged starvation in the rat. The Journal of Clinical Nutrition and Gastroenterology 1991;5:76-183.

67. deBlaauw I., N.E. Deutz, and M.F. von Meyenfeldt. In vivo amino acid metabolism of gut and liver during short and prolonged starvation. American Journal of Physiology 1996;in press.

68. Abumrad N.N, N. Yaxigi, E. Cersosimo, et al. Glutamine metabolism during starvation. Journal of Parenteral and Enteral Nutrition 1990;14:715-75S.

69. Kapadia C.R., F. Muhlbacher, R.J. Smith, and D.W. Wilmore. Alterations in glutamine metabolism in response to operative stress and food deprivation. Surgical Forum 1982;33:19-21.

70. Bennergárd K., L. Lindmark, E. Edén, G. Svaninger, and $K$. Lundholm. Flux of amino acids across the leg in weight-losing cancer patients. Cancer Research 1984:44:387-393

71. Neptune E.M. Jr. Respiration and oxidation of various substrates by ileum in vitro. American Journal of Physiology 1965;209:329-332.

72. Addae S.K., and W.D. Lotspeich. Relation between glutamine utilization and production in metabolic acidosis. American Journal of Physiology 1968;215:269-277.
73. Finch L.R., and F.J. Hird. The uptake of amino acids by isolated segments of rat intestine. I. A survey of factors affecting the measurement of uptake. Biochimica Biophysica Acta 1960;43:268-277.

74 Windmueller H.G., and A.E. Spaeth. Respiratory fuels and nitrogen metabolism in vivo in small intestine of fed rats. The Journal of Biological Chemistry 1980;255:107-112.

75. Pinkus L.M., and H.G. Windmueller. Phosphate-dependent glutaminase of small intestine: localization and role in intestinal glutamine metabolism. Archives of Biochemistry and Biophysics 1977;182:506-517.

76. Windmueller H.G., and A.E. Spaeth. Uptake and metabolism of plasma glutamine by the small intestine. The Journal of Biological Chemistry 1974;249:5070-5079.

77. Newsholme E.A., and A.L. Carrié. Quantitative aspects of glucose and glutamine metabolism by intestinal cells. Gut 1994:S1:S13-S17.

78. Baskerville A., P. Hambleton, and J.E. Benbough Pathological features of glutaminase toxicity. British Journal of Experimental Pathology 1980;61:132-138.

79. Yoshida S., M.J. Leskiw, M.D. Schluter, et al. Effect of total parenteral nutrition, systemic sepsis, and glutamine on gut mucosa in rats. American Journal of Physiology 1992;263:E368-E373.

80. O'Dwyer S.T., R.J. Smith, T.L. Hwang, and D.W Wilmore. Maintenance of small bowel mucosa with glutamine-enriched parenteral nutrition. Journal of Parenteral and Enteral Nutrition 1989;13:579-585.

81. Jacobs D.O., D.A. Evans, K. Mealy, S.T. O'Dwyer, R.J. Smith, and D.W. Wilmore. Combined effects of glutamine and epidermal growth factor on the rat intestine. Surgery 1988:104:358-364.

82. Tamada H., R. Nezu, I. Imamura, et al. The dipeptide alanyl-glutamine prevents intestinal mucosal atrophy in parenterally fed rats. Journal of Parenteral and Enteral Nutrition 1992;16:110-116.

83. Jiang Z.-M., L.-J. Wang, Y. Qi, et al. Comparison of parenteral nutrition supplemented with L-glutamine or glutamine dipeptides. Journal of Parenteral and Enteral Nutrition 1993:17:134-141.

84. Inoue Y., J.P. Grant, and P.J. Snyder. Effect of glutamine-supplemented total parenteral nutrition recovery of the small intestine after starvation atrophy. Journal of Parenteral and Enteral Nutrition 1993;17:165-170.

85. Meritt J., T.A. Witkowski, R. Nagele, E.D. Norcross, and T.P. Stein. Glutamine and smooth muscle morphology of the gut in rats on total parenteral nutrition. Journal of the American College of Nutrition 1989;8:537-544.

86. Hwang T.L., S.T. O'Dwyer, R.J. Smith, and D.W. Wilmore. Preservation of small bowel mucosa using 
glutamine-enriched parenteral nutrition. Surgical Forum 1986;37:56-58.

87. Burrin D.G., R.J. Shulman, C. Langston, and M.C. Storm. Supplemental alanyl-glutamine, organ growth. and nitrogen metabolism in neonatal pigs fed by total parenteral nutrition. Journal of Parenteral and Enteral Nutrition 1994; 18:313-319.

88. Platell C., R. McCauley, R. McCulloch, and J. Hall. The influence of parenteral glutamine and branched-chain amino acids on total parenteral nutrition-induced atrophy of the gut. Journal of Parenteral and Enteral Nutrition 1993:17:348-354.

89. Alverdy J.A., E. Aoys, P. Weiss-Carrington, and D.A. Burke. The effect of glutamine-enriched TPN on gut immune cellularity. Journal of Surgical Research 1992:52:34-38.

90. Burke D.J., J.C. Alverdy, E. Aoys, and G.S. Moss. Glutamine-supplemented total parenteral nutrition improves gut immune function. Archives of Surgery 1989;124:1396-1399.

91. Helton W.S. Editorial: The pathophysiological significance of alterations in intestinal permeability induced by total parenteral nutritrion and glutamine. Journal of Parenteral and Enteral Nutrition 1994;18:289-290.

92. Li J., B. Langkamp-Henken, K. Suzuki, and L.H. Stahlgren. Glutamine prevents parenteral nutritioninduced increases in intestinal permeability. Journal of Parenteral and Enteral Nutrition 1994;18:303-307.

93. Chen X., T. Okuma, K. Okamura, Y. Torigoe, and $Y$. Miyauchi. Glutamine-supplemented parenteral nutrition improves gut mucosa integrity and function in endotoxemic rats. Journal of Parenteral and Enteral Nutrition 1994;18:167-171.

94. Helton W.S., D.O. Jacobs, S. Bonner-Weir, R. Bueno, R.J. Smith, and D.W. Wilmore. Effects of glutamineenriched parenteral nutrition on the exocrine pancreas. Journal of Parenteral and Enteral Nutrition 1990;14:344-352.

95. Li S., M.S. Nussbaum, D.W. MCFadden, et al. Addition of L-Glutamine to total parenteral nutrition and its effects on portal insulin and glucagon and the development of hepatic steatosis in rats. Journal of Surgical Research 1990;48:421-426.

96. Fox A.D., S.A. Kripke, J. De Paula, J.M. Berman, R.G. Settle, and J.L. Rombeau. Effect of a glutamine-supplemented enteral diet on methotrexate-induced enterocolitis. Journal of Parenteral and Enteral Nutrition $1988 ; 12: 325-331$

97. Rombeau J.L. A review of the effects of glutamineenriched diets on experimentally induced enterocolitis. Journal of Parenteral and Enteral Nutrition 1990; 14:1005-105S.
98. Klimberg V.S., W.W. Souba, D.J. Dolson, et al. Prophylactic glutamine protects the intestinal mucosa form radiation injury. Cancer 1990;66:62-68.

99. Souba W.W., V.S. Klimberg, and E.M. Copeland. Glutamine nutrition in the management of radiation enteritis. Journal of Parenteral and Enteral Nutrition 1990;14:106S-108S

100. Karatzas T., S. Scopa, I. Tsoni, et al. Effect of glutamine on intestinal mucosal integrity and bacterial translocation after abdominal radiation. Clinical Nutrition 1991;10:199-205.

101. Spaeth G., T. Gottwald, W. Haas, and M. Holmer. Glutamine peptide does not improve gut barrier function and mucosal immunity in total parenteral nutrition. Journal of Parenteral and Enteral Nutrition 1993:17:317-323.

102. Scott T.E., and J.R. Moellman. Intravenous glutamine fails to improve gut morphology after radiation injury. Journal of Parenteral and Enteral Nutrition 1992; 16:440-444

103. Higashiguchi T., P.-O. Hasselgren, K. Wagner, and 1. Fischer. Effect of glutamine on protein synthesis in isolated intestinal epithelial cells. Journal of Parenteral and Enteral Nutrition 1993:17:307-314.

104. Stein T.P., S. Yoshida, M.D. Schluter, D. Drews, S.A. Assimon, and M.J. Lekiw. Comparison of intravenous nutrients on gut mucosal protein synthesis. Journal of Parenteral and Enteral Nutrition 1994;18:447-452.

105. Flynn W.J., J.R. Gosche, and R.N. Garrison. Intestinal blood flow is restored with glutamine or glucose suffusion after hemorrhage. Journal of Surgical Research 1992;52:499-504.

106. Harward T.R., D. Coe, W.W. Souba, N. Klingman, and J.M. Seeger. Glutamine preserves gut glutathione levels during intestinal ischemia/reperfusion. Journal of Surgical Research 1994;56:351-355.

107. Deitch E.A. Bacterial translocation: the influence of dietary variables. Gut 1994;\$1:\$23-\$27.

108. Deitch E.A., J. Winterton, M. Li, and R. Berg. The gut as a portal of entry for bacteremia. Role of protein malnutrition. Annals of Surgery 1987;205:681-692

109. Fukushima R., L. Gianotti, and J.W. Alexander. The primary site of bacterial translocation. Archives of Surgery 1994:129:53-58.

110. Baron P., L.D. Traber, D.L. Traber, et al. Gut failure and translocation following burn and sepsis. Journal of Surgical Research 1994:57:197-204.

111. Deitch E.A., R. Berg, and R. Specian. Endotoxin promotes the translocation of bacteria from the gut. Archives of Surgery 1987:122:185-190. 
112. Jones W.G., J.P. Minei, A.E. Barber, T.J. Fahey, G.T Shires, and G.T. Shires. Splanchnic vasoconstriction and bacterial translocation after thermal injury. American Journal of Physiology 1991:261:H1190. H1196.

113. Deitch E.A., W.-J. Ma, L. Ma, R. Berg, and R.D. Specian. Endotoxin-induced bacterial translocation: a study of mechanisms. Surgery 1989;106:292-300.

114. Kueppers P.M., T.A. Miller, C.-Y. K. Chen, G.S. Smith, L.F. Rodriguez, and F.G. Moody. Effect of total parenteral nutrition plus morphine on bacterial translocation in rats. Annals of Surgery 1993;217:286-292.

115. Jones W.G., A.E. Barber, J.P. Minei, T.J. Fahey, G.T Shires, and G.T. Shires. Differential pathophysiology of bacterial translocation after thermal injury and sepsis. Annals of Surgery $1991: 214: 24-30$

116. van Goor H., C. Rosman, J. Grond, K. Kooi, G.H Wübbels, and R.P. Bleichrodt. Translocation of bacteria and endotoxin in organ donors. Archives of Surgery 1994:129:1063-1066.

117. Roumen R.M., T. Hendriks, R.A. Wevers, and J A. Goris intestinal permeability after severe trauma and hemorrhagic shock is increased without relation to septic complications. Archives of Surgery 1993;128:453-457

118. Jankowski 1.A., R.A. Goodlad, and N.A. Wright Maintenance of normal intestinal mucosa: function, structure, and adaptation. Gut 1994:\$1:S1-S4

119. Fukushima R., L. Gianotti, J.W. Alexander, and T. Pyles The degree of bacterial translocation is a determinant factor for mortality after burn injury and is improved by prostaglandin analogs. Annals of Surgery 1992:216:438-445.

120. Gennari R., J.W. Alexander, L. Gianotti, T. Eaves-Pyles, and S. Hartmann. Granulocyte macrophage colonystimulating factor improves survival in two models of gut-derived sepsis by improving gut barrier function and modulating bacterial clearance. Annals of Surgery 1994;220:68-76

121. Travis S., and I. Menzies. Intestinal permeability: functional assessment and significance. Clinical Science 1992;82:471-488.

122. Hollander $D$. The intestinal permeability barrier Scandinavian Journal of Gastroenterology 1992:27:721.726.

123. Menzies I.S., M.F. Laker, R. Pounder, et al. Abnormal intestinal permeability to sugars in villous atrophy. Lancet 1979;:1:107-1109.

124. Harris C.E., R.D. Griffiths, N. Freestone, D. Billington, S.T. Atherton, and R.R. Macmillan. Intestinal permeability in the critically ill. Intensive Care Medicine 1992:18:38-41.
125. LeVoyer $T$, W.G. Cioffi, L. Pratt, et al. Alterations in intestinal permeability after thermal injury. Archives of Surgery 1992:127:26-30

126. Parrilli G., R.V. laffaiolli, G. Capuano, G. Budillon, and A.R. Bianco. Changes in intestinal permeability to lactulose induced by chemotherapy Cancer Treatment Reports 1982:66:1435-1436.

127. Deitch E.A. Intestinal permeability is increased in burn patients shortly after injury. Surgery 1990;107:411. 416.

128. O'Dwyer S.T., H.R. Michie, T.R. Ziegler, A. Revhaug, R.J. Smith, and D.W. Wilmore. A single dose of endotoxin increases intestinal permeability in healthy humans. Archives of Surgery 1988;123:1459-1464

129. Pape H.-C., A. Dwenger, G. Regel, et al. Increased gut permeability after multiple trauma. British Journal of Surgery 1994:81:850-852.

130.Ziegler T.R., R.J. Smith, S.T. O'Dwyer, R.H. Demling and D.W. Wilmore. Increased intestinal permeability associated with infection in burn patients. Archives of Surgery 1988; $123: 1313-1319$

131. Wyatt J., H. Vogelsang, W. Hübl, T. Walshöer, and $H$.Lochs. Intestinal permeability and the prediction of relaps in Crohn's disease. Lancet 1993:341:1437-1439.

132. van Elburg R.M. The sugar absorption test. Thesis. University of Groningen, The Netherlands 1995.

133.Ziegler T.R., K. Benfell, R.J. Smith, et al. Safety and metabolic effects of L-glutamine administration in humans. Journal of Parenteral and Enteral Nutrition 1990:14:1375-146S.

134. Lowe D.K., K. Benfell, R.J. Smith, et al. Safety of glutamine-enriched parenteral nutrient solutions in humans. American Journal of Clinical Nutrition 1990:52:1101-1106.

135. Khan K., G. Hardy, B. McElroy, and M. Elia. The stability of L-glutamine in total parenteral nutrition solutions. Clinical Nutrition 1991:10:193-198.

136. Khan K., and M. Elia. Factors affecting the stability of L-glutamine in solution. Clinical Nutrition 1991;10:186192.

137. Fürst P., S. Albers, and P. Stehle. Glutamine-containing dipeptides in parenteral nutrition. Journal of Parenteral and Enteral Nutrition 1990;14:1185-124S.

138. Lochs H., E. Roth, S. Gasic, W. Hübl, E.L. Morse, and S.A. Adibi. Splanchnic, renal, and muscle clearance of alanyl-glutamine in man and organ fluxes of alanine and glutamine when infused in free and peptide forms. Metabolism 1990;39:833-836

139. Adibi S.A., H. Lochs, N.N. Abumrad, H. Daniel, and J.A. Vazquez. Removal of glycyl-glutamine form plasma by individual tissues: mechanisms and impact on amino

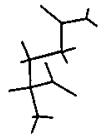


acid fluxes in postabsorption and starvation. Journal of Nutrition 1993;123:325-331.

140. Albers S., J. Wernerman, P. Stehle, E. Vinnars, and P. Fürst. Availability of amino acids supplied by constant intravenous infusion of synthetic dipeptides in healthy man. Clinical Science 1989;76:643-648.

141. Lochs $H$., and W. Hübl. Metabolic basis for selecting glutamine-containing substrates for parenteral nutrition. Journal of Parenteral and Enteral Nutrition 1990;14:1145-1175

142. Fürst P. Glutamine containing dipeptides: an overview Clinical Nutrition 1993;12:62-65

143. Hammarqvist F., J. Wernerman, A. von der Decken, and $E$. Vinnars. Alpha-ketoglutarate preserves protein synthesis and free glutamine in skeletal muscle after surgery. Surgery 1991;109:28-36.

144. Wernerman J., F. Hammarqvist, A. von der Decken, and $E$. Vinnars. Ornithine-alpha-ketoglutarate improves skeletal muscle protein synthesis as assessed by ribosome analysis and nitrogen use after surgery. Annals of Surgery 1987:206:674-678.

145. Hammarqvist F., J. Wernerman, A. von der Decken, and $E$. Vinnars. Ananyl-glutamine counteracts the depletion of free glutamine and the postoperative decline in protein synthesis in skeletal muscle. Annals of Surgery 1990:212:637-644.

146. Hammarquist F., J. Wernerman, R. Ali, A. von der Decken, and $E$. Vinnars. Addition of glutamine to total parenteral nutrition after elective abdominal surgery spares free glutamine in muscle, counteracts the fall in muscle protein synthesis, and improves nitrogen balance. Annals of Surgery 1988:209:455-461.

147. Petersson B., S.-O. Waller, E. Vinnars, and J. Wernerman. Long-term effect of glycyl-glutamine after elective surgery on free amino acids in muscle. Journal of Parenteral and Enteral Nutrition 1994;18:320-325.

148. Stehle P., J. Zander, N. Mertes, et al. Effect of parenteral glutamine peptide supplements on muscle glutamine loss and nitrogen balance after major surgery. Lancet 1989;: :231-233.

149. Walser M. Misinterpretation of nitrogen balances when glutamine stores fall or are replenished. American Journal of Clinical Nutrition 1991:53:1337-1338.

150. Fürst P., P. Stehle, and M. Rennie. Glutamine and nitrogen balance. American Journal of Clinical Nutrition 1992;56:959-960.

151. Barua J.M. E. Wilson, S. Downie, B. Weryk. A. Cuschieri, and M.J. Rennie. The effect of alanyl-glutamine peptide supplementation on muscle protein synthesis in post-surgical patients receiving glutaminefree amino acids intravenously. Proceedings of the Nutritional Society 1992:51:104A-105A.
152. van der Hulst R.R., B.K. van Kreel, M.F. von Meyenfeldt, et al. Glutamine and the preservation of gut integrity. Lancet 1993:334:1363-1365.

153. Tremel H., B. Kienle, L.S. Weilemann, P. Stehle and P. Fürst. Glutamine dipeptide-supplemented parenteral nutrition maintains intestinal function in the critically ill. Gastroenterology 1994;107:1595-1601

154. Scheppach W., C. Loges, P. Bartram, et al. Effect of free glutamine and alanyl-glutamine dipeptide on mucosal proliferation of the human ileum and colon. Gastroenterology 1994:107:429-434.

155. O'Riordain M.G., K.C. Fearon, J.A. Ross, et al. Glutamine supplemented total parenteral nutrition enhances T-lymphocyte response in surgical patients undergoing colorectal resection. Annals of Surgery $1994: 220: 212-221$

156. Ziegler T.R., L.S. Young, K. Bentell, et al. Clinical and metabolic efficacy of glutamine-supplemented parenteral nutrition after bone marrow transplantation. Annals of Internal Medicine 1992;116:821-828

157. Schloerb P.R., and M. Amare. Total parenteral nutrition with glutamine in bone marrow transplantation and other clinical applications (a randomized, double blind study). Journal of Parenteral and Enteral Nutrition 1993:17:407-413.

158. Scheltinga M.R., L.S. Young. K. Bentell, et al. Glutamine-enriched intravenous feedings attenuate extracellular fluid expansion after a standard stress. Annals of Surgery 1991:214:385-395.

159. Young L.S., R. Bye, M. Scheltinga, T.R. Ziegler, D.A Jacobs, and D.W. Wilmore. Patients receiving glutamine-supplemented intravenous feedings report an improvement in mood. Journal of Parenteral and Enteral Nutrition 1993:17:422-427. 


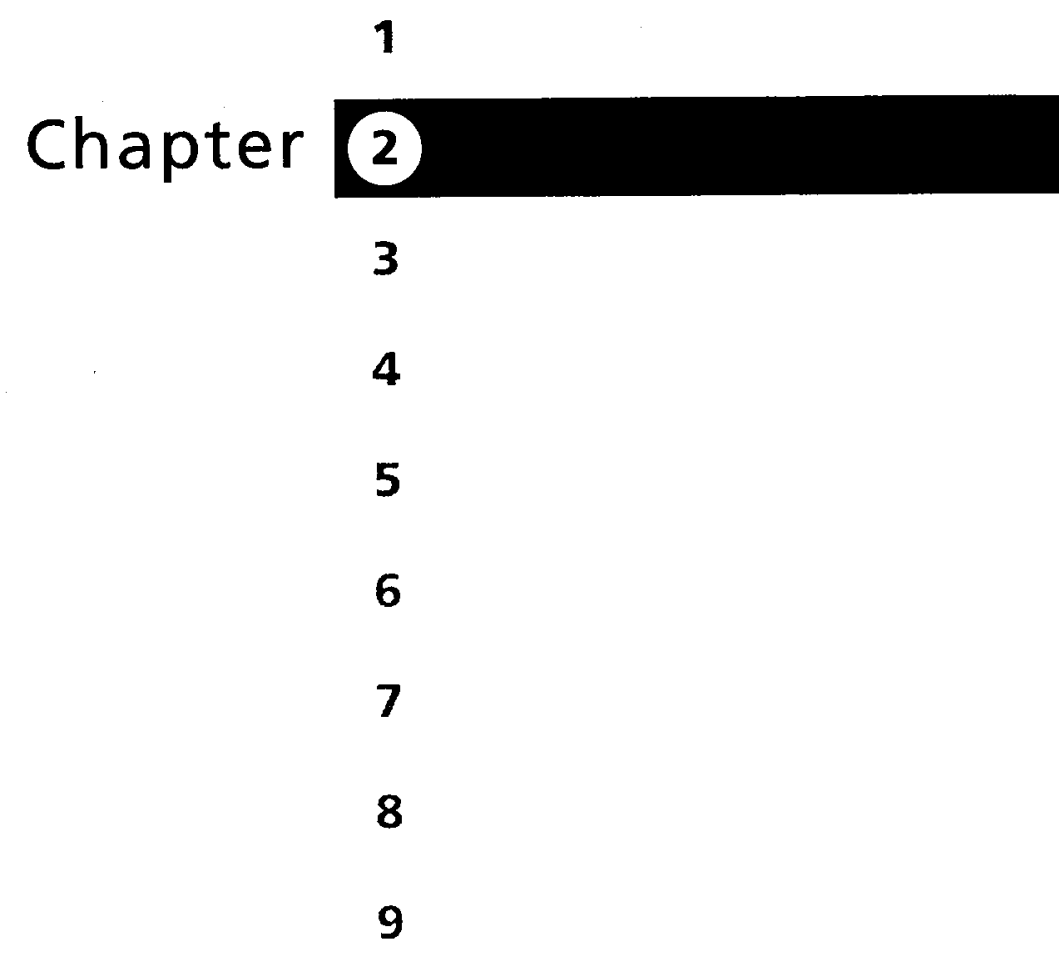




\section{Glutamine extraction by the gut and the effect of nutritional depletion}




\section{Abstract}

Introduction: Glutamine is an important fuel for the intestinal mucosa. However, glutamine pools may become depleted in the cancer-bearing host as a result of tumor consumption and diminished production due to nutritional depletion. As human data are lacking, we investigated glutamine extraction by different sites of the human intestine including tumor and the potential relationship with the degree of nutritional depletion.

Patients and Methods: Thirty-two patients with gastrointestinal malignancies were studied. During surgery blood from an artery and veins draining jejunum, ileum, colon or tumor was sampled. Depletion was estimated by the percentage ideal body weight (PIB).

Results: Fractional glutamine extraction rate in the jejunum was $24 \%$, three times higher than in ileum and colon. PIB correlated with arterial glutamine levels $(r=0.5275$. $\mathrm{p}=0.003$ ). In addition, arterial glutamine concentrations were correlated with extraction in the ileum $(r=-0.8411$. $p<0.001$ ). Colon containing tumor did not extract more glutamine than non-tumor containing colon.

Conclusions: Glutamine is quantitatively a more important substrate for the proximal intestine than for the distal gut. Nutritional depletion results in decreased arterial glutamine concentration which in turn results in diminished extraction. Colon cancer does not function as a glutamine trap and does not contribute to glutamine depletion.

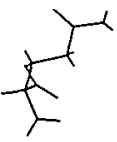


Weight-losing patients have an increased risk to develop postoperative complications $(1,2,3)$. Deterioration of the gut barrier and impaired immune function are thought to cause increased morbidity and mortality in these nutritionally depleted patients $(4,5)$.

It is hypothesized that diminished supply of the non-essential amino acid glutamine, an important substrate for the immune system and the intestine (6), causes impaired immune and gut function in depleted patients. Clinical studies revealed beneficial effects of glutamine addition to parenteral nutrition on gut permeability and morphology, nitrogen balance and hospitalization time (7-10). A diminished glutamine supply may hypothetically be caused by an impaired production due to loss of body protein stores, and due to a diminution of the machinery to produce glutamine. In addition, in cancer patients, increased utilization by rapidly growing tumors may diminish glutamine supply (11). However, recent studies did not provide evidence for glutamine consumption by human colon carcinomas $(12,13)$.

Glutamine extraction by the gut in relation to degree of nutritional depletion is not documented. In the few human studies in which glutamine consumption by the intestinal tract was investigated, portal blood was sampled (14-16). This does not exclusively reflect extraction by only the intestine but also by the other portal drained viscera like the spleen and pancreas (17). Furthermore, extraction of glutamine varies in different parts of the intestinal tract (e.g. jejunum, ileum, colon). In animal studies it has been observed that glutamine is proportionally a more important fuel in the proximal gut compared to the distal gut (18). However, extraction of glutamine at various sites of the human gut is unknown.

The first aim of this study was to evaluate extraction of glutamine and balances of other amino acids, ammonia, glucose and lactate across tumor containing colon, healthy colon, and healthy jejunum and ileum. The second aim was to study the influence of nutritional depletion on glutamine extraction by the intestine.

2.2 Patients and methods

\section{Patients}

Patients admitted for elective gastrointestinal surgery were included in the study. Initially the study was designed to compare substrate balances between non-tumorous tissue and tumorous tissue of the human colon. This study was done in twentyone patients with cancer of the colon. In respectively 18 and 13 tumor-bearing patients also ileum and jejunum were sampled. Patients were excluded if they were insulin-dependent diabetics, metabolically unstable (temperature $>38.5^{\circ} \mathrm{C}$, abscesses), or had impaired cardiac, respiratory, renal, or hepatic function. Percentage weight loss (PWL) in the three months prior to surgery was registered and percentage ideal body weight (PIB) was calculated using tables of the Metropolitan life insurance company (19). Preoperatively, the bowel was irrigated or conservatively prepared. 


\section{Investigative procedure}

All studies were performed during operation under general anaesthesia. After laparotomy the colon tumor was visualized and the major draining vein was isolated and cannulated. Normal colon, distal ileum ( $15 \mathrm{~cm}$ proximal of the ileocecal valve), and jejunum ( $15 \mathrm{~cm}$ distally from the ligament of Treitz) were isolated and draining veins were cannulated. In patients with colon cancer the non-tumorous site of the colon was used to obtain normal colon samples (e.g. in a patient with cancer of the sigmoid, sampling was done in the right colon). To minimize the effect of variations in blood flow on the concentration differences, samples were simultaneously collected and the veins cannulated where of similar size and distance from the corresponding part of the intestine. In addition, samples were obtained by continuous genthe unforced suction of the cannulated vein. Venous and arterial blood was sampled in heparinized syringes.

\section{Sample processing and analysis}

Blood samples were immediately put on crushed ice and centrifuged within 15 minutes. Centrifugation was performed at $4^{\circ} \mathrm{C}$ during 5 minutes at $8,800 \mathrm{~g}$. Samples were frozen in liquid nitrogen and kept at $-80^{\circ} \mathrm{C}$ until determination. Ammonia, glucose and lactate were determined spectrophotometrically by standard enzymatic methods using commercial kits as described previously (20). Plasma amino acids were determined with a fully automated high performance liquid chromatography system as previously described (21).

\section{Tumor histology}

The resected tumors were transported to the department of Pathology. The largest diameter of the unfixed tumor was measured. Specimens were fixed in formalin solution and processed for paraffin sections. For histological examination, hematoxylin and eosin stained sections were used. The tumor type, degree of differentiation, Jass and Dukes classification, and vascularization were assessed. Vascularization was assessed using a simplification of the method used by Vermeulen et al (22). One section per tumor was studied. The entire section was systematically scanned at $\times 100$ magnification in order to find areas of the most intensive vascularization. Whenever a highly vascularized area was encountered, individual vessels were counted on a single $\times 100$ field. Results on the vascularization of the tumor were expressed as the highest number of vessels identified within any single field.

\section{Calculations and statistics}

Data are presented as means with standard error of the mean. Venous minus arterial balances ( $V$ - $A$ ) of amino acids were calculated (venous minus arterial concentration positive $=$ release, venous minus arterial concentration negative $=$ extraction). Fractional extraction was calculated using the following formula: 100\%x(larterial][venous])/[arterial]. The sum of all amino acids (SumAA) was calculated by adding the concentration of all the individual amino acids. The branched chain amino acids (BCAA) were calculated by adding leucine, isoleucine and valine.

Statistical analysis was performed using the Mann-Whitney $U$ test for comparison 
between groups. Significant extraction or release of substrates was tested against zero with a Wilcoxon test. Spearman correlations were performed between variables. The statistical procedures were performed with a SPSS-PC+ software program (23) on a MS-DOS personal computer. The study was approved by the Medical Ethical Committee of the University Hospital Maastricht.

2.3 Results

\section{Patients}

Thirty-two patients, 19 men and 13 women were studied. Mean age of the patients was $70 \pm 2$. Twenty-six patients suffered from colon or rectum cancer, 5 patients had gastric cancer and one patient had a pancreatic carcinoma. Ten patients had suffered weight loss in excess of 10 percent of their usual weight. Three patients received preoperative parenteral nutritional support. Mean percentage of ideal body weight was $101 \pm 3 \%$.

\section{Studies in non-tumorous colon, ileum and jejunum}

There was no significant $V$-A difference of glucose across the colon (table 1). In part this might be due to the high standard deviation of glucose balances. Arterial and venous SumAA were comparable. Quantitatively the largest extraction was observed for glutamine. This was associated with a release of ammonia. In the colon most amino acids exhibited a modest extraction but besides glutamine only the extraction of threonine and valine reached significance. Ammonia, lactate, alanine and taurine were released by normal colon tissue. No difference in arterial-venous balance of the measured energy yielding substrates was observed between the left and right side of the colon (table 2). There was no correlation between arterial glutamine concentrations and extraction in the colon (figure 1)

In analogy to the colon a high extraction of glutamine was found in the ileum. This was associated with ammonia release. Also lactate, glutamate, glycine, alanine, citrulline, arginine and taurine were released by the ileum. In the ileum a significant correlation between arterial glutamine concentration and extraction was observed $(r=$ $-0.8411, p<0.001$, figure 1 ).

Significant extraction or release of substrates was most pronounced in the jejunum. In the jejunum the correlation found between arterial glutamine concentrations and extraction did not reach significance $(p<0.2)$. Similar as in colon and ileum release of ammonia was associated with glutamine extraction. Glutamine extraction was related to ammonia release in ileum and jejunum (figure 2). In addition to ammonia, release was observed for glutamate, glycine, citrulline, alanine, arginine and taurine. Again, in the jejunum neither glucose extraction nor lactate release were significantly different from zero.

$V$-A differences and fractional extraction of glutamine was significantly higher in the jejunum compared to ileum and colon (figure 3). Fractional extraction of glutamine by the jejunum was $24 \%$, three times higher than in ileum and colon for which extraction was respectively 9 and 8 percent. As a consequence of high glutamine 
extraction alanine and ammonia release were significantly higher in the jejunum as compared to ileum and colon (figure 4). Significant differences for citrulline release were observed with a gradual increase of release from the distal towards the proximal gut.

\begin{tabular}{|c|c|c|c|c|c|c|c|c|}
\hline \multirow{3}{*}{$\begin{array}{l}\text { Amm } \\
\text { Glucose }\end{array}$} & \multicolumn{2}{|c|}{ Tumor } & \multicolumn{2}{|c|}{ Colon } & \multicolumn{2}{|c|}{ lleum } & \multicolumn{2}{|c|}{ Jejunum } \\
\hline & 39.3 & $\pm 9.9 * *$ & 30.1 & $\pm 8.2^{\star \star}$ & 33.2 & $\pm 7.3 *$ & 65.4 & $\pm 6.5^{\star \star} \neq \ddagger$ \\
\hline & -0.6 & $\pm 0.3^{\star \star}$ & -0.3 & \pm 0.3 & 0.2 & $\pm 0.2 \neq$ & 0.1 & \pm 0.211 \\
\hline Lact & 0.5 & $\pm 0.1 * \star t$ & 0.2 & $\pm 0.1 * \star$ & 0.1 & \pm 0.1 & 0.0 & $\pm 0.1+t$ \\
\hline GLU & 0.9 & \pm 1.9 & 2.0 & \pm 1.9 & 20.6 & $\pm 7.5 * n$ & 25.7 & $\pm 5.6 \star \S$ \\
\hline ASN & 0.5 & \pm 0.7 & -0.9 & \pm 0.9 & 7.2 & $\pm 3.5 * \S \S$ & 3.4 & \pm 1.5 \\
\hline SER & -14.6 & $\pm 7.8^{\star \star}$ & -11.2 & \pm 8.5 & -4.2 & $\pm 9.8 \neq$ & -2.7 & \pm 3.6 \\
\hline GLN & -22.8 & \pm 5.0 * & -32.2 & $\pm 7.5 * *$ & -44.8 & $\pm 5.6 * \pi$ & -119.7 & 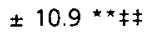 \\
\hline GLY & 4.6 & $\pm 6.0^{\star}$ & -2.9 & \pm 7.0 & 15.2 & $\pm 8.3 * \star \S \S$ & 16.0 & $\pm 3.0 * * t \dagger$ \\
\hline THR & -3.4 & \pm 1.9 & -5.0 & $\pm 2.4^{*}$ & 2.3 & $\pm 3.1 \pi$ & 1.1 & \pm 2.7 \\
\hline HIS & -1.1 & \pm 1.0 & -3.2 & \pm 1.7 & $\cdot 0.7$ & \pm 1.5 & -2.1 & \pm 1.4 \\
\hline CIT & -0.1 & \pm 0.4 & -0.2 & \pm 0.5 & 8.4 & $\pm 1.7 * * \pi$ & 30.4 & $\pm 4.0^{\star \star} \neq \ddagger$ \\
\hline ALA & 23.8 & $\pm 4.0 * \star$ & 20.2 & $\pm 5.0^{* *}$ & 44.4 & $\pm 11.4 * \star$ & 75.3 & $\pm 10.3^{\star *} \neq \ddagger$ \\
\hline TAU & 7.9 & $\pm 4.8 *$ & 6.8 & $\pm 2.3^{\star \star}$ & 31.1 & $\pm 13.0 * \star n$ & 13.4 & $\pm 3.7^{\star \star}$ \\
\hline ARG & 1.6 & \pm 1.2 & 0.5 & \pm 1.4 & 10.5 & $\pm 3.3 * \star 7$ & 9.3 & $\pm \quad 2.0^{* *} \S$ \\
\hline$\alpha A B A$ & 0.4 & \pm 0.3 & -0.3 & \pm 0.5 & 1.3 & $\pm 0.7 *$ & 1.4 & $\pm \quad 0.7$ \\
\hline TYR & -0.8 & \pm 1.1 & -1.9 & $\pm \quad 1.4$ & 2.2 & $\pm 1.7 * \eta$ & 2.0 & \pm 1.4 \\
\hline VAL & -2.5 & \pm 2.2 & -7.1 & \pm 3.3 * & 3.6 & $\pm 2.7 \S \S$ & 2.1 & \pm 3.6 \\
\hline MET & 0.1 & \pm 0.4 & -0.2 & \pm 0.5 & 1.3 & $\pm 0.5 * \S \S$ & 1.3 & \pm 0.6 \\
\hline ILE & -0.9 & \pm 1.1 & -2.8 & \pm 1.8 & 1.8 & \pm 1.6 & 1.9 & $\pm \quad 1.4$ \\
\hline PHE & -0.3 & \pm 0.9 & -1.4 & \pm 1.2 & 1.4 & $\pm \quad 1.4$ & 1.2 & \pm 1.2 \\
\hline TRP & -0.4 & \pm 0.4 & -0.5 & \pm 0.6 & 0.7 & \pm 0.5 & 0.1 & \pm 0.6 \\
\hline LEU & -1.8 & \pm 2.7 & -3.8 & \pm 3.3 & 4.1 & \pm 2.8 & 3.8 & \pm 2.8 \\
\hline LYS & 2.1 & $\pm \quad 5.5$ & 9.3 & \pm 8.4 & 2.0 & \pm 6.6 & -5.9 & \pm 9.7 \\
\hline$B C A A$ & -5.1 & \pm 5.3 & -13.6 & \pm 8.0 & 9.5 & $\pm 6.7 \S \S$ & 7.7 & \pm 7.6 \\
\hline SumAA & -6.7 & \pm 31.4 & -40.2 & \pm 45.5 & 108.2 & \pm 65.4 & 57.9 & \pm 40.3 \\
\hline
\end{tabular}

Table 1. V-A differences across isolated parts of the human gut.

Venous minus arterial concentrations of amino acids, ammonia, glucose and lactate in colon, ileum, jejunum and tumor. Concentrations are given in $\mu \mathrm{mol} / /$ except for lactate and glucose $(\mathrm{mmo} / /)$. Significant uptake or release $(+$ =uptake, - =release) is indicated with: ${ }^{*}=p<0.05$ and ${ }^{*}=p<0.01$. Significant differences between groups are indicated with: $\ddagger \neq=p<0.05$ jejunum versus colon, ileum and tumor, $\xi=p<0.01$ jejunum versus colon and tumor, $\|=p<0.01$ jejunum versus tumor, $t \dagger=p<0.05$ jejunum versus colon, $\eta=p<0.05$ ileum versus colon and tumor, $\S \S=p<0.05$ ileum versus colon, $\neq=p<0.05$ ileum versus tumor, $t=p<0.01$ tumor versus colon, ileum and jejunum.

\begin{tabular}{l|rr} 
& Right colon $(n=10)$ & Left colon $(n=10)$ \\
\hline Ammonia & $38.6 \pm 14.9$ & $24.6 \pm 8.6$ \\
Glucose & $-0.3 \pm 0.3$ & $-0.4 \pm 0.5$ \\
Lactate & $0.2 \pm 0.1$ & $0.2 \pm 0.1$ \\
Glutamine & $-26.3 \pm 7.8$ & $-39.4 \pm 13.8$ \\
\hline
\end{tabular}

Table 2. Extraction and release of ammonia, lactate, glucose and glutamine in right and left colon.

Venous minus arterial concentration differences are presented for the left and right hemicolon. No significant differences were observed. 


\section{Effect of nutritional depletion.}

PWL was not related to differences for glucose, lactate and amino acid extraction or release in the colon. Ammonia release in colon, however, was lower in patients with a PWL of more than $10 \%$ (figure 5). The difference in ammonia release was associated with a decreased extraction of glutamine, although the difference between weight losing and weight stable patients did not reach significance. In addition, in patients with a PIB below $95 \%$, ammonia release in the colon was lower compared to patients with a PIB above $95 \%$. In the ileum a modest correlation between PIB and extraction of glutamine was observed $(r=0.4182, p=0.08)$. In the jejunum PIB and glutamine balance were not significantly related. An effect of PWL on substrate metabolism in ileum or jejunum could not be demonstrated. However, the groups were too small for statistical analysis. Arterial glutamine concentrations were correlated with $\mathrm{PIB}(r=0.5275, p<0.01$, figure 6$)$.
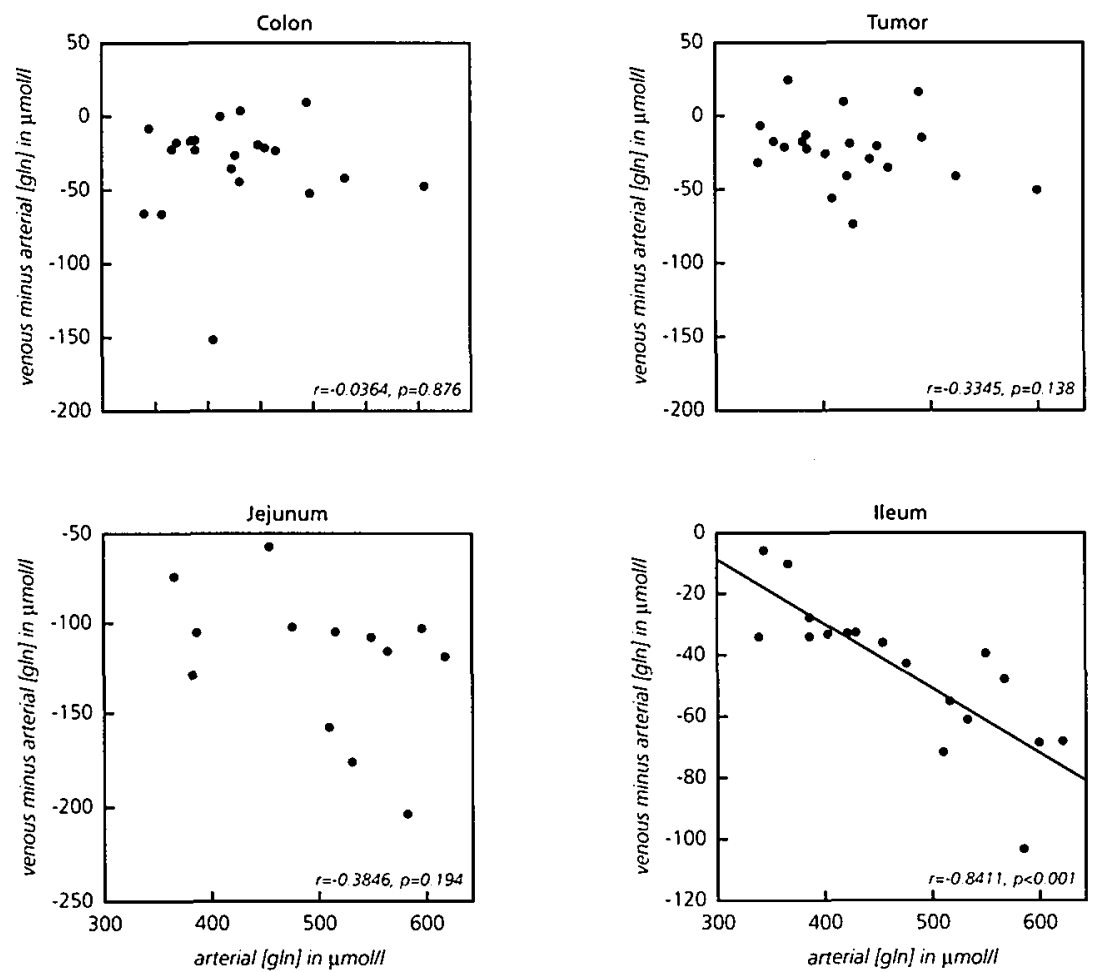

Figure 1. Correlations between arterial levels of glutamine and V-A differences of glutamine across colon, tumor, ileum and jejunum. Amino acids expressed in $\mu \mathrm{mol} / \mathrm{l}$. 

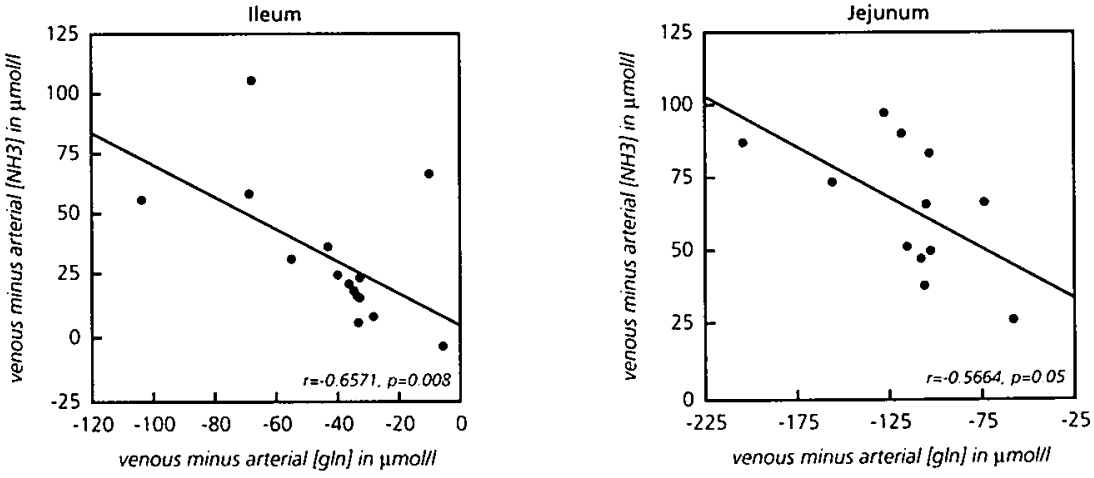

Figure 2. Relation between ammonia release and glutamine uptake in ileum and jejunum expressed in $\mu \mathrm{mo} / \mathrm{l}$

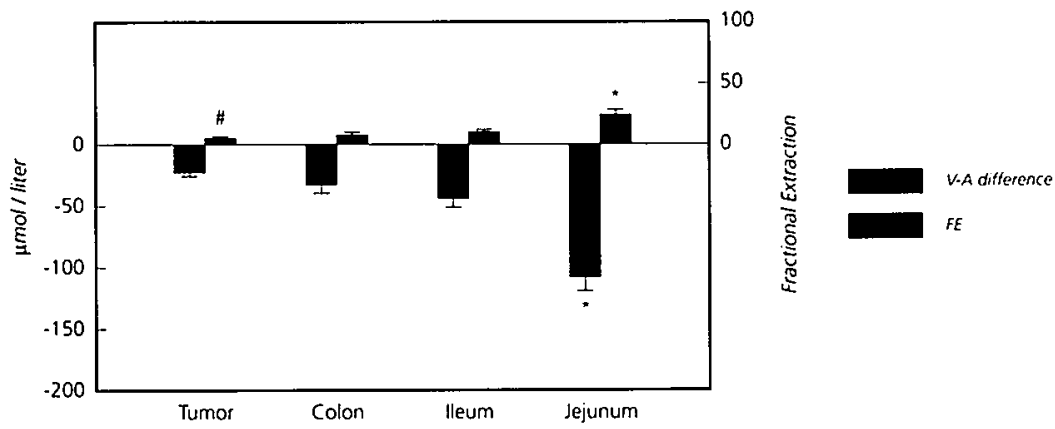

Figure 3. V-A differences and fractional extraction rates for glutamine across colon, ileum, jejunum and tumor.

Values are means \pm SEM. FE $=$ Fractional extraction. ${ }^{*}=p<0.005$ versus colon, ileum and tumor. $\#=p<0.05$ versus ileum.
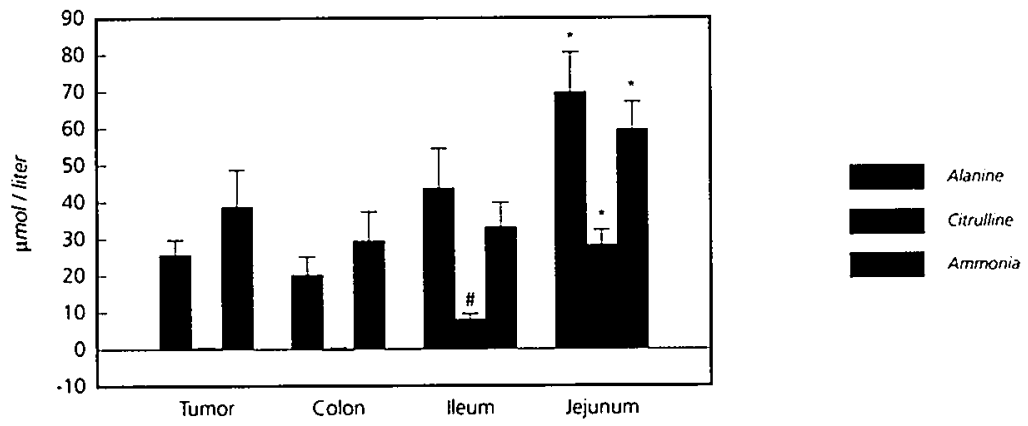

Figure 4. Venous minus arterial balances for alanine, citrulline and ammonia across colon, ileum, jejunum and tumor. Values are means \pm SEM. ${ }^{*}=0<0.05$ versus colon, ileum and tumor, $\#=p<0.01$ versus colon and tumor. 


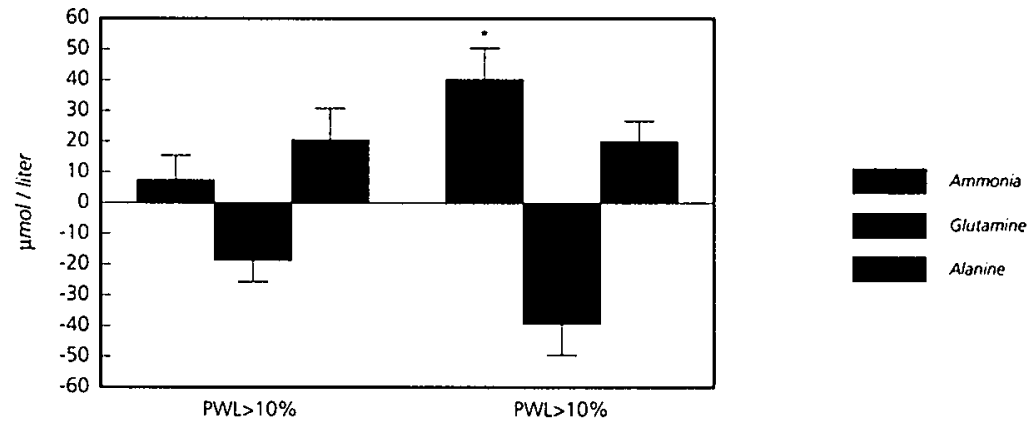

Figure 5. V-A balances for ammonia and glutamine across colon in weight-losing and weight stable patients.

Values are means \pm SEM. PWL = percentage of weightloss three months before surgery. ${ }^{*}=p<0.05$ versus weight-losing patients.

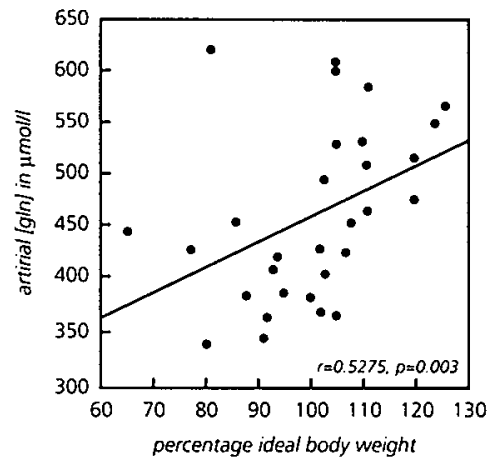

Figure 6. Relation between arterial glutamine level and percentage ideal body weight

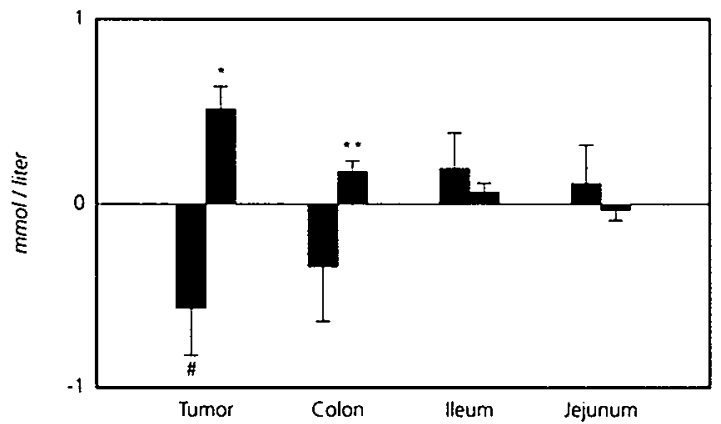

Figure 7. V-A balances for lactate and glucose across colon. Values are means \pm sem. ${ }^{\star}=p<0.01$ versus colon, ileum and jejunum, ${ }^{\star \star}=p<0.05$ versus jejunum, $\#=p<0.05$ versus ileum and jejunum. 


\section{Studies in cancer containing colon}

In tumor containing colon glutamine extraction was observed. In addition, serine was taken up across the tumorous part of the colon. Glucose was taken up by the tumor containing tissue, in contrast with healthy parts of the gut. Ammonia, lactate, glycine, alanine and taurine were released by tumor tissue. For a correct interpretation of the data it is important to notice that there was no net extraction of amino acids by the tumor containing colon.

The only major difference between normal colon and tumor containing colon was a threefold higher lactate release by the tumor containing part of the colon $(p<0.01$, figure 7). In addition, tumor containing colon was the only site were glucose extraction was significantly different from zero.

The effect of tumor characteristics on substrate utilization is presented in table 3 . In this study no significant effect of tumor type, degree of differentiation, Jass or Duke classification, tumor size, and vascularization could be observed.

\begin{tabular}{|c|c|c|c|c|c|}
\hline Tumor characteristic (n) & Glutamine & Ammonia & Glucoses & Lactate & \\
\hline \multicolumn{6}{|l|}{ Tumor type } \\
\hline adenocarcinoma (16) & $-20.5 \pm 5.8$ & $36.0 \pm 10.5$ & $-0.6 \pm 0.3$ & $0.5 \pm$ & 0.1 \\
\hline mucinous adenoca (4)* & $-34.6 \pm 12.8$ & $55.3 \pm 32.7$ & $-0.8 \pm 0.5$ & $0.3 \pm$ & 0.3 \\
\hline \multicolumn{6}{|l|}{ Differentiation } \\
\hline well-intermediate (12) & $-23.4 \pm 7.2$ & $35.4 \pm 12.7$ & $-0.7 \pm 0.4$ & $0.5 \pm$ & 0.2 \\
\hline intermediate-poor $(6)^{\star}$ & $-15.5 \pm 5.0$ & $49.9 \pm 24.2$ & $-0.1 \pm 0.1$ & $0.5 \pm$ & 0.1 \\
\hline \multicolumn{6}{|l|}{ Dukes classification } \\
\hline Dukes A-B (10) & $-28.7 \pm 9.3$ & $23.7 \pm 5.9$ & $-1.0 \pm 0.5$ & $0.4 \pm$ & 0.1 \\
\hline Dukes C.D (10)* & $-17.8 \pm 4.9$ & $55.9 \pm 17.0$ & $-0.3 \pm 0.1$ & $0.6 \pm$ & 0.2 \\
\hline \multicolumn{6}{|l|}{ Jass classification } \\
\hline Jass $\geq 2(7)$ & $-21.5 \pm 11.5$ & $19.9 \pm 5.2$ & $-1.3 \pm 0.8$ & $0.3 \pm$ & 0.1 \\
\hline Jass $>2(9)^{\star}$ & $-21.0 \pm 5.5$ & $49.9 \pm 17.2$ & $-0.2 \pm 0.1$ & $0.6 \pm$ & 0.2 \\
\hline \multicolumn{6}{|l|}{ Tumor size } \\
\hline $\operatorname{diam} .<4 \mathrm{~cm}(9)$ & $-27.8 \pm 5.1$ & $40.9 \pm 18.7$ & $-0.8 \pm 0.5$ & $0.6 \pm$ & 0.2 \\
\hline diam. $\geq 4 \mathrm{~cm}(10)^{*}$ & $-19.9 \pm 9.6$ & $41.7 \pm 12.8$ & $-0.6 \pm 0.2$ & $0.4 \pm$ & 0.2 \\
\hline \multicolumn{6}{|l|}{ Tumor vascularization } \\
\hline$<30$ vessels/field (8) & $-15.1 \pm 7.7$ & $35.1 \pm 17.1$ & $-0.4 \pm 0.2$ & $0.2 \pm$ & 0.2 \\
\hline$\geq 30$ vessels/field $(12)^{\star}$ & $-28.7 \pm 6.9$ & $43.0 \pm 13.5$ & $-0.7 \pm 0.4$ & $0.6 \pm$ & 0.2 \\
\hline
\end{tabular}

Table 3. Extraction and release of ammonia, lactate, glucose and glutamine depending on tumor characteristics. Tumor balances for glutamine, glucose, ammonia and lactate depending on different tumor characteristics. No significant differences were observed for the criteria presented. * remaining cases not classified. 
This study clearly shows that glutamine is extracted at all locations in the human intestine with the highest fractional extraction in the jejunum. This extraction of glutamine was found to be associated with release of the metabolic products of glutamine degradation in the enterocyte: ammonia, alanine and citrulline. Also, glutamine extraction in the ileum was found to be related to the arterial concentration of glutamine.

A drawback of the method of selective sampling used in this study compared to portal vein sampling is the lack of flow measurements $(17,24)$. Segmental flow measurement in isolated parts of the bowel would require invasive surgical techniques (isolation of specific parts of the vascular tree of the healthy bowel and even of the bowel wall itself) which is ethically unacceptable. Furthermore, the influence of the trauma of the surgical procedure itself would have modifying effects on the obtained flow data and would therefore make the interpretation of the obtained data very difficult even in the experimental animal. It is important to notice that the magnitude of the measured $V$-A differences should be interpreted with care, because regional flow differences may have a modifying effect on these differences. Therefore, less attention should be given to small differences in balances between the several parts of the intestine. However, despite absence of flow measurement, the data obtained in this study provide interesting information. First, the direction of $\mathrm{V}$-A difference is measured: extraction vs release. This provides qualitative data about intestinal metabolism of substrates. Second, within each region $V$-A differences of separate substrates may be compared to one another, because flow effects would affect $V$-A differences to the same magnitude. Third, differences in V-A balances between the regions due to differences in blood flow would have a quantitatively equal effect on all substrates measured. When only one substrate or several related substrates are more extracted or released in one part of the intestine it strongly supports the conclusion that this is not caused by differences in regional flow but due to increased metabolism of the specific substrate.

Neptune (25) discussed glutamine metabolism in the intestine observing the oxidation of ${ }^{14} \mathrm{C}$ glutamine to ${ }^{14} \mathrm{CO}_{2}$ by incubated ileal tissue of various animal species. Subsequently, numerous in vitro and in vivo studies confirmed the importance of circulating glutamine for the intestine $(18,26-28)$. Early in vivo human studies in which arterial and hepatic venous blood was sampled did not provide information concerning the relative contribution of the liver and the other splanchnic organs to amino acid metabolism (14-16). More recently, glutamine extraction by the portal drained viscera in humans was studied. Extraction varies from $3 \%$ in septic patients (29) to $14 \%$ in healthy individuals undergoing elective surgery for uncomplicated cholelithiasis (30). In trauma patients $V$-A differences of amino acids were studied several days after surgery. Glutamine was the only amino acid extracted at a rate of approximately $15 \%$ (31). These studies suggest that the gut is indeed an important consumer of glutamine in man. However, $V$-A fluxes obtained by measuring the portal vein concentration of amino acids represent not only the small intestine, large intestine and stomach, but also the pancreas and spleen (17). Our data extend the former observations in that there is selective extraction of glutamine by ileum, 
jejunum and colon. In the literature it is suggested that the proximal colon may have a preference for glutamine metabolism, whereas the left colon uses the short chain fatty acids preferably (32). Recent in vitro studies however, have demonstrated glutamine utilization in the proximal as well as in the distal colon $(33,34)$. In this study no difference in glutamine balance between the left and right hemicolon was observed. The higher extraction of glutamine by the jejunum compared to the rest of the intestine may imply that especially the proximal intestine is dependent on glutamine. Therefore, addition of glutamine to (par)enteral nutrition probably has the greatest effects on the proximal gut (35). It is unlikely that the high extraction in the jejunum is explained by flow differences, because the extraction and release of other amino acids, not related to glutamine metabolism are not affected.

Figure 8 illustrates the theoretical pathways of glutamine and arginine metabolism in man which may explain the results of this study. Glutamine extraction in ileum and jejunum was associated with release of citrulline, glutamate, alanine and a small but significant amount of arginine. It is generally accepted that the gut has a major role in arginine metabolism by the production of citrulline serving as a precursor for arginine synthesis in the kidney (36-38). Arginine production by the gut itself has been reported in newborn mice (39). To our knowledge production of arginine has not been reported in the adult animal or in humans. However the enzymes argininosuccinate synthase (ASS) and argininosuccinate lyase (ASL), which convert citrulline to arginine are present in the intestine, albeit in small amounts (39). These results also indicate that especially the jejunum contributes to citrulline release. Impaired glutamine metabolism by the gut may result in decreased citrulline release and consequently impaired arginine production by the kidneys. In addition to arginine production from citrulline in the kidney, the gut itself releases arginine. The release of glycine and taurine in the jejunum and especially the ileum most likely reflects the deconjugation of bile acids in the gut and the re-uptake of glycine and taurine derived from deconjugation.

Ammonia production by the intestine is long ascribed to urease activity of intestinal bacteria. However, the current view is that most of the gut ammonia is derived from the amide nitrogen atom of glutamine (40). Although this was not the primary objective, the observations in the current study also indicate that in the post-absorptive state in man ammonia production is predominantly a metabolic process in the proximal bowel. In the absorptive state the contribution of bacteria mediated ammonia production may still be substantial. This bacteria mediated ammonia production would then largely take place in the distal ileum and colon.

In nutritionally depleted patients colonic ammonia production is reduced by about $75 \%$. The reduction in ammonia release was associated with a decrease in glutamine extraction, which however did not reach significance $(p<0.2)$, (figure 5$)$. Decreased uptake of glutamine during starvation associated with decreased ammonia and alanine release has been described in an animal model (41). An increase of glutamine levels from 400 to $600 \mu \mathrm{mol} / \mathrm{l}$ resulted in a threefold increase of glutamine extraction in the ileum (figure 1). This is in line with experimental evidence that uptake of glutamine is dependent on the arterial glutamine concentration and in line with the $\mathrm{Km}$ of glutaminase of approximately $0.6 \mathrm{mmol} / \mathrm{l}(42)$. If we assume that nutritional 
depletion coincides with decreased production of glutamine in muscle, this may be the cause of the observed reduced arterial levels of glutamine present in nutritional depletion. Therefore, nutritional depletion itself may result in impaired supply of glutamine and thus reduced extraction of glutamine. The impaired glutamine extraction observed in this study may explain the decreased mucosal glutamine concentrations in nutritional depletion (43). If we push this line of reasoning even further we may hypothesize that depletion leads to decreased production of glutamine in peripheral tissues, which leads to decreased arterial levels and decreased glutamine extraction, which in turn leads to decreased citrulline production in the gut, and subsequently causes a decrease in precursors for arginine production. This may be relevant to many arginine mediated processes.

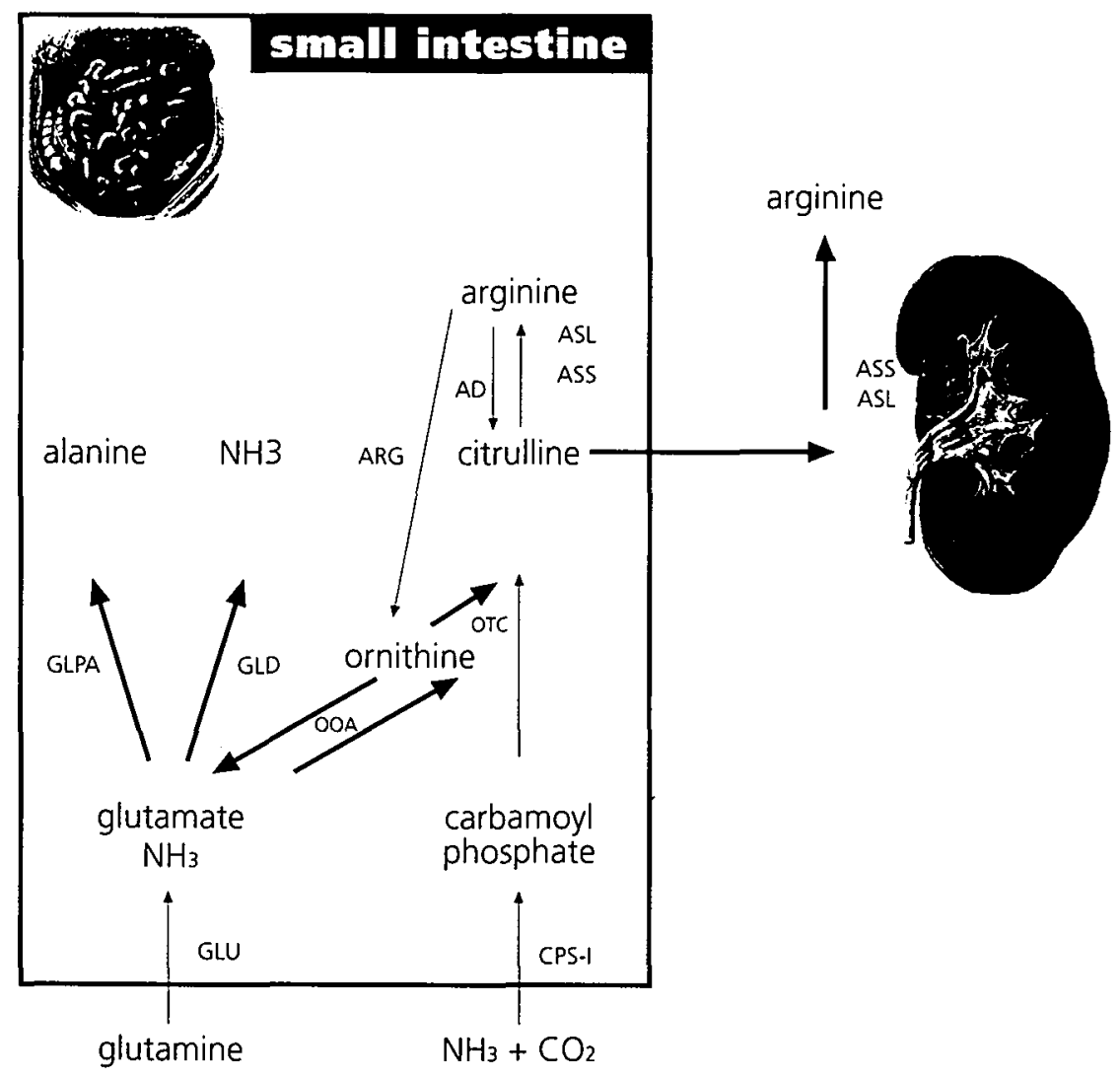

Figure 8. Interorgan relationships in glutamine and arginine metabolism in man.

ASS = argininosuccinate synthetase, ASt = argininosuccinate lyase, CPS-I = carbamyl phosphate synthetase-I, OTC = ornithine transcarbamylase, $G L U=$ glutaminase, $G L D=$ glutamate dehydrogenase, GLPA = glutamic-pyruvic aminotransferase, $O O A=$ ornithine-oxoacid aminotransferase, $A D=$ arginine deiminase, $A R G=$ arginase. 
Malignant cells, like other rapidly dividing cells, oxidize glutamine for energy supply at a rapid rate (11). A high tumor load may therefore theoretically result in a decreased availability of glutamine for other tissues. However, glutamine uptake has not been demonstrated in vivo in human carcinomas $(12,13)$. This is in line with our study in which glutamine was extracted by the tumor at a similar rate as by normal colon. Assuming that blood flow through colonic cancer tissues is not substantially increased compared to normal colonic tissue flow this implies that colon cancerous tissue does not substantially contribute to a depletion of glutamine. To asses whether increased vascularization might have an effect on V-A glutamine balance histological sections were examined. Theoretically, increased vascularization may be associated with increased flow and subsequently decreased $V$-A concentration difference of glutamine. However, no significant difference in balance between highly and modestly vascularized tumors was observed. In addition, other tumor characteristics were not related to differences in substrate balances. Tumor was the only site with significant glucose consumption confirming the observation that human carcinomas rely predominantly on glucose for their energy supply (12). Tumor cells exhibit a high rate of aerobic glycolysis. Although tumor cells possess the full complement of TCA cycle enzymes and carriers of the respiratory chain, a substantial part of the glucose is converted to lactate and not completely oxidized (44). This is clearly demonstrated by the release of lactate by the tumor in this study.

In conclusion, glutamine extraction in the ileum and most likely also in the jejunum is dependent on arterial glutamine concentrations. Nutritional depletion causes reduction of the extraction of glutamine in the gut by reducing arterial glutamine concentrations. The observations in this study provide a potential explanation for the beneficial effects of glutamine on villous height and mucosal barrier in nutritionally depleted patients (10). Tumor containing colon tissue does not seem to be an important glutamine consumer. Consequently, colon cancer does not function as a glutamine trap. 
1. Studley H.O. Percentage of weight loss. A basic indicator fo surgical risk in patients with chronic peptic ulcer. Journal of the American Medical Association 1936: 106:458-460.

2. Von Meyenfeldt M.F., W.J. Meijerink, M.M. Rouflart, M.T. Buil-Maassen, and P.B. Soeters. Perioperative nutritional support: a randomised clinical trial. Clinical Nutrition 1992;11:180-186

3. Windsor J.A., and G.L. Hill. Weight loss with physiologic impairment. A basic indicator of surgical risk. Annals of Surgery 1987;207:290-296

4. Souba W.W., V.S. Klimberg, D.A. Plumley, et al. The role of glutamine in maintaining a healthy gut and supporting the metabolic response to injury and infection. Journal of Surgical Research 1990;48:383-391.

5. Wilmore D.W., R.J. Smith, S.T. O'Dwyer, D.O. Jacobs, T.R. Ziegler, and X.-D. Wang. The gut: a central organ after surgical stress. Surgery 1988; 104:917-923.

6. Dudrick P.S., and W.W. Souba. The role of glutamine in nutrition. Current Opinion in Gastroenterology 1991:7:299-305

7. Ziegler T.R., L.S. Young, K. Benfell, et al. Clinical and metabolic efficacy of glutamine-supplemented parenteral nutrition after bone marrow transplantation Annals of Internal Medicine 1992;1 16:821-828.

8. Stehle P., I. Zander, N. Mertes, et al. Effect of parenteral glutamine peptide supplements on muscle glutamine loss and nitrogen balance after major surgery. Lancet 1988;1:231-233.

9. Hammarqvist F., J. Wernerman, R. All, A. von der Decken, and E. Vinnars. Addition of glutamine to total parenteral nutrition after elective abdominal surgery spares free glutamine in muscle, counteracts the fall in muscle protein synthesis, and improves nitrogen balance. Annals of Surgery 1989:209:455-461.

10. van der Hulst R.R., B.K. van Kreel, M.F. von Meyenfeldt, et al. Glutamine and the preservation of gut integrity. Lancet 1993:334:1363-1365.

11. Souba W.W. Glutamine and cancer. Annals of Surgery 1993;6:615-728.

12. Holm E., E. Hagmüller, U. Staedt, et al. Substrate balances across colonic carcinomas in humans. Cancer Research. 1995:55:1373-1378

13. Hagmüller E., H.B. Kollmar, H.J. Günther, E. Holm and $\mathrm{M}$. Trede. Protein metabolism in human colonic carcinomas: in vivo investigations using a modified tracer technique with $L-[1-13 C]$ leucine. Cancer Research. 1995;55:1160-1167.
14. Erikson L.S., M. Olsson, and O. Björk. Splanchnic metabolism of amino acids in healthy subjects: effect of 60 hours of fasting. Metabolism 1988;37:11591162.

15. Marliss E.B., T.T. Aoki, T. Pozefsky, A.S. Most, and G.F. Cahill. Muscle and splanchnic glutamine and glutamate metabolism in post-absorptive and starved man. The Journal of Clinical Investigation 1971:50:814-817.

16. Lochs H., E. Roth, S. Gasic, W. Hübl, E.L. Morse, and S.A. Adibi. Splanchnic, renal, and muscle clearance of alanyl-glutamine in man and organ fluxes of alanine and glutamine when infused in free and peptide forms. Metabolism 1990;39:833-836.

17. Deutz N.E., P.L. Reijven, G. Athanasas, and P.B. Soeters. Post-operative changes in hepatic, intestinal. splenic and muscle fluxes of amino acids and ammonia in pigs. Clinical Science 1992;83:607-613.

18. Windmueller H.G. Glutamine utilization by the small intestine. Advances in Enzymology 1982;53:201-237.

19. Anonymus. Metropolitan Life Insurance Company. New weight standard for men and women. Bulletin Metropolitan Life Insurance Foundation 1983:64:1. 4

20. Dejong C.H., M.T. Kampman, N.E. Deutz, and P.B. Soeters. Altered glutamine metabolism in rat portal drained viscera and hindquarter during hyperammonemia. Gastroenterology 1992;102:936-948.

21. van Eijk H.M., D.R. Rooyackers, and N.E. Deutz. Rapid routine determination of amino acids in plasma by high-performance liquid chromatography with a 2-3 $\mu \mathrm{m}$ spherisorb ODS II column. Journal of Chromatography 1993;620:143-148.

22. Vermeulen P.B., D. Verhoeven, H. Fierens, et al. Microvessel quantification in primary colorectal carcinoma: an immunohistochemical study. British Journal of Cancer 1995:71:340-343.

23. Norusis M.1. (ed). SPSS/PC+ V3.1 Base manual for the IBM PC/XT/AT and PS/2. SPSS Chicago, 1988.

24. van Berlo C.L., A.E. van den Bogaard, M.C. Bost, and P.B. Soeters. A technique to study splanchnic metabolism in the unrestrained conscious pig. Laboratory Animal Sciences 1988:38:463-466.

25. Neptune E.M. Jr. Respiration and oxidation of various substrates by ileum in vitro. American Journal of Physiology 1965;209:329-332.

26. Windmueller H.G., and A.E. Spaeth. Respiratory fuels and nitrogen metabolism in vivo in small intestine of fed rats. The Journal of Biological Chemistry 1980:255:107-113. 
27. Windmueller H.G., and A.E. Spaeth. Uptake and metabolism of plasma glutamine by the small intestine. The Journal of Biological Chemistry 1974:249.5070-5079.

28. Souba W.W., K. Herskowitz, R.M. Salloum, M.K. Chen, and T.R. Austgen. Gut glutamine metabolism. Journal of Parenteral and Enteral Nutrition 1990;145:455-495.

29. Souba W.W., K. Herskowitz, and V.S. Klimberg. The effects of sepsis and endotoxemia on gut glutamine metabolism. Annals of Surgery 1990;211:543-551.

30. Felig P., J. Wahren, I. Karl, E. Cerasi, R. Luft, and D.M. Kipnis. Glutamine and glutamate metabolism in normal and diabetic subsjects. Diabetes 1973;22:573576.

31. Mc Anena O.J., F.A. Moore, E.E. Moore, T.N. Jones, and $\mathrm{P}$. Parsons. Selective uptake of glutamine in the gastrointestinal tract: confirmation in a human study. Bristish Journal of Surgery 1991;78:480-482.

32. Roediger W.E. Role of anaerobic bacteria in the metabolic welfare of the colonic mucosa. Gut 1980;21:793-798.

33. Scheppach W., C. Loges, P. Bartram, et al. Effect of free glutamine and alanyl-glutamine dipeptide on mucosal proliferation of the human ileum and colon. Gastroenterology 1994;107:429-434.

34. Fleming S.E., D. Fitch, S. DeVries, M.L. Liu, and C Kight. Nutrient utilization by cells isolated from rat jejunum, cecum and colon. Journal of Nutrition $1991 ; 121: 869-878$.

35. Tamada H., R. Nezu, I. Imamura, et al. The dipeptide alanyl-gluamine prevents intestinal mucosal atrophy in parenterally fed rats. Journal of Parenteral and Enteral Nutrition 1992;16:110-116.

36. Brosnan J.T. The role of the kidney in amino acid metabolism and nutrition. Canadian Journal of Physiology and Pharmacology 1987;65:2355-2362.

37. Featherson W.R., Q.R. Rogers, and R.A. Freedland. Relative importance of kidney and liver in synthesis of arginine by the rat. American Journal of Physiology 1973;224:127-129.

38. Dejong C.H., N.E. Deutz, and P.B. Soeters. Metabolic adaptation of the kidney to hyperammonemia during chronic liver insufficiciency in the rat. Hepatology 1993;18:890-902.

39. Hurwitz R., and N. Kretchmer. Development of arginine-synthesizing enzymes in mouse intestine. American Journal of Physiology 1986:251:G103. G110.
40. Newsholme E.A., and A.R. Leech. Metabolism of ammonia. In: Biochemistry for the medical sciences $P p$ 481-508. Newsholme E.A., and Leech A.R. (ed). John Wiley and Sons Ltd. Chichester, 1992.

41. Dejong C.H., N.E. Deutz, and P.B. Soeters. Inter-organ nitrogen exchange during prolonged starvation in the rat. Journal of Clinical Nutrition and Gastroenterology 1991:6:176-183.

42. Inoue Y., J. Epat, D.J. Frohnapple, H. Epstein, E.M. Copeland, and W.W. Souba. Effect of total parenteral nutrition on amino acid and glucose transport by the human small intestine. Annals of Surgery 1993:217:604-614

43. van der Hulst R.R., N.E. Deutz, M.F. von Meyenfeldt, J.M. Elbers, R.W. Stockbrügger, and P.B. Soeters. Decrease of mucosal glutamine concentration in the nutritionally depleted patient. Clinical Nutrition 1994;13:228-233.

44. Newsholme E.A., and A.R. Leech. Catabolism of carbohydrates. In: Biochemistry for the medical sciences Pp 167-245. Newsholme E.A., and Leech A.R. (ed). John Wiley and Sons Ltd. Chichester, 1992. 
Glutamine extraction by the gut and the effect of nutritional depletion 


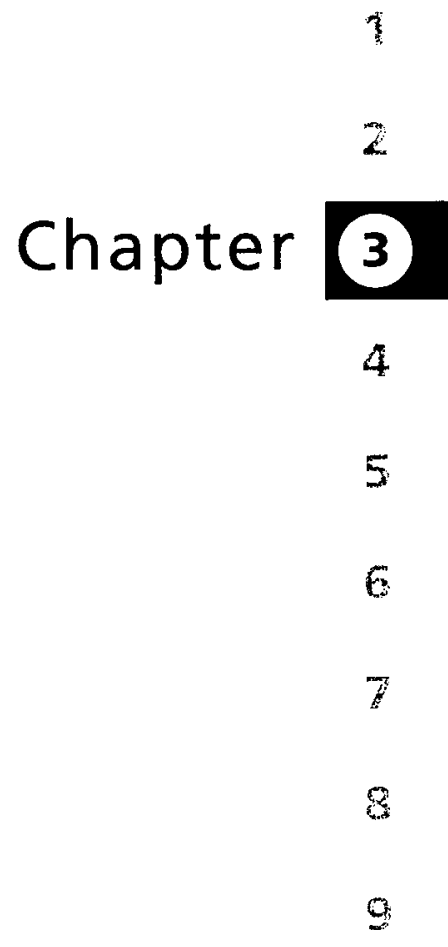




\section{Nutritional depletion and mucosal glutamine concentration}

R.R.W.J. van der Hulst, N.E.P. Deutz, M.F. von Meyenfeldt, J.M.H. Elbers, R.W. Stockbrügger, P.B. Soeters. 
Introduction: A diminished glutamine delivery by peripheral tissues is suggested to play an important role in the etiology of postoperative complications of nutritionally depleted patients. Decreased glutamine supply to the gut mucosa in these nutritionally depleted patients may have important consequences for the integrity of the gut mucosa barrier. To evaluate whether glutamine concentration in the gut mucosa of depleted patients is altered, patients with either a fat-free mass index below $90 \%$ or percentage ideal body weight below $90 \%$ as a result of weight loss were studied.

Patients and Methods: Twenty-two patients admitted to the University Hospital Maastricht and 14 controls were studied. After an overnight fast, venous blood was sampled and duodenal biopsies were obtained by endoscopy. Plasma and tissue amino acids were measured. Fat-free mass was determined by bioelectrical impedance measurement.

Results: In 10 depleted patients glutamine concentration duodenal mucosa was $2883 \pm 250 \mu \mathrm{mol} / \mathrm{kg}$ dry weight. Concentration of alanine was $2570 \pm 263 \mu \mathrm{mol} / \mathrm{kg}$ dry weight. In the non-depleted patients glutamine and alanine concentrations were respectively $3463 \pm 171 \mu \mathrm{mol} / \mathrm{kg}$ dry weight and $3540 \pm 315 \mu \mathrm{mol} / \mathrm{kg}$ dry weight. Concentrations in controls were $3296 \pm 176 \mu \mathrm{mol} / \mathrm{kg}$ dry weight for glutamine and $3682 \pm 372 \mu \mathrm{mol} / \mathrm{kg}$ dry weight for alanine. Concentrations for alanine and glutamine were significantly lower in depleted patients compared to nondepleted patients. Also, alanine and glutamine concentrations were significantly correlated with percentage ideal body weight $(r=0.43, p<0.005$ for glutamine and $r=0.62$. $p<0.001$ for alanine) and fat-free mass index $(r=0.42$. $p<0.05$ for glutamine and $r=0.48, p<0.01$ for alanine) Conclusions: This study suggests that in patients depletion is related to decreased plasma and mucosa glutamine and alanine concentration. 
Malnutrition is associated with an increased rate of postoperative morbidity and mortality (1-3). An impaired host metabolic and immune response may play an important role in the underlying pathophysiological mechanism. It has been suggested that a diminished integrity of the intestinal mucosa barrier promotes cholestasis and multiple organ failure. These phenomena have been linked to bacterial translocation and endotoxaemia (4). Mucosa cells have a high protein turnover rate and energy requirement and therefore need adequate supply of substrate. Insufficient supply could impair gut integrity (5).

Glutamine is the most abundant free amino acid in the body and is mainly produced in and released from muscle tissue (6). A substantial part is consumed in the splanchnic area (5,7-9). Windmueller (10-12), demonstrated that glutamine is the preferred fuel for oxidative metabolism in the enterocyte. Furthermore, glutamine is used as a precursor for purine and pyrimidine synthesis, necessary for DNA synthesis in rapidly dividing cells like enterocytes (13). Therefore, mucosal atrophy, observed during total parenteral nutrition (TPN), is possibly due to the absence of glutamine in the TPN mixture (14-15). In line with this hypothesis we recently showed that villous height and intestinal permeability is preserved in patients receiving parenteral nutrition supplemented with glutamine (16).

To evaluate whether the glutamine concentration in the gut mucosa is related to the presence of nutritional depletion, patients with a fat-free mass index below $90 \%$ or percentage ideal body weight below $90 \%$ as a result of recent weight loss were studied.

3.2 Patients and methods

\section{Patients}

Patients between 18 and 80 years of age, in a metabolically stable condition (temperature between 36.5 and $38^{\circ} \mathrm{C}$, no intra-abdominal abscesses, no signs of respiratory or cardiac failure) and admitted to the department of surgery, were eligible to enter the study. Patients with renal or liver failure, diabetes mellitus, ileus, congenital metabolic disorders, and patients who received parenteral nutrition within 3 weeks prior to the study were excluded from the study. Patients with complaints of dyspepsia in whom duodenal biopsies revealed no histological abnormalities were evaluated as a control group for mucosal amino acid concentrations. Control values for plasma amino acids were obtained from age and sex matched post-absorptive healthy persons. The study was approved by the Medical Ethical Committee of the University Hospital Maastricht. From every patient, written informed consent was obtained.

\section{Study design}

Fat-free mass was estimated in 18 patients and 9 controls using the bioimpedance technique and the formula by Segal (17). Fat-free mass index (PIFFM) was calculated as the percentage fat-free mass of the ideal fat-free mass, defined as $88 \%$ of ideal body weight for men and $78 \%$ of ideal body weight for women. Ideal body weight 
was calculated from body length, body weight and wrist circumference using the Metropolitan Life Insurance tables 1983 (18). Clinical depletion was defined as a PIFFM below 90 percent. If PIFFM was not available, depletion was defined as a body weight below 90 percent of ideal weight (PIB). Patients were overnight fasted before collection of blood and tissue samples.

\section{Sample processing and analysis}

Mucosal biopsies were obtained from the second part of the duodenum via a fiberendoscope. At the same time, venous blood samples were drawn from a major draining vein in the cubital fossa. Blood samples were kept on ice immediately after collection. Centrifugation was performed at $4^{\circ} \mathrm{C}$ during 5 minutes at $2200 \mathrm{~g}$ within 10 minutes after sampling. After centrifugation, $100 \mu$ of plasma was deproteinized with $4 \mathrm{mg}$ sulphosalicylic acid (art. no. 10346; BDH Chemicals, Brunschwig Amsterdam), thoroughly mixed, frozen in liquid nitrogen and stored at $-80^{\circ} \mathrm{C}$ until analysis.

The duodenal mucosa specimen was collected in a cooled preweighed Eppendorf vial with $100 \mu \mathrm{l} 5 \%$ sulfosalicyc acid containing norvaline (art. no 37162; BDH Chemicals Ltd., Poole, England) in a concentration of $0.5 \mathrm{mM}$ as internal standard for the amino acid determinations. The vials were immediately frozen in liquid nitrogen and stored at $-80^{\circ} \mathrm{C}$ until analysis. For determination, the vials were thawed and weight was determined. During this procedure, temperature was kept below $4^{\circ} \mathrm{C}$. Wet weight, obtained after substraction of the preweighed weight, was not reliable because in several cases the weight obtained after thawing of the vials was lower compared to the preweighed weight. This phenomenon was probably due to evaporation. In addition, a decrease in wet weight after freezing was recently reported by Alhman (19).

The vials were allowed to stand on ice for $10 \mathrm{~min}$. In this period, the content of the vial was homogenized by repeated vortex mixing. The homogenates were centrifugated for $15 \mathrm{~min}$ at $4^{\circ} \mathrm{C}$ at $8800 \mathrm{~g}$. A sample of $30 \mu \mathrm{l}$ of the supernatant was used for amino acid determination. Amino acids were determined by HPLC as described previously (20). To obtain dry weight, the SSA was washed out from the sediment. Aqua ( $1 \mathrm{ml}$ ) was added to the vial, vortex mixing was applied, and the vial was centrifugated for 5 min at $4^{\circ} \mathrm{C}$ at $8800 \mathrm{~g}$. The supernatant was removed carefully. This procedure was repeated three times. The vial was freeze dried. Dry weight was obtained after subtracting the weight of the preweighed empty vial from the weight of the vial after freeze drying.

\section{Calculations and statistics}

Amino acid concentrations in mucosa were expressed as $\mu \mathrm{mol}$ per $\mathrm{kg}$ dry weight. Results are presented as means \pm SEM. Levels of significance were set at $p<0.05$ unless stated otherwise. Group comparison for statistical significance was performed using the Mann-Whitney test. Spearman rank correlation coefficients were calculated for mucosal and plasma amino acids and percentage ideal body weight and fatfree mass index. The statistical procedures were performed with a SPSS-PC+ software program (21) on a MS-DOS personal computer. 


\begin{tabular}{|c|c|c|c|c|c|c|c|}
\hline & Age (yr.) & Sex & Diagnoses & Weight (kg) & Lenght $(\mathrm{cm})$ & PIB (\%) & PIFFM (\%) \\
\hline \multicolumn{8}{|c|}{ Depleted } \\
\hline 1 & 67 & $M$ & Small bowel fistula & 60 & 175 & 87 & \\
\hline 2 & 45 & $M$ & Crohn's disease & 63 & 170 & 88 & \\
\hline 3 & 24 & $\mathrm{~F}$ & Crohn's disease & 40 & 160 & 76 & 88 \\
\hline 4 & 21 & $M$ & Crohn's disease & 53 & 182 & 77 & 80 \\
\hline 5 & 36 & $\mathrm{~F}$ & Crohn's disease & 58 & 170 & 92 & 88 \\
\hline 6 & 77 & $\mathrm{~F}$ & Pseudo Obstruction & 61 & 163 & 94 & 79 \\
\hline 7 & 31 & $\mathrm{~F}$ & Crohn's disease & 47 & 168 & 81 & 83 \\
\hline 8 & 23 & $M$ & Ulcerative colitis & 61 & 177 & 87 & 88 \\
\hline 9 & 75 & $F$ & Large bowel carcinoma & 65 & 165 & 97 & 85 \\
\hline 10 & 44 & $F$ & Large bowel carcinoma & 62 & 183 & 90 & 88 \\
\hline \multicolumn{8}{|c|}{ Non-Depleted } \\
\hline 1 & 67 & $\mathrm{~F}$ & Crohn's disease & 55 & 153 & 101 & \\
\hline 2 & 36 & $M$ & Vertical banded gastroplasty & 98 & 195 & 111 & \\
\hline 3 & 33 & $M$ & Ulcerative colitis & 87 & 178 & 122 & \\
\hline 4 & 33 & $M$ & Crohn's disease & 62 & 175 & 89 & 95 \\
\hline 5 & 40 & $M$ & Crohn's disease & 59 & 172 & 89 & 98 \\
\hline 6 & 22 & $M$ & Crohn's disease & 58 & 175 & 89 & 94 \\
\hline 7 & 43 & $M$ & Ulcerative colitis & 83 & 183 & 113 & 100 \\
\hline 8 & 24 & $M$ & Ulcerative colitis & 79 & 183 & 107 & 98 \\
\hline 9 & 77 & $\mathrm{~F}$ & Large bowel carcinoma & 60 & 168 & 96 & 93 \\
\hline 10 & 70 & M & Small bowel fistula & 70 & 173 & 96 & 92 \\
\hline 11 & 77 & $M$ & Large bowel carcinoma & 62 & 172 & 97 & 101 \\
\hline 12 & 31 & $F$ & Pancreatitis & 60 & 174 & 98 & 97 \\
\hline \multicolumn{8}{|c|}{ Controls } \\
\hline 1 & 60 & $F$ & Gastooesophagal reflux & 66 & 164 & 101 & \\
\hline 2 & 46 & $M$ & Dyspepsia, no pathol findings & 96 & 183 & 122 & \\
\hline 3 & 36 & $M$ & Dyspepsia, no pathol findings & 87 & 172 & 119 & \\
\hline 4 & 21 & $\mathrm{~F}$ & Dyspepsia, no pathol findings & 53 & 170 & 91 & \\
\hline 5 & 26 & $M$ & Mild gastitis & 61 & 187 & 84 & \\
\hline 6 & 52 & $M$ & Benign peptic ulcer & 66 & 171 & 91 & \\
\hline 7 & 41 & $\mathrm{~F}$ & Gastooesophagal reflux & 83 & 164 & 126 & 122 \\
\hline 8 & 36 & $\mathrm{~F}$ & Dyspepsid, no pathol findings & 49 & 162 & 77 & 80 \\
\hline 9 & 40 & M & Dyspepsia, no pathol findings & 62 & 166 & 91 & 89 \\
\hline 10 & 27 & $\mathrm{~F}$ & Dyspepsia, no pathol findings & 50 & 167 & 74 & 96 \\
\hline 11 & 75 & $\mathrm{~F}$ & Dyspepsia, no pathol findings & 67 & 167 & 100 & 90 \\
\hline 12 & 70 & M & Dyspepsia, no pathol findings & 56 & 163 & 86 & 89 \\
\hline 13 & 62 & $F$ & Benign peptic ulcer & 69 & 164 & 105 & 102 \\
\hline 14 & 72 & $M$ & Dyspepsia, no pathol findings & 94 & 169 & 134 & 112 \\
\hline
\end{tabular}

Table 1. Patient data.

$P I B=$ percentage ideal body weight, $P I F F=$ fat-free mass index 


\subsection{Results}

\section{Patients}

Patient characteristics are summarized in table 1.13 men and 9 women (mean age $45 \pm 4$ ) were included in the study. 13 patients were treated for inflammatory bowel disease. 8 patients exhibited a PIFFM below 90 percent. In addition, 2 patients with a weight below 90 percent of ideal weight were also defined as clinically depleted. For both patient groups, medication and laboratory parameters are summarized in table 2 .

\begin{tabular}{|c|c|c|c|c|c|}
\hline & Non- & epleted & Depl & & \\
\hline Medication & & & & & \\
\hline Sulfasalazine & 5 & & 7 & & \\
\hline Corticosteroids (n) & 5 & & 3 & & \\
\hline Labatory results of blood & & & & & \\
\hline Total protein $(g / l)$ & 65 & \pm 1 & 60 & \pm & 2 \\
\hline Albumin & 34 & \pm 2 & 29 & & 2 \\
\hline Prealbumin & 0.2 & \pm 0.02 & 0.1 & \pm & 0.02 * \\
\hline Leucocytes & 9.8 & \pm 0.8 & 9.8 & \pm & 0.8 \\
\hline Trombocytes $\left(10^{9} /\right)$ & 372 & \pm 45 & 423 & \pm & 57 \\
\hline ESR $\quad(\mathrm{mm} / \mathrm{hr})$ & 26 & \pm 7 & 47 & \pm & 10 \\
\hline$(\mathrm{mmo} / /)$ & 7.7 & \pm 0.3 & 7.4 & \pm & 0.4 \\
\hline
\end{tabular}

Table 2. Clinical parameters patient groups.

$\star=p<0.05$ Mann-Whitney. Labatory values presented as means \pm SEM.

\begin{tabular}{|c|c|c|c|c|c|c|c|c|c|c|}
\hline & $\begin{array}{l}\text { Contro } \\
\text { Mean }\end{array}$ & \pm SEM & $\begin{array}{l}\text { Non- } \\
\text { Mean }\end{array}$ & $\begin{array}{l}\text { eple } \\
\pm\end{array}$ & $\begin{array}{l}\text { ted } \\
\text { SEM }\end{array}$ & & $\begin{array}{l}\text { Deple } \\
\text { Mean }\end{array}$ & & SEM & \\
\hline GLU & 51 & \pm 4 & 58 & \pm & 10 & & 55 & \pm & 10 & \\
\hline$A S N$ & 50 & \pm 2 & 46 & \pm & 3 & & 42 & \pm & 6 & * \\
\hline GLN & 677 & \pm 22 & 620 & \pm & 42 & & 540 & \pm & 58 & $\# \star \star \star$ \\
\hline GLY & 229 & \pm 14 & 232 & \pm & 16 & & 185 & \pm & 20 & $\# \star$ \\
\hline THR & 134 & \pm 6 & 117 & \pm & 8 & & 103 & \pm & 14 & * \\
\hline HIS & 84 & \pm 4 & 62 & \pm & 5 & $\star \star$ & 53 & \pm & 4 & $\star *$ \\
\hline $\mathrm{CIT}$ & 35 & \pm 2 & 29 & \pm & 4 & & 18 & \pm & 3 & $\# \star \star \star$ \\
\hline ALA & 356 & \pm 30 & 277 & \pm & 20 & * & 202 & \pm & 24 & $\# * *$ \\
\hline TAU & 40 & \pm 2 & 50 & \pm & 10 & & 38 & \pm & 8 & \\
\hline ARG & 77 & \pm 5 & 79 & \pm & 5 & & 73 & \pm & 12 & \\
\hline$\alpha A B A$ & 20 & \pm 1 & 18 & \pm & 3 & & 22 & \pm & 11 & \\
\hline TYR & 58 & \pm 3 & 53 & \pm & 4 & & 42 & \pm & 4 & $\# \star \star \star$ \\
\hline VAL & 241 & \pm 10 & 178 & \pm & 14 & $\star \star$ & 195 & \pm & 34 & $\star \star$ \\
\hline MET & 24 & \pm 1 & 22 & \pm & 1 & & 20 & \pm & 4 & $\star$ \\
\hline ILE & 65 & \pm 4 & 63 & \pm & 7 & & 62 & \pm & 15 & \\
\hline PHE & 58 & \pm 2 & 51 & \pm & 4 & $\star$ & 58 & \pm & 10 & \\
\hline TRP & 54 & \pm 2 & 30 & \pm & 2 & $\star \star$ & 23 & \pm & 4 & $\star \star *$ \\
\hline LEU & 134 & \pm 7 & 102 & \pm & 11 & $\star$ & 119 & \pm & 26 & $\star$ \\
\hline LYS & 159 & \pm 6 & 171 & \pm & 18 & & 151 & \pm & 19 & \\
\hline$B C A A$ & 440 & \pm 19 & 342 & \pm & 32 & $\star \star$ & 375 & \pm & 76 & $\star$ \\
\hline Sumeaa & 953 & \pm 31 & 794 & \pm & 61 & $\star *$ & 783 & \pm & 125 & $\star \star$ \\
\hline Sumaa & 2647 & \pm 74 & 2363 & \pm & 129 & $\star \star$ & 2099 & \pm & 255 & $\star \star \star$ \\
\hline
\end{tabular}

Table 3. Plasma amino acid concentrations $(\mu \mathrm{mol} / \mathrm{l})$.

* $p<0.01$ versus control, * $p<0.05$ versus control, $\# p<0.05$ versus non-depleted. $B C A A=$ sum of leucine, isoleucine and valine. Sumeaa $=$ sum of all essential amino acids, Sumaa $=$ sum of all amino acids. 


\begin{tabular}{|c|c|c|c|c|c|c|c|c|c|c|}
\hline & $\begin{array}{l}\text { Control } \\
\text { Mean }\end{array}$ & \pm & SEM & $\begin{array}{l}\text { Non-De } \\
\text { Mean }\end{array}$ & $\begin{array}{l}\text { olete } \\
\pm\end{array}$ & SEM & $\begin{array}{l}\text { Depleted } \\
\text { Mean }\end{array}$ & \pm & SEM & \\
\hline GLU & 21495 & \pm & 1132 & 22327 & \pm & 1178 & 21464 & \pm & 1315 & \\
\hline ASN & 3776 & \pm & 997 & 1916 & \pm & 703 & 1542 & \pm & 835 & \\
\hline GLN & 3296 & \pm & 176 & 3463 & \pm & 171 & 2883 & \pm & 250 & * \\
\hline GLY & 6857 & \pm & 582 & 7145 & \pm & 673 & 5428 & \pm & 470 & \\
\hline THR & 1364 & \pm & 109 & 1351 & \pm & 106 & 1150 & \pm & 112 & \\
\hline HIS & 626 & \pm & 45 & 696 & \pm & 192 & 706 & \pm & 269 & \\
\hline CIT & 689 & \pm & 53 & 795 & \pm & 140 & 582 & \pm & 135 & \\
\hline ALA & 3682 & \pm & 372 & 3540 & \pm & 315 & 2570 & \pm & 263 & $\# \star$ \\
\hline TAU & 21721 & \pm & 1528 & 20405 & \pm & 1850 & 18213 & \pm & 3100 & \\
\hline ARG & 1006 & \pm & 144 & 973 & \pm & 81 & 920 & \pm & 137 & \\
\hline$\alpha A B A$ & 168 & \pm & 29 & 175 & \pm & 30 & 127 & \pm & 29 & \\
\hline TYR & 790 & \pm & 91 & 752 & \pm & 52 & 659 & \pm & 143 & \\
\hline VAL & 1318 & \pm & 131 & 1289 & \pm & 72 & 1252 & \pm & 131 & \\
\hline MET & 254 & \pm & 41 & 316 & \pm & 37 & 278 & \pm & 61 & \\
\hline ILE & 645 & \pm & 61 & 671 & \pm & 60 & 614 & \pm & 86 & \\
\hline PHE & 643 & \pm & 58 & 655 & \pm & 58 & 647 & \pm & 101 & \\
\hline TRP & 135 & \pm & 20 & 112 & \pm & 14 & 99 & \pm & 22 & \\
\hline LEU & 1208 & \pm & 115 & 1385 & \pm & 112 & 1311 & \pm & 219 & \\
\hline LYS & 1220 & \pm & 123 & 1310 & \pm & 105 & 1094 & \pm & 148 & \\
\hline BCAA & 3252 & \pm & 361 & 3345 & \pm & 226 & 3178 & \pm & 424 & \\
\hline Sumeaa & 7048 & \pm & 619 & 7785 & \pm & 532 & 7152 & \pm & 1004 & \\
\hline Sumaa & 70529 & \pm & 2532 & 69118 & \pm & 2628 & 61373 & \pm & 5079 & \\
\hline
\end{tabular}

Table 4. Intramucosal amino acid concentrations ( $\mu \mathrm{mol} / \mathrm{kg}$ dry weight)

$\# p<0.05$ versus control, ${ }^{*} p<0.05$ versus non-depleted. For abbreviations see table 3 .

\section{Plasma amino acid concentrations}

Concentrations of amino acids in plasma (table 3) of the patient groups were in general decreased compared to controls, consisting of 14 patients with dyspepsia complaints (mean age $47 \pm 5$ ). In addition, tyrosine, glycine, glutamine, citrulline and alanine were decreased in the depleted patient group compared with the nondepleted patient group. In the patients, alanine was correlated with PIB $(r=0.46$, $p<0.05)$ and PIFFM $(r=0.58, p<0.01)$. No significant correlations were observed between plasma glutamine and weight parameters.

\section{Mucosa amino acid concentrations}

In mucosal biopsies, glutamate showed the highest concentration (table 4). Measurement of serine and aspartate was not possible due to peak overlap with other substrates in the chromatogram. In the depleted patient group, glutamine and alanine were significantly decreased compared to the non-depleted patient group (table 4). Compared to controls, alanine was decreased in the depleted group. No significant differences in total amount of essential amino acids, or branched chain amino acids were observed. Although corticosteroids are known to affect glutamine metabolism no differences in plasma or mucosa concentrations were observed between patients receiving corticosteroid therapy and those who did not (table 5). In addition, no differences in plasma and mucosa glutamine, alanine, and total amino nitrogen concentration were observed between patients with different diseases (table 6). 
A correlation was observed between mucosal alanine and $P I B(r=0.62, p<0.001$, figure 1) and PIFFM ( $r=0.48, p<0.01)$. A correlation was also observed for mucosal glutamine and PIB ( $r=0.43, p<0.005$, figure 1). Mucosal glutamine was not correlated with PIFFM in the whole population. However, within the patient group, a significant correlation was observed ( $r=0.42, p<0.05)$.

The ratio of plasma to mucosa alanine and glutamine, calculated by dividing plasma concentration by mucosa concentration, was not different between the study groups (table 7). Differences in plasma and mucosa glutamine and alanine between the study groups were similar, suggesting a relation between these amino acids in plasma and mucosa. However, a significant correlation could not be demonstrated.

\begin{tabular}{|c|c|c|c|c|c|c|c|}
\hline \multirow[b]{2}{*}{ PLASMA } & \multicolumn{3}{|c|}{ Corticosteroids +} & \multicolumn{3}{|c|}{ Corticosteroids - } & \\
\hline & & & & & & & \\
\hline Gin & 612 & \pm & 87 & 567 & \pm & 35 & NS \\
\hline Ala & 280 & \pm & 39 & 222 & \pm & 16 & NS \\
\hline$B C A A$ & 445 & \pm & 100 & 303 & \pm & 27 & NS \\
\hline $\begin{array}{l}\text { Sumaa } \\
\text { MUCOSA }\end{array}$ & 2477 & \pm & 310 & 2118 & \pm & 138 & NS \\
\hline Gin & 3102 & \pm & 257 & 3255 & \pm & 204 & NS \\
\hline Ala & 3374 & \pm & 502 & 2942 & \pm & 237 & NS \\
\hline$B C A A$ & 7387 & \pm & 765 & 7559 & \pm & 727 & NS \\
\hline Sumaa & 65515 & \pm & 5353 & 65644 & \pm & 3307 & NS \\
\hline
\end{tabular}

Table 5. Amino acid concentrations in patients with and without corticosteroids For abbreviations see table 3 . NS = Not significant.

\begin{tabular}{|c|c|c|c|c|c|c|c|c|c|c|}
\hline & $\begin{array}{l}\text { IBD } \\
\text { Mean }\end{array}$ & \pm & SEM & $\begin{array}{l}\text { Cancer } \\
\text { Mean }\end{array}$ & \pm & SEM & $\begin{array}{l}\text { NoCa/N } \\
\text { Mean }\end{array}$ & $\begin{array}{l}\mathrm{O} B \mathrm{BD} \\
\pm\end{array}$ & SEM & \\
\hline \multicolumn{11}{|l|}{ PLASMA } \\
\hline Gin & 571 & \pm & 53 & 556 & \pm & 47 & 648 & \pm & 100 & NS \\
\hline Ala & 258 & \pm & 25 & 224 & \pm & 29 & 215 & \pm & 46 & NS \\
\hline$B C A A$ & 400 & \pm & 60 & 294 & \pm & 23 & 312 & \pm & 91 & NS \\
\hline Sumaa & 2273 & \pm & 204 & 2147 & \pm & 158 & 2245 & \pm & 449 & NS \\
\hline \multicolumn{11}{|l|}{ MUCOSA } \\
\hline $\mathrm{Gin}$ & 3032 & \pm & 204 & 3604 & \pm & 355 & 3240 & \pm & 368 & NS \\
\hline $\mathrm{Ala}$ & 3111 & \pm & 346 & 3335 & \pm & 190 & 2766 & \pm & 689 & NS \\
\hline$B C A A$ & 3177 & \pm & 292 & 3547 & \pm & 496 & 3222 & \pm & 676 & NS \\
\hline Sumaa & 62555 & \pm & 3765 & 70441 & \pm & 5104 & 69430 & \pm & 7439 & NS \\
\hline
\end{tabular}

Table 6. Diagnostic group in relation to amino acid concentrations For abbreviations see table 3 . NS is not significant 


\begin{tabular}{l|llllll} 
& \multicolumn{4}{|c}{ Non-Depleted } & \multicolumn{2}{l}{ Depleted } \\
& Mean \pm SEM & Mean \pm SEM & \\
\hline Gin & 0.18 & \pm 0.02 & 0.20 & \pm 0.04 & NS \\
Ala & 0.09 & \pm 0.01 & 0.09 & \pm 0.02 & NS \\
BCAA & 0.11 & \pm 0.01 & 0.14 & \pm 0.05 & NS \\
Sumaa & $0.033 \pm 0.003$ & $0.036 \pm 0.009$ & NS \\
\hline
\end{tabular}

Table 7. Ratio plasma to mucosa amino acid concentration.

Ratios are obtained by dividing plasma amino acid concentration by mucosa amino acid concentration. For abbreviations see table 3 . NS = Not significant.
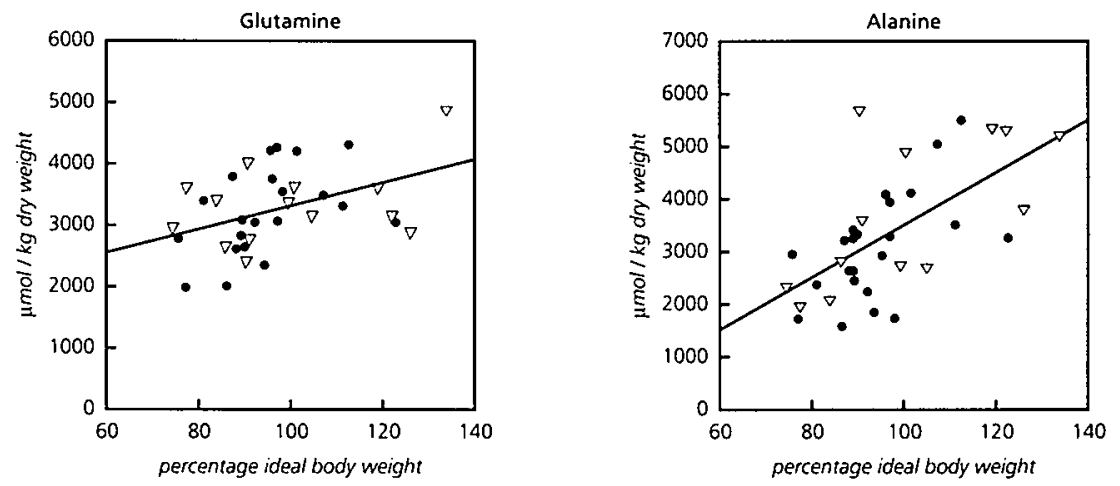

Figure 1. Correlations between percentage ideal body weight and mucosal glutamine and alanine.

Left panel: The correlation between intramucosal glutamine values and percentage ideal body weight $(r=0.43$, p<0.005, $\bullet=$ patients, $\nabla=$ controls).

Right panel: The correlation between intramucosal alanine values and percentage ideal body weight $(r=0.62, p<0.001$, $\bullet=$ patients, $\nabla=$ controls).

3.4 Discussion

This study demonstrates that clinically depleted patients have a decrease in mucosal glutamine and alanine compared to non-depleted patients and controls, although the difference of glutamine between depleted and control patients was of marginal significance $(p=0.1)$. Also, the decrease of the (non)-essential amino acids in plasma of both patient groups was found more pronounced in the depleted patient group.

The obtained values were within the range of Ollenschläger et al (22). In that study the mean glutamine concentration in the control group was lower compared to the values in this study. This might be explained by the differences between the control groups used in the two studies. The control group in the study by Ollenschlägger was more heterogenous compared to the control group in this study. In addition, histological abnormalities were observed in a subset of their controls. 
The non-depleted and depleted patient groups were well-matched for diagnosis and medication. Although not significant, the higher ESR and lower albumin in the depleted patient group might reflect an increased disease activity in these patients. In patients it is impossible to analyze the effects of the ongoing disease process and depletion isolated from each other. It is likely that a more prolonged and severe disease process will automatically result in more severe depletion.

A decrease in mucosa glutamine concentration could theoretically be a reflection of decreased supply of glutamine, impaired membrane transport, decreased proteolysis or increased glutaminase activity. Glutamine synthetase activity in the gut is very low (12) and probably has little influence on mucosa glutamine concentrations. Therefore, decreased production in the gut itself is unlikely to be the cause of decreased glutamine concentrations in the depleted patient. In addition, it seems unlikely that net protein synthesis is increased during starvation. In depleted patients, utilization of glutamine might be increased, but this seems to be unlikely as glutaminase activity has been found to be decreased in starved animals (11). Furthermore, because the ratio between plasma and mucosa glutamine (table 5) is unaltered, a change in membrane transport is an unlikely cause. Therefore, the observed decrease of mucosa glutamine and alanine seems to reflect an impaired supply from the plasma pool. If mucosa glutamine concentrations were to be maintained on normal levels in the presence of low plasma concentrations, the membrane transport system has to be up-regulated. The low plasma concentration in addition to an apparent decreased capacity to up-regulate glutamine transport systems, could therefore be an important factor in the observed decreased glutamine concentration. Although theoretically the function of the intestinal cell may be affected by the decreased mucosa glutamine concentration, this remains to be established.

In summary, the observations in this study suggest that in patients depletion appears to be related to decreased plasma and mucosa glutamine and alanine concentrations. 
1. The Veterans Affairs Total Parenteral Nutrition Cooperative Study Group. Perioperative total parenteral nutrition in surgical patients New England Journal of Medicine 1991:325:525-532.

2. Campos A.C, and M.M Meguid. A critical appraisal of the usefulness of perioperative nutritional support. American Journal of Clinical Nutrition 1992:55:117130.

3. von Meyenfeldt M.F., W.J. Meijerink, M.M Rouflart, et al. Perioperative nutritional support: a randomised clinical trial. Clinical Nutrition 1992;11:180-186.

4. Wilmore D.W., R.J. Smith, S.T. O'Dwyer, D.O. Jacobs, T.R. Ziegler, and X.-D. Wang. The gut: a central organ after surgical stress. Surgery 1988;104:917-923.

5. Souba W.W., V.S. Klimberg, D.A. Plumley, et al. The role of glutamine in maintaining a healthy gut and supporting the metabolic response to injury and infection. Journal of Surgical Research 1990;48:383-391.

6. Newsholme E.A., and M. Parry-Billings. Properties of glutamine release from muscle and its importance for the immune system. Journal of Parenteral and Enteral Nutrition 1990;14:635-67S.

7. Deutz N.E., P.L. Reijven, G. Athanasas, and P.B. Soeters. Postoperative changes in hepatic, intestinal, splenic and muscle amno acids and ammonia fluxes in pigs. Clinical Science 1992;83:607-614.

8. Dechelotte P., D. Darmaun, M. Rongier, et al. Absorption and metabolic effects of enterally administered glutamine in humans. American Journal of Physiology 1991;260:G677-G682.

9. Darmaun D., B. Messing, B. Just, et al. Glutamine metabolism after small intestinal resection in humans. Metabolism 1991;40:42-44.

10. Windmueller H.G., and A.E. Spaeth. Uptake and metabolism of plasma glutamine by the small intestine. The Journal of Biological Chemistry 1974;249:5070-5079.

11. Windmueller H.G., and A.E. Spaeth. Respiratory fuels and nitrogen metabolism in vivo in small intestine of fed rats. The Journal of Biological Chemistry 1980;255:107-112

12. Windmueller H.G. Glutamine utilization by the small intestine. Advances in Enzymology 1982;53:201-237.

13. Ashy A.A., and M.S Ardawi. Glucose, Glutamine, and ketone-body metabolism in human enterocytes. Metabolism 1988;37:602-609.

14. O'Dwyer S.T., R.J. Smith, T.L. Hwang, and D.W. Wilmore. Maintenance of small bowel mucosa with glutamine-enriched parenteral nutrition. Journal of Parenteral and Enteral Nutrition 1989;13:579-585.
15. Lo C.W., and W.A. Walker. Changes in the gastrointestinal tract during enteral or parenteral feeding. Nutrition Reviews 1989;47:193-198.

16. van der Hulst R.R., B.K. van Kreel, M.F. von Meyenfeldt, et al. Glutamine and the preservation of gut integrity. Lancet, 1993;341:1363-1365.

17. Segal K.R., M. van Loan, P.I. Fitzergald, et al. Lean body mass estimation by biolelectrical impedance analysis: a four site cross-validation study. American Journal of Clinical Nutrition 1988;74:7-14.

18. Anonymus. Metopolitan Life Insurance Company. New weight standard for men and women. Bulletin Metropolitan Life Insurance Foundation 1983;64:14.

19. Ahlman B., C.-E. Leijonmarck, C. Lind, et al. Free amino acids in bopsy specimens from the human colonic mucosa. Journal of Surgical Research 1993:55:647.653.

20. van Eijk H.M., M.A. van der Heijden, C.L. van Berlo, and P.B. Soeters. Fuliy automated liquid-chromatographic determination of amino acids. Clinical Chemistry 1988;34:2510-2513.

21. Norusis M.l. (ed). SPSS/PC+V3.1 Base manual for the IBM PCIXT/AT and PS/2. SPSS Chicago, 1988.

22. Ollenschläger G., K. Langer, H.M. Steffen, et al. Intracellular free amino acid patterns in duodenal and colonic mucosa. Clinical Chemistry 1990;36:378-381 


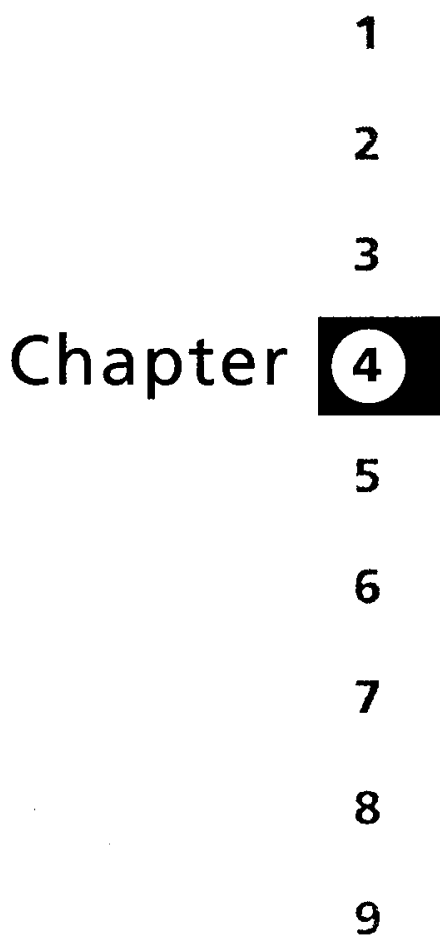




\section{Nutritional depletion and gut permeability}

R.R.W.J. van der Hulst, M.F. von Meyenfeldt, B.K. van Kreel, F.B.J.M. Thunnissen,

R-J.M. Brummer, J-W. Arends, P.B. Soeters 


\section{Abstract}

Introduction: Nutritional depletion increases postoperative complication risk. Disturbances in metabolic and immune related processes, possibly mediated through the gut, are important in the underlying pathophysiological mechanism. This study was performed to evaluate changes in intestinal integrity in relation to nutritional depletion.

Patients and Methods: In 26 patients in need of parenteral nutrition nutritional depletion was estimated by the percentage ideal body weight (PIB) or percentage ideal fat-free mass (PIFFM). Patients were defined depleted when they had a PIFFM and/or PIB less than $90 \%$. To assess intestinal barrier function a lactulose-mannitol (UM) test was performed. Control values for the LM test were obtained from 12 controls. Duodenal biopsies were taken and villous height, crypt depth, number of IgA producing plasma cells, intra-epithelial lymphocytes and proliferating index were determined.

Results: L/M ratio's were higher in patients compared to controls. The LM ratio was increased and villous height was decreased in depleted patients. Depletion was not associated with differences in the number of immune cells or proliferating index. However, the number of IgA producing plasma cells was positively correlated with the $\mathrm{LM}$ ratio.

Conclusions: This study shows that nutritional depletion is associated with increased intestinal permeability and a decrease in villous height.

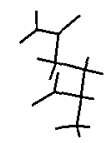


The association between nutritional depletion, septic complications $(1,2)$ and increased mortality rates (3) in postoperative patients is well established. The exact underlying mechanism is not known.

It has been hypothesized that the gut plays an important role in the development of complications in the postoperative patient (4). An important function of the healthy gut is to prevent bacteria and endotoxins from reaching the portal circulation. This physiological barrier is maintained by the mucus layer, the epithelial cells with their tight junctions, and the gut associated lymphoid tissue (GALT). Impairment of one or several components of this intestinal barrier may result in bacterial translocation or endotoxaemia $(5,6)$.

Glutamine, a conditional essential amino acid, is used as fuel for rapidly dividing cells, e.g. enterocytes and lymphocytes $(7,8)$. A diminished glutamine supply during parenteral nutrition and enteral starvation results in morphological changes and increased intestinal permeability (9). Recently, we showed that nutritional depletion is associated with decreased concentrations of glutamine in the intestinal mucosa (10). Therefore, nutritional depletion, via decreased glutamine supply, may impair intestinal barrier function.

In animal experiments protein malnutrition results in an increased risk of endotoxin related bacterial translocation and increased susceptibility to the lethal effects of endotoxins $(11,12)$. The purpose of this study was to investigate the potential relationship between nutritional depletion, intestinal morphology and permeability in man.

4.2 Patients and methods

\section{Patients}

Metabolically stable patients (temperature between 36.5 and $38^{\circ} \mathrm{C}$, no intra-abdominal abscesses, no signs of respiratory or cardiac failure) between 18 and 80 years of age admitted to the nutritional support team were eligible to enter the study. All patients were admitted because they were not allowed or unable to receive enteral nutrition. The study was performed before parenteral nutrition was initiated. Patients with renal or liver failure, diabetes mellitus, ileus, congenital metabolic disorders, and patients who received parenteral nutrition within 3 weeks prior to the study were excluded from the study. For control values of the lactulose/mannitol test a control group of 12 healthy persons was studied. Patients were fasted overnight and were studied in the morning. Blood was collected for routine biochemical indices, total protein, albumin, and prealbumin.

Percentage of ideal body weight (PIB) was calculated using the Metropolitan Life Insurance Company tables 1983 (13). In twenty patients a bio-impedance measurement was performed to estimate fat-free mass using a standard formula (14). The percentage of ideal fat-free mass (PIFFM) was calculated assuming an ideal fat-free mass to be respectively 88 and 78 percent of the ideal body weight for men and women. Patients were classified nutritionally depleted if their PIFFM was less than $90 \%$ or, in case no PIFFM was calculated (6 patients), if their PIB was less than $90 \%$. 
The study was approved by the Medical Ethical Committee of the University Hospital Maastricht. From every patient written informed consent was obtained.

\section{Permeability tests}

After a duodenoscopy during which biopsies were taken a catheter was positioned in the duodenal bulb and a solution containing 10 grams of lactulose, 0.5 gram of mannitol and 5 grams of D-xylose in $65 \mathrm{ml}$ of water (osmolality $=1474 \mathrm{mOsm} / \mathrm{kg}$ ) was infused during 1 minute. Patients had to empty their bladder before the endoscopy and were asked to collect all urine voided during the next 6 hours. The collected urine was preserved with $5 \mathrm{ml}$ thymol $10 \%$. Control values for lactulose/mannitol/xylose absorption were obtained from twelve healthy volunteers without any evidence of systemic or gastrointestinal disease. In the control group the solution was given orally. Urinary lactulose and mannitol were determined by gas-liquid chromatography (15). Xylose was measured enzymatically (16). Excretion percentages and lactulose/mannitol ratio were determined as previously described (15).

\section{Intestinal histology}

Intestinal biopsies were taken from the second part of the duodenum distal to the level of the hepatopancreatic ampulla. Specimens of the duodenum were immediately fixed either in ethanol (two specimens for PCNA staining) or in Bouin's solution (two specimens for villous and crypt measurement and immunohistochemical staining of plasma cells and lymphocytes). Fixed tissues were then carefully oriented and embedded in paraffin. For each staining at least 6 well oriented sections of $4 \mu \mathrm{m}$ thickness were obtained at different levels of the specimen. Quantitative measurements were performed by one of the authors (RVDH) with coded sections without knowledge regarding the identity of the corresponding patients. Control biopsies from healthy persons were not obtained for ethical reasons.

For morphometry, sections were stained with hematoxylin and eosin. Morphometry measurements for villous height and crypt depth were performed using an automatic interactive analysis system (Jandel video analysis system, Erkath, Germany) as has been described recently (9). Means for villous height (from the tip of the villous to the villous-crypt junction) and crypt depth (from the villous-crypt junction to the base of the crypt) were expressed in micrometers. Villous height and crypt depth were measured only in well oriented sections of the duodenal specimens. The progressive mean for villous height was counted in three sections for at least 20 subsequent villi. The graphic display showed a stable pattern after measuring 10 villi. Therefore 10 villi and crypts were measured. The intra- and interobserver coefficient of variation (CV $=$ standard deviation/mean $\times 100 \%$ ) for villous height and crypt depth were $3 \%$ and $7 \%$, respectively.

Proliferating duodenal crypt cells were detected using immunostaining for proliferating cellular nuclear antigen (PCNA). Tissue sections were deparaffinized with xylol and washed with ethanol $100 \%$. Endogenous peroxidase activity was blocked with $\mathrm{H}_{2} \mathrm{O}_{2} 0.6 \%$ in methanol for $15 \mathrm{~min}$. Subsequently, sections were incubated with target unmasking fluid (TUF, Monosan, The Netherlands) $10 \mathrm{~min}$. at $90^{\circ} \mathrm{C}$, washed with TRIS buffered saline (TBS) and incubated with 1:300 diluted antibody to PCNA 
(PC10, Dako, M879) for $60 \mathrm{~min}$. at $37^{\circ} \mathrm{C}$ followed by washing in TBS and incubation with peroxidase labeled rabbit anti-mouse 1:200 (P270, Dako). Immunoreactivity was demonstrated using DAB (3,3 diaminobenzidine D-5637, Sigma) and sections were counterstained with hematoxylin-eosin. The PCNA labeling index was obtained by dividing the number of positive PCNA cells in crypts by the total number of enterocytes in the crypt multiplied with 100 . The progressive mean was determined for PCNA in at least 30 subsequent crypts. A stable pattern was obtained after measuring 10 crypts. Therefore, PCNA labeling index was obtained after counting 10 crypts as described by Sarraf et al (17). The intra and interobserver CV for PCNA were 3\% and $5 \%$, respectively.

For IgA and CD3 immunostaining, the same blocking and hydration procedure was used. Sections were incubated with an antibody to IgA (Rabbit anti-human IgA, A 408 Dako), or an antibody to CD3 (Rabbit anti-human T-cell CD3, A 452 Dako) for 45 minutes at room temperature. After washing with TBS, peroxidase labeled swine antirabbit (P217, Dako, The Netherlands) and DAB was applied. Plasma cells were counted in the lamina propria and expressed as the number of cells per high power field as described by Alverdy et al (18). At least 10 high power fields were counted. A correction was made for the surface of lamina propria using a transparent test grid overlay with a random dot design as described by Aherne (19). Quantitative measurement of CD3 positive cells in the epithelium (intra-epithelial lymphocytes $=\mathrm{IEL}$ ) was obtained by counting lymphocytes present in 10 villi or in relation with 1000 enterocytes. IEL presence was expressed as the number of lymphocytes counted per 100 enterocytes (20). The quantification procedure of IEL and IgA cells was similar as the procedure for PCNA counting. Since the fraction of IgA and CD3 expressing cells was higher than the number of PCNA expressing cells theoretically a similar or lower CV and progressive mean is to be expected. Therefore IEL and IgA counting were performed in respectively 10 villi and 10 high power fields.

\section{Calculations and statistics}

Results are presented as means \pm SEM. Levels of significance were set at $p<0.05$. Group comparison for statistical significance was performed using the Mann-Whitney $U$ test. The Pearson test was used for correlation analysis. The statistical procedures were performed with a SPSS-PC+ software program (21) on a MS-DOS personal computer.

4.3 Results

\section{Patients}

In twenty-six patients submitted to the care of the nutritional support team intestinal biopsies were taken. Intestinal permeability was studied in 23 of these patients. Patients were treated for inflammatory bowel disease $(n=15, \mid B D)$, cancer $(n=6, C a)$, and other diagnoses (NoCa/NolBD) namely: subileus $(n=1)$, pancreatitis $(n=1)$, pyloric stenosis $(n=1)$, and fistula $(n=2)$. Patient data are summarized in table 1 . Fourteen patients were considered nutritionally depleted, because they had a PIFFM of less than 
$90 \%$ (8 patients) or a PIB less than $90 \%$ (6 patients). The lactulose/mannitol control group consisted of 6 men and 6 women with a mean age of $31 \pm 3$ yrs and weight of $70 \pm 5 \mathrm{~kg}$.

\section{Permeability tests}

No significant differences in lactulose/mannitol (UM) ratio nor in absolute excretion percentages between the different patient groups were observed (table 2). All patients had higher $U M$ ratio's compared to controls (figure 1). Patients who were considered to be nutritionally depleted did have a higher lactulose/mannitol (LM) ratio than patients who were not nutritionally depleted ( $p<0.05$, figure 1). Excretion

\begin{tabular}{|c|c|c|c|c|c|}
\hline & Non-D & epleted & Depl & & \\
\hline $\begin{array}{l}\text { Patient data } \\
\text { Sex (male/female) }\end{array}$ & $9 / 3$ & & $7 / 7$ & & \\
\hline Diagnose & 7 & & 7 & & \\
\hline & 2 & & 4 & & \\
\hline Cancer & $i$ & & 1 & & \\
\hline Fistula & 1 & & - & & \\
\hline Gastric stenosis & - & & 1 & & \\
\hline Diverticulitis & 1 & & - & & \\
\hline $\begin{array}{l}\text { Pancreatitis } \\
\text { Subileus }\end{array}$ & - & & 1 & & \\
\hline Medication & 5 & & 8 & & \\
\hline Sulfasalazine & 5 & & 4 & & \\
\hline Corticosteroids & & & & & \\
\hline Labatory results of blood & & & & & \\
\hline Total protein $(\mathrm{g} /)$ & & \pm 1 & 62 & & 2 \\
\hline Albumin & & & 29 & & 2 \\
\hline Prealbumin & 0.2 & \pm 0.02 & 0.1 & \pm & 0.02 * \\
\hline Leucocytes & 9.8 & \pm 0.8 & 8.7 & \pm & 0.8 \\
\hline Trombocytes & 372 & \pm 45 & 389 & \pm & 46 \\
\hline$(\mathrm{mm} / \mathrm{hr})$ & & \pm 7 & 43 & \pm & 8 \\
\hline$(\mathrm{mmol} / \mathrm{l})$ & 7.7 & \pm 0.3 & 7.5 & \pm & 0.3 \\
\hline
\end{tabular}

Table 1. Clinical parameters patient groups.

* $=p<0.05$ Mann-Whitney. IBD = inflammatory bowel disease

\begin{tabular}{|c|c|c|c|c|c|c|c|c|c|}
\hline $\begin{array}{llll}\ddots & \ddots\end{array} \quad \therefore$ & \multicolumn{3}{|c|}{$\begin{array}{l}\text { IBD } \\
(n=14)\end{array}$} & \multicolumn{3}{|c|}{$\begin{array}{l}\text { Cancer } \\
(n=5)\end{array}$} & \multicolumn{3}{|c|}{$\begin{array}{l}\text { NoCa/NolBD } \\
(n=4)\end{array}$} \\
\hline LM ratio & 0.14 & \pm & 0.03 & 0.14 & \pm & 0.04 & 0.10 & \pm & 0.06 \\
\hline Lactulose $\%$ & 1.7 & \pm & 0.4 & 1.6 & \pm & 1.0 & 0.9 & \pm & 0.8 \\
\hline Mannitol \% & 13.3 & \pm & 2.6 & 12.7 & \pm & 6.7 & 8.4 & \pm & 2.8 \\
\hline Villous height $(\mu m)$ & 472 & \pm & 16 & 416 & \pm & 31 & 446 & \pm & 34 \\
\hline Crypt depht & 162 & \pm & 12 & 185 & \pm & 20 & 148 & \pm & 7 \\
\hline IEL ( $n / 100$ enterocytes) & 28 & \pm & 2 & 21 & \pm & 4 & 27 & \pm & 4 \\
\hline$(n / \mathrm{HPF})$ & 65 & \pm & 3 & 76 & \pm & 9 & 61 & \pm & 7 \\
\hline
\end{tabular}

Table 2. Diagnostic group in relation to lactulose/mannitol permeability.

$\mathrm{IBD}=$ inflammatory bowel disease, $\mathrm{IEL}=$ intra-epithelial lymphocytes, $\mathrm{PCNA}=$ proliferative cellular nuclear antigen, HPF $=$ high power field. Ll=labeling index.

No significant differences were observed between the three different groups of patients. 
percentages of lactulose, mannitol and xylose in depleted patients were not significantly different from non-depleted patients (table 3 ).

The $\mathrm{L} M$ ratio was correlated with the number of IgA plasma cells in the lamina propria (figure 2). No correlation was observed between $L M$ ratio and the number of intra-epithelial lymphocytes, villous height, crypt depth or proliferative activity.

\section{Intestinal histology}

There were no significant differences in morphological parameters between the three patient categories (table 2). PIB and PIFFM were both positively correlated to villous height (figure 3). Thus, nutritional depletion was associated with a decrease in villous height. Villous height in the depleted group seemed to be lower compared to a recently described healthy control group (9). No significant differences were observed between depleted and non-depleted patients regarding crypt depth, plasma cells, proliferative activity or percentage of intra-epithelial lymphocytes (table 4). These parameters were all within the ranges given in the literature $(9,17,22-25)$. The decrease in villous height was not associated with a decrease in proliferative activity. On the contrary, with decreasing villous height proliferative activity was significantly increased (corr.- 0.42, $\mathrm{p}=0.03$ ) (figure 4).
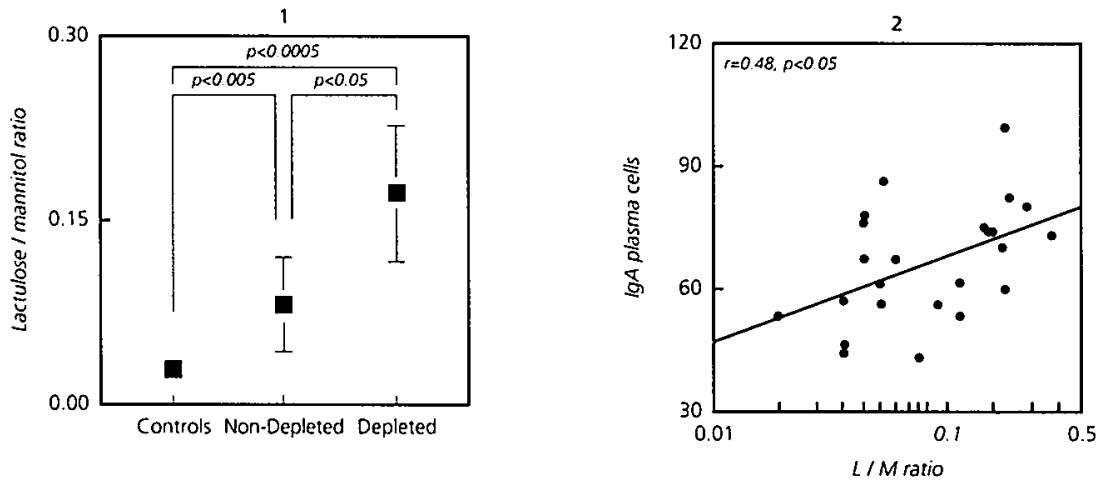

Figure 1. Nutritional depletion and lactulose/mannitol permeability.

Nutritional depletion was associated with an increased intestinal permeability. Control versus depleted and non-depleted $p<0.05$. Depleted versus non-depleted $p<0.05$.

Figure 2. Correlation between IgA plasma cells in the lamina propria and permeability.

An increase in permeability was associated with an increase in number of IgA producing plasma celis in the lamina propria of the duodenum.

\begin{tabular}{|c|c|c|c|c|c|c|c|c|c|}
\hline \multirow{4}{*}{$\begin{array}{l}\text { Lactulose \% } \\
\text { Mannitol \% } \\
\text { Xylose \% }\end{array}$} & \multicolumn{3}{|c|}{$\begin{array}{l}\text { Control } \\
(n=12)\end{array}$} & \multicolumn{3}{|c|}{$\begin{array}{l}\text { Non-Depleted } \\
(n=10)\end{array}$} & \multicolumn{3}{|c|}{$\begin{array}{l}\text { Depleted } \\
(n=13)\end{array}$} \\
\hline & 0.5 & \pm & $0.1^{\star}$ & 0.9 & \pm & 0.3 & 2.0 & \pm & 0.5 \\
\hline & 19.2 & \pm & 2.6 * & 11.5 & \pm & 1.6 & 12.9 & \pm & 3.5 \\
\hline & 29.9 & \pm & $1.8^{\star}$ & 18.1 & \pm & 4.2 & 20.6 & \pm & 3.4 \\
\hline
\end{tabular}

Table 3. Nutritional depletion and urinary excretion percentages.

${ }^{*}=p<0.05$ versus depleted and non-depleted. 


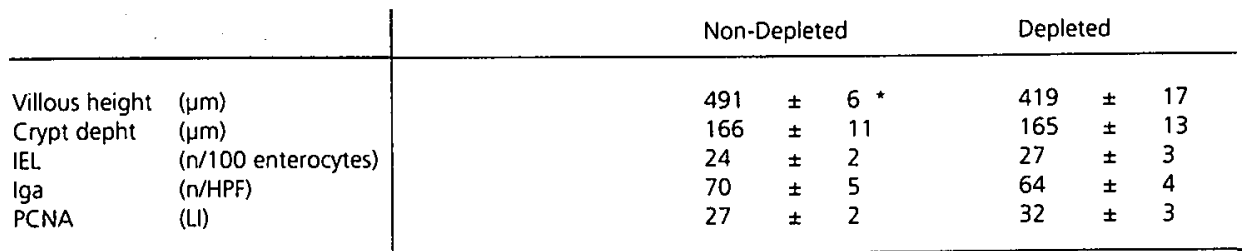

Table 4. Nutritional depletion and mucosal morphology

$\mathrm{IEL}=$ Intra-epithelial lymphocytes, $\mathrm{PCNA}=$ proliferative cellular nuclear antigen, $\mathrm{HPF}=$ high power field. Laboratory values presented as means \pm SEM. ${ }^{*}=p<0.01$
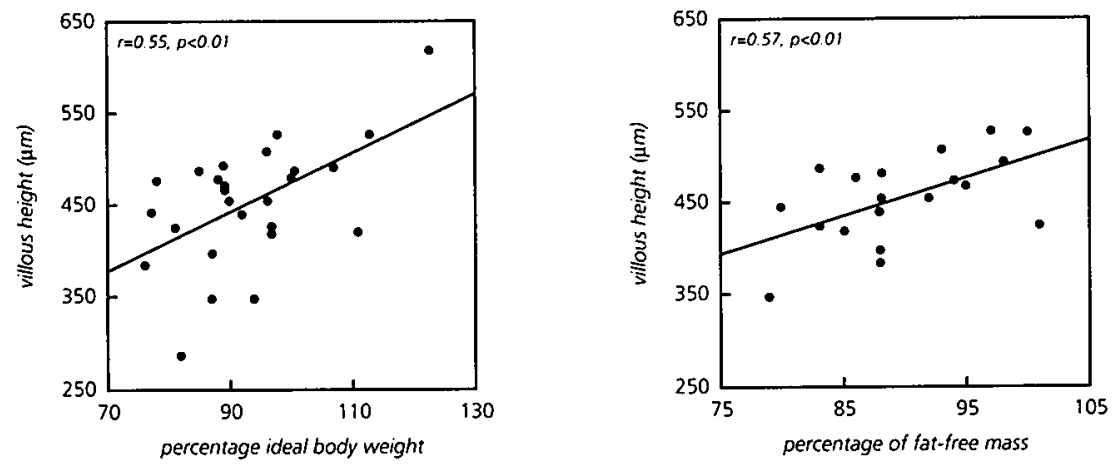

Figure 3. Correlation between villous height and nutritional depletion.

Percentage ideal body weight (PIB) and percentage of ideal fat-free mass (PIFFM) were correlated with villous height in the duodenum.

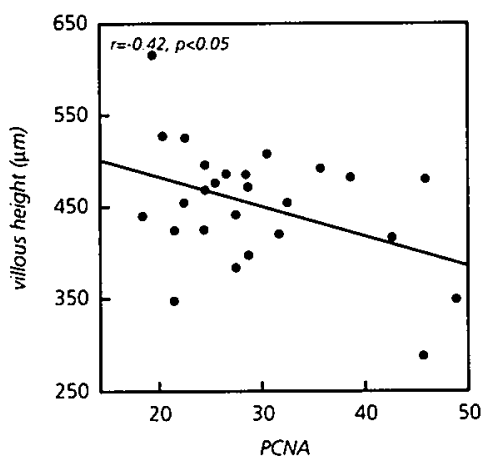

Figure 4. Correlation between villous height and PCNA.

Villous height and PCNA were slightly negatively correlated. 
This study was performed to assess the relationship between nutritional depletion, intestinal permeability and morphology. The association between nutritional depletion and intestinal permeability in man was first described by Maxton et al (26). Starvation in obese patients and nutritional depletion in patients without gastrointestinal disease receiving enteral nutrition was associated with increased permeability. In our study intestinal permeability and intestinal morphology were assessed in nutritionally depleted patients, unable or not allowed to receive enteral nutrition. Before parenteral nutrition was initiated, intestinal permeability was measured and duodenal biopsies were obtained and related to the degree of depletion. For ethical reasons duodenal biopsies were not taken in the control group and permeability in the control group was measured by giving the test solution orally. This may have biased the differences in permeability between patients and controls. In the control group the solution was diluted by the gastric juice before entering the duodenum. In the patient group the solution was infused undiluted into the duodenal bulb. The hyperosmotic solution used may have accentuated increased permeability in patients with minimal villous atrophy or may have increased permeability even in the normal intestine $(27,28)$. In addition, the effect of taking biopsies on intestinal permeability measurements is unknown. Therefore, differences between controls and patients may be confounded by the use of hyperosmotic stress and the taking of biopsies. However, the differences in permeability between controls and patients with inflammatory bowel disease were comparable to data previously published (29). Furthermore, the main purpose of this study was not to compare patients with controls but to compare depleted and non-depleted patients, in which the method of permeability measurement was the same. Permeability proved to be clearly increased in the nutritionally depleted patient group as compared to the non-depleted group. The ratio between crypts and villi is often used to describe changes in intestinal morphology e.g. coeliac disease. As in animal models of nutritional depletion both villous height and crypt depth are decreased (30) changes in villous height and crypt depth may disappear when calculating a villous/crypt ratio. Therefore, in this study crypt depth and villous height were presented separately. The decrease of villous height in nutritionally depleted patients is in line with experimental observations in chronic malnourished rats (30). Furthermore, a study on the effect of alcohol on mucosa morphology in man showed weight parameters to relate to mucosa morphology, thus supporting our observations (31). Assuming that PCNA positive cells traverse normally through the cell cycle, the observation that proliferative activity is increased associated with a reduced villous height suggests that the enterocytes have a decreased cell life.

Nutritional depletion results in increased bacterial translocation in animal experiments (11). The gut barrier is of critical importance in the prevention of translocation of bacteria and their products into the portal circulation and the mesenteric lymph nodes. Although translocation of endotoxins through an intact intestinal mucosa does not occur in humans (32), the concept of translocation may be complex and must be studied in relation to intestinal morphology and factors causing changes in intestinal morphology. Several factors contribute to the intestinal barrier function. The 
first factor is the mucous layer. Elimination of the mucous layer results in a notable increase in the number of bacteria directly adherent to the enteric surface and an increased dissemination of normal intestinal bacteria to extraintestinal tissues such as the liver and spleen (5). The second part of the intestinal barrier is the epithelium itself, consisting of enterocytes, mucus producing goblet cells, APUD cells, and intraepithelial lymphocytes. The epithelial cells are bound by so called tight junctions in the zona occludens (33). The gut associated lymphoid tissue forms the third part of the intestinal barrier. It is composed of intra-epithelial lymphocytes, immune cells in the lamina propria (plasma cells, lymphocytes, macrophages and eosinophils), aggregates of lymphocytes called Peyer's patches and the cells in the mesenteric lymph nodes (5).

The dual sugar only tests the epithelium part of the intestinal barrier. Theoretically an increase in lactulose/mannitol permeability may be caused by a decrease in mannitol absorption and/or an increase in lactulose absorption. Decreased mannitol absorption is a result of a diminished absorptive area (34). Increased permeation of lactulose may in theory be due to a facilitated diffusion of lactulose into the crypt region as a consequence of decreased villous height. Because the tight junctions in the crypt region are more permeable this will result in an increased diffusion of lactulose (35).

The morphologic data suggest that a decrease in villous height is at least partially responsible for the changes in LM ratio between the non-depleted and depleted patients. The data on mannitol and xylose absorption, however, do not prove that there is a difference in absorption between the non-depleted and depleted patients, because there was no difference in mannitol and xylose excretion between these two groups. In contrast, lactulose excretion was higher in the depleted patients. Therefore, it seems that the decreased villous height results in a facilitated diffusion of lactulose into the crypt area resulting in increased lactulose permeability and increased $L / M$ ratio. The comparable xylose excretion between non-depleted and depleted patients suggests that the development of nutritional depletion is not the result of changes in absorption and therefore, that the observed differences in permeability between the patient groups are secondary to nutritional depletion, and are not causing nutritional depletion. Without doubt it remains difficult to separate cause and effect when studying nutritional depletion in relation to intestinal permeability. However, our data add further support to the findings of Maxton et al (26) who showed that intestinal permeability increased as a result of starvation.

Another explanation for an increased lactulose/mannitol ratio may be an increased lactulose permeation due to loosening of the tight junctions (34). Tight junctions are permeable to small molecules. They constitute a dynamic complex which is involved in the regulation of nutrient uptake (33). In disease, loosening of the tight junctions is thought to be a result of production of oxygen radicals by neutrophils invading the epithelium $(36,37)$. Activation of neutrophils seems to be an important factor in the pathogenesis of tissue injury (38). In the gut neutrophils may become activated by endotoxins absorbed by the gut. There is little evidence that there is translocation of endotoxins in the intact gut. However, endotoxin uptake occurs in the diseased intestine (32). Also, endotoxin increases intestinal permeability in humans (39). In 
addition, intestinal permeability is increased in critically ill patients (40). Neutrophils may also become activated by the production of interferon- $\gamma$ by intra-epithelial lymphocytes (41). Intra-epithelial lymphocytes are the first cells of the immune system that are exposed to potentially pathogenic organisms and play a key role in gut barrier function (42). In addition to neutrophil activation, interferon- $\gamma$ has also a direct effect on the loosening of tight junctions (43).

In this study the number of intra-epithelial lymphocytes was not significantly related to permeability. In animals the number of immune cells in the epithelium as well as in the lamina propria of the small bowel decrease during pure nutritional depletion $(44,45)$. In clinical depletion and in malnutrition in Third World countries, however, comparable amounts of cells or even increased numbers of immune cells are found in the intestine (46). This may be the result of activation of gut immune cells possibly caused by translocation of bacteria or their products. The activated intraepithelial lymphocytes may subsequently directly or indirectly increase epithelial permeability. Indicative for an activation of the gut associated immune cells is the relation between plasma IgA cells and L/M ratio. One study of patients with primary IgA deficiency did not show increased permeability in these patients (47). The plasma IgA cells therefore do not seem to regulate intestinal permeability directly. The increased number of IgA cells in patients with increased permeability must indicate loss of gut barrier function against immune stimulating agents and shows that the LM test not only reflects sugar permeation in these patients .

The difference in permeability between the controls and non-depleted patients is mainly caused by a decreased mannitol absorption in the patient population (table 3). Also, a small increase in lactulose excretion was observed in the patient group. The increased lactulose excretion in patients may be caused by the difference in route of administration of the solution given in the patient group compared to the controls. Although mannitol absorption was decreased in the non-depleted patient group, villous height was in the normal range (9). A possible explanation for this observation could be that the changes causing decreased mannitol absorption in the patients are located distal from the duodenum where the intestinal biopsies were taken.

In conclusion, nutritional depletion results in increased "epithelial permeability" probably caused by a facilitated diffusion of macromolecules into the crypt area as a result of decreased villous height, but also possibly as a result of opening of tight junctions. In addition, increased lactulose-mannitol permeability in nutritional depletion is associated with an increased number of IgA plasma cells in the lamina propria. 
1. Studley H.O. Percentage of weight loss. A basic indicator fo surgical risk in patients with chronic peptic ulcer. Journal of the American Medical Association 1936:106:458-460.

2. Von Meyenfeldt M.F., W.J. Meijerink, M.M. Rouflart, M.T. Buil-Maassen, and P.B. Soeters. Perioperative nutritional support: a randomised clinical trial. Clinical Nutrition 1992;11:180-186.

3. Windsor J.A., and G.L. Hill. Weight loss with physiologic impairment. A basic indicator of surgical risk. Annals of Surgery 1987:207:290-296.

4. Wilmore D.W., R.J. Smith, S.T. O'Dwyer, D.O. Jacobs, T.R. Ziegler, and X.-D. Wang. The gut: a central organ after surgical stress. Surgery 1989;104:917-923.

5. Wells C.L., M.A. Maddaus, and R.L. Simmons. Poposed mechanisms for the translocation of intestinal bacteria. Reviews of Infectious Diseases 1989;10:958-979.

6. Alexander J.W., S.T. Boyce, G.F. Babcock, et al. The process of microbial translocation. Annals of Surgery $1990 ; 212: 496-512$

7. Windmueller H.G., and A.E. Spaeth. Respiratory fuels and nitrogen metabolism in vivo in small intestine of fed rats. The Journal of Biological Chemistry 1980;255:107-113

8. Newsholme E.A., B. Crabtree, and M.S. Ardawi. Glutamine metabolism in lymphocytes: its biochemical, physiological and clinical importance. Quarterly Journal of Experimental Physiology 1985;76:473-489.

9. van der Hulst R.R., B.K. van Kreel, M.F, von Meyenfeldt, et al. Glutamine and the preservation of gut integrity. Lancet 1993:334:1363-1365.

10. van der Hulst R.R., N.E. Deutz, M.F. von Meyenfeldt, J.M. Elbers, R.W. Stockbrügger, and P.B. Soeters Decrease of mucosal glutamine concentration in the nutritionally depleted patient. Clinical Nutrition 1994:13:228-233.

11. Deitch E.A., J. Winterton, M. Li, and R.D. Berg. The gut as a portal of entry for bacteremia. Role of protein malnutrition. Annals of Surgery 1987;205:681-692.

12. Deitch E.A., D. Xu, L. Qi, R.D. Specian, and R.D. Berg. Protein malnutrition alone and in combination with endotoxin impairs systemic and gut-associated immunity. Journal of Parenteral and Enteral Nutrition 1992;16:25-31

13. Anonymus. Metropolitan Life Insurance Company. New weight standard for men and women. Bulletin Metropolitan Llfe Insurance Foundation. 1983:64:1-4

14. Segal K.R., M. van Loan, P. Fitzergald, A. Hodgdon, and T.B. van Itallie. Lean body mass estimation by biolelectrical impedance analysis: a four site cross-val- idation study. American Journal of Clinical Nutrition 1988;74:7-14.

15. Shippee R.L., A.A. Johnson, W.G. Cioffi, J. Lasko, T.E. LeVoyer, and B.S. Jordan. Simultaneous determination of lactulose and mannitol in urine of burn patients by gas-liquid chromatography. Clinical Chemistry 1992;38:343-5

16. Eberts $T$., R. Sample, M. Glick, and H. Ellis. A simplified colorimetric micromethod for xylose in serum or urine with phloroglucinol. Clinical Chemistry 1979;25:1440-3.

17. Saraf C.E., C.S. MCCormick, G.R. Brown, et al. Proliferating cell nuclear antigen immunolocalization in gastro-intestinal epithelia. Digestion 1991;50:85. 91.

18. Alverdy J.A., E. Aoys, P. Weiss-Carrington, and D.A Burke. The effect of glutamine-enriched TPN on gut immune cellularity. Journal of Surgical Research 1992;52:34-38.

19. Aherne W.A., and M.S. Dunnil Morphometry. Edward Ainold Publish Ltd. London. 1982.

20. Mitchison H.C., H.A. Mardini, S. Gillespie, A. Zaitoun, and C.O. Record. A pilot study of fluticasone propionate in untreated coeliac disease. Gut 1991:32:260265.

21. Norusis M.J. (ed). SPSS/PC+ V3.1 Base manual for the IBM PCIXT/AT and PS/2. SPSS Chicago, 1988

22. Arranz E., J. Bode, K. Kingstone, and A. Ferguson. Intestinal antibody proliferation of coeliac disease: association with $\gamma / \delta \mathrm{T}$ cell receptor expression by intraepithelial lymphocytes, and other indices of potential coeliac disease. Gut 1994;35:476-482.

23. Chandra R.K. and M. Wadhwz. Nutritional modulation of intestinal mucosal immunity. Immunological Investigations 1989;18:119-126.

24. Domagala W., K. Marlicz, D. Bielicki, and M. Osborn. Increased PCNAVcyclin index correlates with severity of duodenitis defined by histological criteria. Virchows Archives A Pathology, Anatomy and Histopathology 1993:422:345-349.

25. Kultlu T., N. Brousse, C. Rambaud, F. Le Deist, J. Schmitz, and N. Cerf-Bensussan. Numbers of $T$ cell receptor (TCR) $\alpha \beta+$ but not of TCR $\gamma / \delta+$ intra-epithelial lymphocytes correlate with the grade of villous atrophy in coeliac patients on a long term normal diet. Gut 1993;34:208-214.

26. Maxton D.G., J.S. Mensies, B. Slavin, and R.P. Thompson. Small-intestinal function during enteral feeding and starvation in man. Clinical Science 1989:77:401-406. 
27. Wheeler P.G., I.S. Menzies, and B. Creamer. Effect of hyperosmolar stimuli and coeliac disease on the permeability of the human gastrointestinal tract. Clinical Science in Molecular Medicine 1978;54:495-501.

28. Laker M.F., and I.S. Menzies. Increase in human intestinal permeability following ingestion of hypertonic solutions. Journal of Physiology 1977;265:881894

29. Wyatt J., H. Vogelsang, W. Hübl, T. Waldhöer, and H. Lochs. Intestinal permeabiltiy and the prediction of relapse in Crohn's disease. Lancet 1993;341;14371439.

30. Guiraldes E., and J.R., Hamilton. Effect of chronic malnutrition on intestinal structure, epithelial renewal, and enzymes in suckling rats. Pediatric Research 1981:15:930-934

31. Person J., N.O. Berg, K. Sjölund, R. Stenling, and R.H. Magnusson. Morphological changes in the small intestine after chronic alcohol consumption. Scandinavian Journal of Gastroenterology 1990;25:173-184.

32. van Deventer S.J., J.W. ten Cate, and G.N. Tytgat. Intestinal endotoxemia: clinical significance. Gastroenterology 1988:94:825-831.

33. Madara J.L. Loosening tight junctions. The Journal of Clinical Investigation 1989;83:1089-1094.

34. Travis S, and I. Menzies. Intestinal permeability: functional assessment and significance. Clinical Science 1992:82:471-488.

35. Hollander $D$. The intestinal permeability barrier. Scandinavian Journal of Gastroenterology 1992;27:721.726.

36. Nash S., J. Stafford, and J.L. Madara. Effects of polymorphonuclear leuckocyte transmigration on the barrier function of cultured intestinal epithelial monolayers. The Journal of Clinical Investigation 1987;80:1104-1113.

37. von Ritter C., M.B. Grisham, M. Hollwarth, W. Inauen, and D.N. Granger. Neutrophil-derived oxidants mediate formyl-methionyl-leucyl-phenylalanine-induced increases in mucosal permeability in rats. Gastroenterology 1989:97:778-780.

38. Glauser M.P., G. Zanetti, J.-D. Baumgartner, and J. Cohen. Septic shock: pathogenesis. Lancet 1991;338:732-736.

39. O'Dwyer S., H.R. Michie, T.R. Ziegler, A. Revhaug, R.J. Smith, and D.W. Wilmore. A single dose of endotoxin increases intestinal permeability in humans. Archives of Surgery 1988;123:1459-1464.

40. Harris C.E., R.D. Griffiths, N. Freestone, D. Billington, S.T. Atherton, and R.R. Macmillan. Intestinal perme- ability in the critically ill. Intensive Care Medicine 1992;18:38-41.

41. Helton W.S. Editorial: The pathophysiologic significance of alterations in intestinal permeability induced by total parenteral nutrition. Journal of Parenteral and Enteral Nutrition 1994;18:289-290.

42. Gautreaux M.D., E.A. Deitch, and R.D. Berg. T lymphocytes in host defence against bacterial translocation from the gastrointestinal tract. Infection and Immunity 1994;62:2874-2884.

43. Madara J.L., and J. Stafford. Interferon- $\gamma$ directly affects barrier function of cultured intestinal epithelial monolayers. The Journal of Clinical Investigation 1989:83:724-727

44. Maffei H.V., M.A. Rodrigues, J.L. de Camargo, and A.O. Campana. Intra-epithelial lymphocytes in the jejunal mucosa of malnourished rats. Gut 1980;21:3236.

45. Chandra R.K., and M. Wadhwa. Nutritional modulation of intestinal mucosa immunity. Immunologica! Investigations 1989;18:119-126.

46. Sullivan P.B., and M.N. Marsh. Small intestinal mucosal histology in the syndrome of persistent diarrhoea and malnutrition: a review. Acta Paediatrica 1992;3815:72-77.

47. Gillon J., G.R. Barclay, P.L. Yap, and A. Ferguson. Food antibodies, intestinal permeability and HLA status in IgA deficient blood donors identified by a new rapid screening test. Clinical Allergy 1986:16:583588 . 
1

2

3

4

Chapter 5

6

7

8

9 


\section{The role of parenteral}

glutamine administration in preserving mucosal glutamine concentration 


\section{Abstract}

Introduction: The small intestine has been identified as an important site of metabolism of glutamine. The impairment of gut mucosa integrity during total parenteral nutrition (TPN) has been ascribed to a diminished supply of glutamine, due to the lack of glutamine in standard TPN. In addition, nutritional depletion diminishes glutamine availability in the intestine. The uptake of glutamine in the gut is dependent on the plasma glutamine concentration. This study was performed to observe changes in plasma and mucosa amino acid content during infusion of standard TPN and during infusion of TPN supplemented with glutamine.

Patients and Methods: Twenty patients were randomly allocated to an experimental (GT, TPN containing $0.23 \mathrm{~g}$ glutamine/kg.day) and a control group (ST, standard TPN). Patients received the iso-nitrogenous and iso-caloric TPN during 10-14 days. After an overnight fast, before TPN was started, biopsies were taken from the duodenum. Amino acid concentrations were determined in the biopsies. Blood was taken for routine laboratory measurements and amino acid determination. This procedure was repeated on the last day of TPN infusion.

Results: Plasma glutamine in the GT group rose about $25 \%$ whereas plasma glutamine concentrations in the ST group remained unchanged. Mucosa glutamine rose with about $75 \%$ in the GT group whereas in the ST group no increase was observed. The rise of total plasma and mucosa amino acids was equal in both groups. The rise in plasma and mucosa glutamine was limited to nutritionally depleted patients.

Conclusions: In conclusion, parenteral glutamine administration increases plasma and subsequently mucosa glutamine, specifically in depleted patients. 
Total parenteral nutrition (TPN) has greatly improved survival of patients that cannot be fed enterally. Certain nutrients, however, are insoluble (e.g. tyrosine) or are unstable (e.g. glutamine) in solution and for that reason limit their use in parenteral nutrition (1). For glutamine, a key energy substrate for rapidly dividing cells such as immune cells and enterocytes (2), this means that it is omitted from standard TPN and may therefore become deficient.

TPN results in intestinal villous atrophy and increased intestinal permeability $(3,4)$. The hypothesis is that these changes originate from a lack of glutamine in parenterally fed patients, caused by the absence of glutamine from standard TPN and decreased glutamine supply from muscle associated with nutritional depletion. This is supported by the fact that glutamine added to TPN preserves intestinal morphology and integrity $(4,5)$. In addition, parenteral glutamine administration preserves muscle glutamine concentration after surgery (6). Glutamine uptake by the gut seems to be dependent on plasma glutamine concentration (7). It is hypothesized that a diminished glutamine release from muscle in nutritional depletion and a lack of exogenous supply of glutamine may decrease plasma glutamine concentration and subsequently lower mucosa glutamine concentration. Maintenance of plasma glutamine concentration by means of glutamine supplementation may preserve mucosa glutamine concentration within normal ranges. To test this hypothesis amino acid concentrations were studied in plasma and mucosa during TPN with or without addition of glutamine in nutritionally depleted and non-depleted patients.

5.2 Patients and methods

\section{Patients}

Metabollically stable patients (temperature between 36.5 and $38^{\circ} \mathrm{C}$, no intra-abdominal abscesses, no signs of respiratory or cardiac failure) in need of TPN, were eligible to enter the study. Patients with renal or liver failure, diabetes mellitus, ileus, congenital metabolic disorders, and patients who had received parenteral nutrition within 3 weeks prior to the study were excluded. After obtaining written informed consent patients were randomly allocated to receive glutamine-dipeptide enriched TPN (GT) or standard TPN (ST). The groups were balanced for the presence of inflammatory bowel disease and neoplastic disease, and were studied prior to surgery. Percentage ideal body weight (PIB) was calculated from body length, body weight and wrist circumference using the Metropolitan Life Insurance tables 1983 (8). Nutritional depletion was defined as a PIB below 90 percent.

The study was approved by the Medical Ethical Committee of the University Hospital Maastricht.

\section{Study design}

After an overnight fast, patients underwent a duodenoscopy at which intestinal biopsies were taken from the second part of the duodenum, distally to the papilla of Vater. At the same time, venous blood samples were drawn from a major draining vein in the cubital fossa. TPN was started on the same day at $6 \mathrm{pm}$. Blood sampling, and duodenoscopy with biopsies were repeated on the last day of the study, 
during infusion of TPN.

All investigators but the pharmacist were blinded for the randomization. Patients received TPN for a period of at least 10 and maximally 14 days. During the study period a maximum of $500 \mathrm{ml}$ water or tea per day was allowed orally. The GT and ST solutions were isonitrogenous, isocaloric, and isovoluminous. Patients received 0.25 $\pm 0.01 \mathrm{~g} \mathrm{~N}$ and $190 \pm 7 \mathrm{KJ} / \mathrm{kg}$ body weight daily. In the GT group $0.23 \pm 0.01 \mathrm{~g}$ glutamine $/ \mathrm{kg}$ bodyweight was given; non-protein energy $(158 \pm 6 \mathrm{KJ} / \mathrm{kg}$ bodyweight per day) was derived in equal amounts from glucose and fat (20\% "Intralipid", Kabi Pharmacia). The GT group received TPN supplemented with the dipeptides glycyl-Ltyrosine and glycyl-L-glutamine. Compared to the ST formula the GT solution had a lower amount of total essential amino acids (table 1).

\section{Sample processing and analysis}

The methodology for amino acid determination in duodenal mucosa specimen and plasma has recently been described in detail elsewhere (8). In summary blood samples were kept on ice immediately after collection. Centrifugation was performed at $4^{\circ} \mathrm{C}$ during 5 minutes within 10 minutes after sampling. After centrifugation, plasma was deproteinized, frozen in liquid nitrogen and stored at $-80^{\circ} \mathrm{C}$ until analysis. Duodenal biospies were collected in cooled pre-weighed Eppendorf vials with $100 \mu \mathrm{l}$ $5 \%$ sulfosalicylic acid containing norvaline as internal standard. The vials were immediately frozen in liquid nitrogen and stored at $-80^{\circ} \mathrm{C}$ until analysis. The content of the vial was homogenized by vortex mixing during 10 minutes. After centrifugation the supernatant was used for amino acid determination. Both plasma and homogenate amino acid concentrations were determined as described previously (9). Dry weight was determined after freeze drying.

\section{Calculations and statistics}

Amino acid concentrations in mucosa were expressed as $\mu \mathrm{mol}$ per $\mathrm{kg}$ dry weight. Results are presented as means \pm SEM. Levels of significance were set at $p<0.05$ unless stated otherwise. Group comparison for statistical significance was performed using the Mann-Whitney test, between groups and with the Wilcoxon test within groups. The statistical procedures were performed with a SPSS-PC+ software program (10) on a MS-DOS personal computer.

\begin{tabular}{|c|c|c|c|c|c|c|c|c|c|c|c|}
\hline & ST & GT & & ST & GT & & ST & GT & & ST & GT \\
\hline Glutamate & 2.0 & 1.6 & Arginine & 4.1 & 3.3 & Tryptophane & 0.68 & 0.56 & Proline & 2.4 & 2.0 \\
\hline Glutamine & 0.0 & 5.9 & Tyrosine & 0.072 & 0.67 & Leucine & 2.8 & 2.3 & Serine & 1.6 & 1.3 \\
\hline Glycine & 2.8 & 3.3 & Valine & 2.6 & 2.1 & Lysine & 3.2 & 2.6 & SUMNAA & 20.2 & 23.8 \\
\hline Threonine & 2.0 & 1.6 & Methionine & 2.0 & 1.6 & Aspartate & 1.2 & 1.0 & SUMEAA & 20.7 & 16. \\
\hline Histidine & 2.4 & 2.0 & isoleucine & 2.0 & 1.6 & Cysteine & 0.20 & 0.0 & BCAA & 7.5 & 6.1 \\
\hline Alanine & 5.8 & 4.7 & Phenylalanine & 2.8 & 1.7 & & & & & & \\
\hline
\end{tabular}

Table1. Composition of the amino acid solution $(g /)$.

SUmNAA = sum non-essential amino acids, SUmEAA $=$ sum essential amino acids, $8 C A A=$ branched chain amino acids. 


\section{Patients}

Twenty patients with a mean age of 44 (range 21 to 70 years) participated in the study. Patients were treated for gastrointestinal inflammation $(n=14)$, malignant disease $(n=4)$, gastrointestinal obstruction $(n=1)$, or fistula $(n=1)$. Nine patients were considered clinically depleted because they had a PIB below 90\% $(84 \pm 2)$. Routine blood parameters were not different between the two study groups at the start of the study (table 2). The endoscopies did not reveal macroscopic abnormalities of the mucosa of the duodenum.

\begin{tabular}{|c|c|c|c|c|c|}
\hline & & ST & & GT & \\
\hline Total protein & $(\mathrm{o} / \mathrm{l})$ & 65 & \pm 1 & 63 & \pm 2 \\
\hline Albumin & $(\mathrm{g} / 1)$ & 33 & \pm 2 & 32 & \pm 2 \\
\hline Prealbumin & $(g / l)$ & 0.19 & \pm 0.02 & 0.15 & \pm 0.03 \\
\hline Leucocytes & $\left(10^{9} / 1\right)$ & 9.3 & \pm 1.1 & 92 & \pm 0.8 \\
\hline Trombocytes & $\left(10^{9} /\right)$ & 379 & \pm 61 & 405 & \pm 51 \\
\hline ESR & $(\mathrm{mm} / \mathrm{hr})$ & 36 & \pm 12 & 31 & \pm 7 \\
\hline $\mathrm{Hb}$ & $(\mathrm{mmol} / \mathrm{l})$ & 8.0 & \pm 0.5 & 7.5 & \pm 0.3 \\
\hline
\end{tabular}

Table 2. Laboratory parameters patient groups at first day.

Laboratory values presented as means \pm SEM.

\section{Plasma amino acid concentrations}

Concentrations of most amino acids in plasma (table 3) were increased at the end of the parenteral nutrition period during ongoing TPN in both patient groups. The increase in the concentration of the free plasma amino acids histidine, alanine, arginine, valine, methionine, phenylalanine, and lysine was less pronounced in the glutamine enriched group. Alpha-aminobutyric acid and leucine only increased in the control group. Glutamine was increased with about $25 \%$ in the GT group whereas glutamine was unaltered in the control group. Total amino nitrogen increased about $45 \%$ in the control and $40 \%$ in the GT group.

\section{Mucosa amino acid concentrations}

In mucosal biopsies, threonine, alanine, alpha-amino butyric acid and valine were increased in both patient groups. Glutamine rose with about $75 \%$ in the GT group. In addition, in the GT group glycine and tyrosine increased significantly, whereas methionine increased only in the control group (table 4). The sum of all amino acids did not exhibit a significant increase in either of the two groups. Glutamate showed the highest concentration of all amino acids in the mucosa in all patients. In relation to the low glutamine levels this reflects the high glutaminase activity in mucosa.

In table 5 the ratios are given for alanine, glutamine, branched chain amino acids and the sum of all amino acids together. Amino acids in plasma were increased to a higher extent compared to mucosa. This is reflected in an increased plasma to mucosa amino acid ratio. The relative increase of glutamine in mucosa was higher compared to plasma ( $75 \%$ versus $25 \%$ ) although the plasma-mucosa ratio was not significantly altered. 

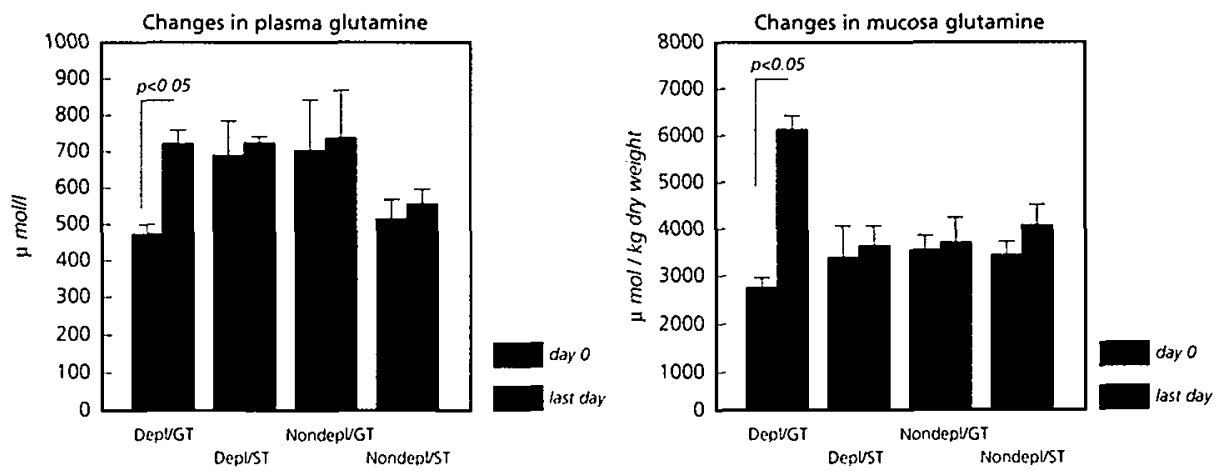

Figure 1. Plasma and mucosa glutamine concentrations before and during TPN with (GT) or without glutamine (ST). In nutritionally depleted (depl) patients $(n=9)$ plasma as well as mucosa concentrations were increased if glutamine was given. In the depleted patients receiving standard parenteral nutrition, as well as in all non-depleted (nondepl) patients $(n=11)$ no change in glutamine concentrations were observed.

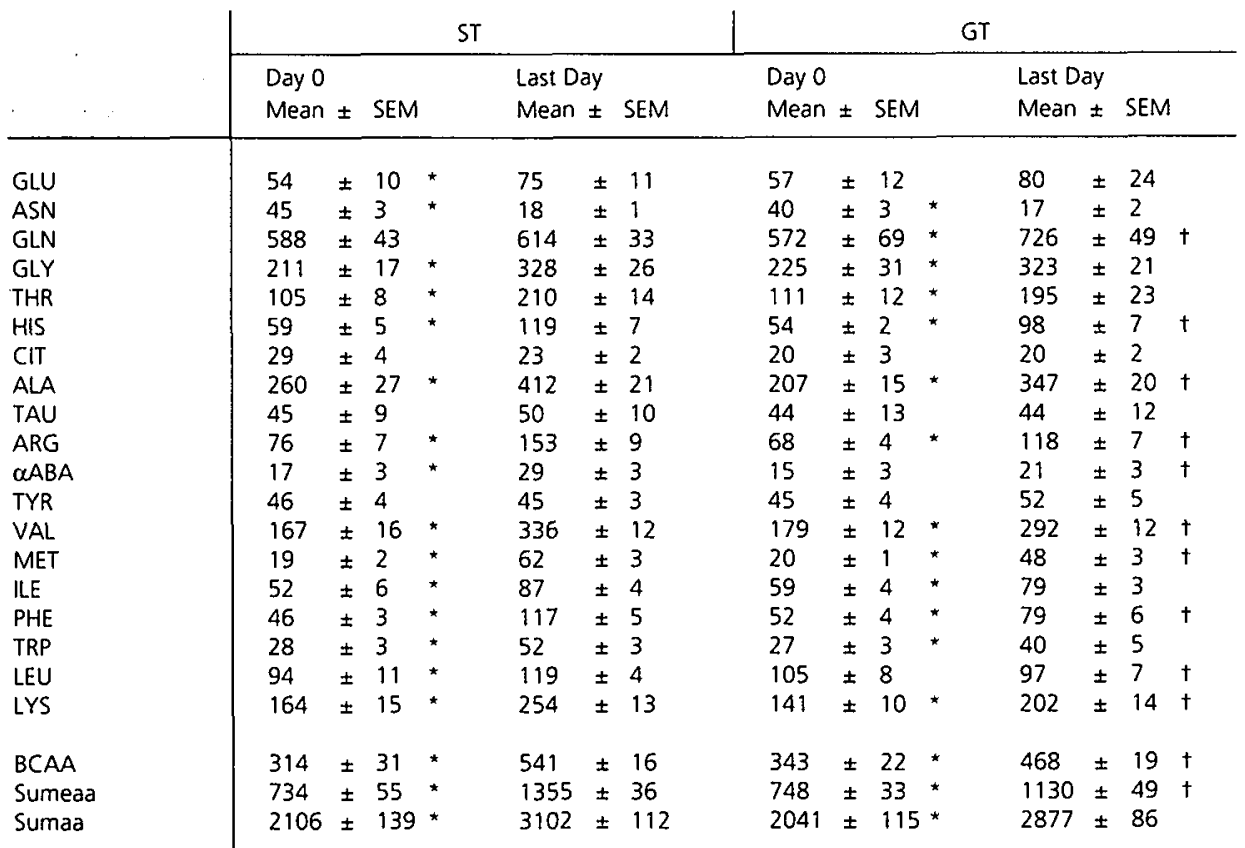

Table 3. Plasma amino acid concentrations ( $\mu$ mol/ $/)$ before starting TPN and after 2 weeks of TPN during infusion. * $p<0.05$ day 0 versus last day. $+p<0.05$ last day ST versus last day $G T$. SumAA = sum all amino acids, SumEaa $=$ sum essential amino acids, BCAA $=$ sum of branched chain amino acids. 


\section{Effect of nutritional depletion}

In nutritionally depleted patients mucosa glutamine was decreased compared to non-depleted patients at the start of the study (table 6). All the other amino acids were comparable between the depleted and non-depleted patients. In plasma only alanine was significanlty decreased in the depleted patients.

In the non-depleted patient group plasma and mucosa glutamine concentrations were unaltered during parenteral nutrition with or without glutamine (figure 1). In depleted patients, however, glutamine addition to the TPN solution resulted in a significant rise of plasma and mucosa glutamine concentrations in contrast to depleted patients receiving the control solution in whom plasma and mucosa glutamine concentration remained unchanged.

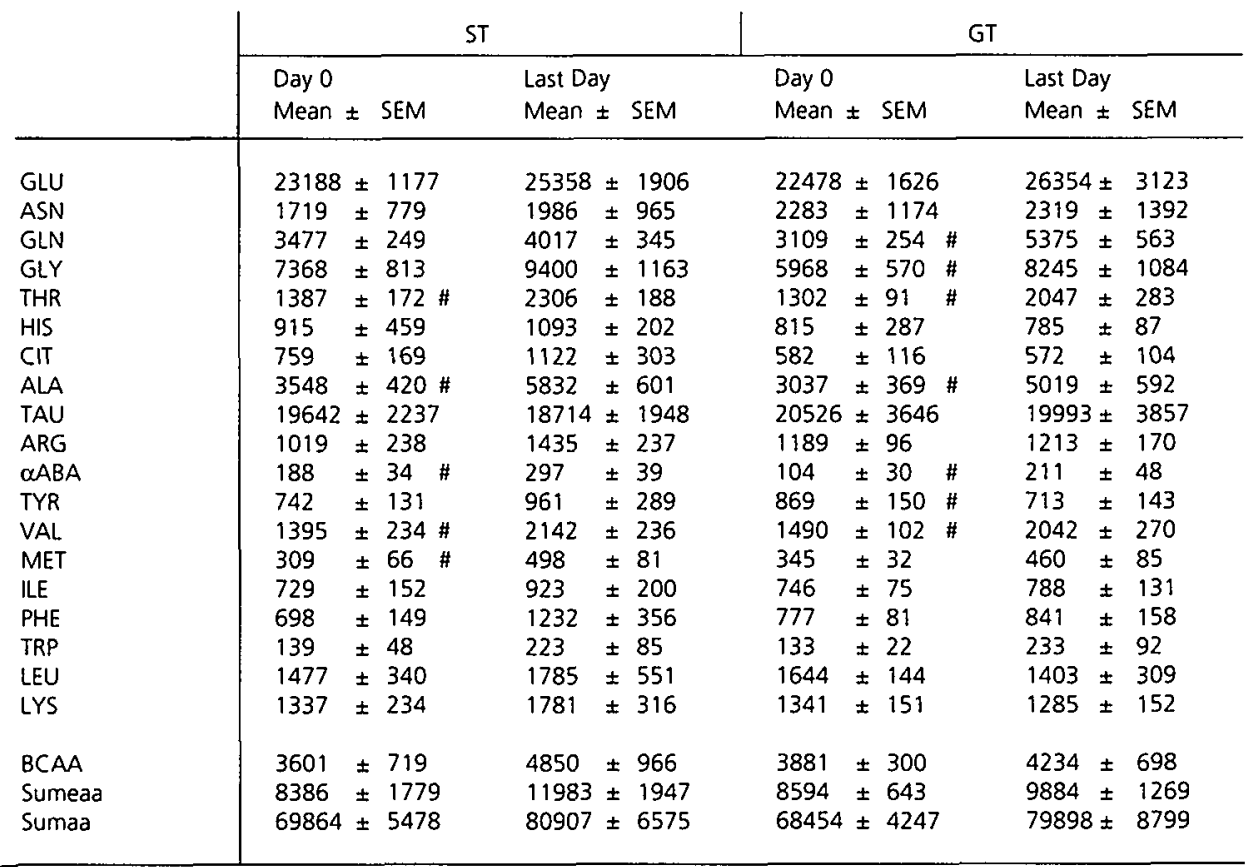

Table 4. Intramucosal amino acid concentrations ( $\mu$ mol/ $\mathrm{kg}$ dry weight) before TPN and after 2 weeks of TPN during infusion.

$\# p<0.05$ versus last day. For abbreviations see table 3 . 


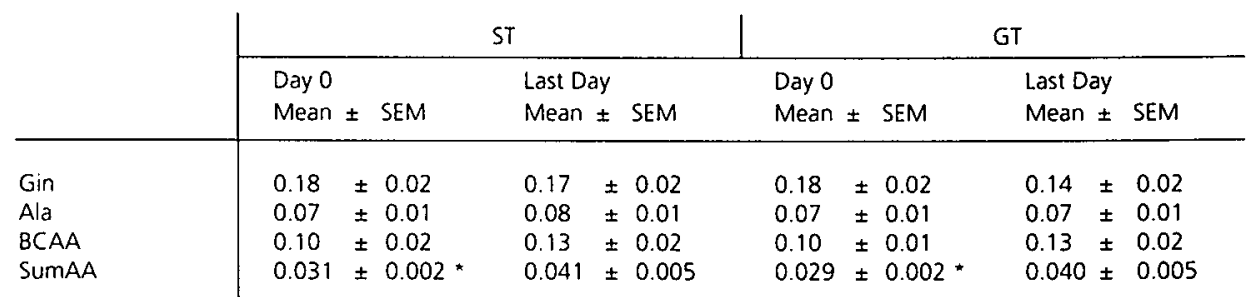

Table 5. Ratio plasma to mucosa amino acid concentration.

Ratios are obtained by dividing plasma amino acid concentration by mucosa amino acid concentration. " $p<0.05$ day 0 versus last day. For abbreviations see table 3.

\begin{tabular}{l|lll|ll}
\multirow{2}{*}{} & \multicolumn{2}{|c}{ Mucosa $(\mu \mathrm{mol} / \mathrm{kg}$ dry weight) } & \multicolumn{3}{c}{ Plasma $(\mu \mathrm{mol} / \mathrm{l})$} \\
\cline { 2 - 6 } & $\begin{array}{l}\text { Non-Depleted } \\
\text { Mean } \pm \text { SEM }\end{array}$ & $\begin{array}{l}\text { Depleted } \\
\text { Mean } \pm \text { SEM }\end{array}$ & $\begin{array}{l}\text { Non-Depleted } \\
\text { Mean } \pm \text { SEM }\end{array}$ & $\begin{array}{l}\text { Depleted } \\
\text { Mean } \pm \text { SEM }\end{array}$ \\
\hline Gin & $3664 \pm 174$ & $2962 \pm 269 *$ & $606 \pm 47$ & 554 & \pm 47 \\
Ala & $3590 \pm 441$ & $3051 \pm 363$ & $254 \pm 17$ & 213 & \pm 27 \\
BCAA & $3298 \pm 267$ & $4153 \pm 779$ & $311 \pm 30$ & $346 \pm 24$ \\
SumAA & $70122 \pm 3942$ & $68353 \pm 6014$ & $2120 \pm 140$ & $2027 \pm 113$
\end{tabular}

Table 6. Plasma and mucosa amino acids in depleted versus non-depleted patients. ${ }^{*} \mathrm{p}<0.05$ depleted versus non-depleted. For abbreviations see table 3 .

\subsection{Discussion}

This study was performed to evaluate intestinal mucosa amino acid concentrations in relation to plasma amino acids during TPN with or without addition of glutamine. Nutritional depletion is associated with decreased glutamine levels in the intestinal mucosa (7). This may cause mucosa abnormalities and an impaired barrier function of the gut. Decreased availability of glutamine may also be the cause of increased permeability and villous atrophy during treatment with glutamine-free parenteral nutrition (4).

The adequacy of parenteral nutrition is to some degree reflected in plasma amino acid concentrations, which therefore may be used to estimate amino acid requirements $(11.12)$. In our control group almost all amino acid concentrations rose significantly during the period of parenteral nutrition. Only citrulline, tyrosine and taurine did not exhibit a rise in concentration. The ratio of amino acid concentrations between the post-absorptive state and during steady state parenteral nutrition can be used to obtain insight into the adequacy of nutrition. A ratio ranging between 1.0 and 1.6 is assumed to reflect an adequate intake, a higher value means excessive intake and ratios less than 1 suggest inadequate intake (13). In this respect both solutions showed for some amino acids excess intake (ST: threonine, histidine, arginine, alpha 
amino acids, valine, methionine, isoleucine, phenylalanine, tryptophane; GT: threonine, histidine, alanine, arginine and methionine) and for some amino acids inadequate intake (ST: asparagine, citrulline; GT: asparagine), although in the control group ratios were more frequent "abnormal" than in the glutamine group. Except for glutamine most of the other plasma amino acids increased to a higher extent in the control group compared to the glutamine group. This difference can be explained by the composition of the solution infused in the control group (table 1).

In both patient groups some amino acids were increased in mucosa. The extent of increase was related to the plasma changes of amino acids. This increase, however, was lower in plasma compared to mucosa as reflected in the ratio. The plasma/mucosa ratio of glutamine tended to decrease in the GT group, because the relative rise in concentration was much higher in mucosa than in plasma. The concentrations of free amino acids in mucosa is therefore not solely a reflection of the plasma amino acid concentration. Changes in ratios are theoretically caused by changes in transport velocity or intracellular metabolism of the substrate. During TPN a $26-44 \%$ decrease in carrier mediated transport velocity of glucose and amino acids except glutamine is observed (14). This results in lower tissue concentrations, and therefore in higher plasma/tissue ratios. This may be in line with our findings. In the glutamine free group the glutamine plasma-mucosa ratio is unaltered whereas total AA ratio was increased. This may be caused by the effect of parenteral nutrition on transport velocity of $A A$ whereas glutamine transport is less affected compared to other amino acids. This line of thinking is confirmed by the fact that in the glutamine supplemented group the glutamine ratio even tended to decrease in contrast to total AA ratio.

Recently, it was observed that nutritional depletion is associated with decreased plasma and mucosa glutamine levels (7). This observation was confirmed in this study. Nutritionally depleted patients benefited more from the addition of glutamine to the TPN solution when compared to non-depleted patients. This suggests that in a non-depleted patient glutamine supplementation has no beneficial effect and is thus unnecessary. In contrast, a true glutamine deficiency may develop in nutritionally depleted patients either as a result of nutritional depletion itself or as a result of the absence of glutamine in TPN. In addition, it is remarkable that in nutritionally depleted patients glutamine concentrations in mucosa rise to supranormal levels (>6000 $\mu \mathrm{mol} / \mathrm{kg}$ dry weight), suggesting a diminished glutamine degradation potential which is in line with experimental work, showing decreased glutaminase activity during starvation (15).

In conclusion, the initial hypothesis that administration of glutamine may preserve plasma glutamine concentration and thus mucosa glutamine concentration was confirmed in this study. This effect is, however, limited to nutritionally depleted patients in which plasma glutamine concentrations are already decreased before TPN therapy is started. 
1. Adibi S.A., W. Fekl, P. Fürst, and M. Oehmke (ed). Dipeptides as new substrates in nutrition therapy. München Karger, 1987.

2. Lacey I.M., and D.W. Wilmore. Is glutamine a conditionally essential amino acid? Nutrition Reviews 1990;48:297-309.

3. Johnson L.R., E.M. Copeland, and P.S. Dudrick Structural and hormonal alterations in the gastrointestinal tract of parenterally fed rats. Gastroenterology 1975;68:1177-1183.

4. van der Hulst R.R., B.K. van Kreel., M.F. von Meyenfeldt, et al. Glutamine and the preservation of gut integrity. Lancet 1993:341:1363-1365.

5. Li J., B. Langkamp-Henken, K. Suzuki, and L.H. Stahlgren. Glutamine prevents parenteral nutritioninduced increases in intestinal permeability. Journal of Parenteral and Enteral Nutrition 1994:18:303-307.

6. Hammarqvist F., J. Wernerman, R. All, A. von der Decken, and $\mathrm{E}$. Vinnars. Addition of glutamine to total parenteral nutrition after elective abdominal surgery spares free glutamine in muscle, counteracts the fall in muscle protein synthesis, and improves nitrogen balance. Annals of Surgery 1989;209:455-61.

7. van der Hulst R.R., N.E. Deutz, M.F. von Meyenfeldt, J.M. Elbers, R.W. Stockbrügger, and P.B. Soeters. Decrease of mucosal glutamine concentration in the nutritionally depleted patient. Clinical Nutrition 1994; 13:228-233

8. Anonymus. Metopolitan Life Insurance Company. New weight standard for men and women. Bulletin Metropolitan Life Insurance Foundation 1983:64:14.

9. van Eijk H.M., D.R. Rooyackers, and N.E. Deutz. Rapid routine determination of amino acids in plasma by high-performance liquid chromatography with a $2-3$ $\mu \mathrm{m}$ spherisorb ODS II column. Journal of Chromatography 1993;620:143-148.

10. Norusis M.J. (ed) SPSS/PC+ V3.1 Base manual for the IBM PC/XT/AT and PS/2. SPSS Chicago, 1988.

11. Blackburn G.L., and L.L. Moldawer. An evaluation of techniques for estimating amino acid requirements in hospitalized patients. In: Amino acids: metabolism and medical application Pp. 265-290. Blackburn G.L., Grant J.P., and Young V.R. (ed). Boston Wright, 1983.

12. Young V.R., R.D. Yang, and C. Medith. Modulation of amino acid metabolism by protein and energy intakes. In: Amino acids: metabolism and medical application Pp. 13-28. Blackburn G.L., Grant J.P., and Young V.R. (ed). Boston Wright, 1983.
13. Bergström J., P. Fürst, and E. Vinnars. Effect of a test meal, without and with protein, on muscle and plasma free amino acids. Clinical Science 1990;79:331. 337.

14. Inoue $Y$., J. Epat, D.J. Frohnapple, H. Epstein., E.M. Copeland, and W.W. Souba. Effect of total parenterat nutrition on amino acid and glucose transport by the human small intestine. Annals of Surgery 1993:217:604-614.

15. Windmueller H.G., and A.E. Spaeth. Respiratory fuels and nitrogen metabolism in vivo in small intestine of fed rats. The Journal of Biological Chemistry 1980:255:107-112. 
1

2

3

4

5

Chapter 6

7

8

9

$\pm$ 
The role of parenteral glutamine administration in preserving gut integrity 


\section{Abstract}

Introduction: Parenteral glutamine dipeptide has been demonstrated to exert a beneficial effect on overall nitrogen balance in postoperative patients. Experimental animal data furnish evidence that specifically the gut may benefit from such treatment.

Patients and Methods: As this hypothesis has never been tested in humans 20 patients admitted for total parenteral nutrition and not receiving enteral nutrition were randomly allocated to receive parenteral nutrition, enriched with glycyl-L-glutamine (GT), or standard parenteral nutrition (ST). The solutions given were isonitrogenous, isocaloric and isovoluminous $(0.25 \pm 0.01 \mathrm{~g} \mathrm{~N}$ and $190 \pm$ $7 \mathrm{KJ} / \mathrm{kg}$ bodyweight daily). Mucosal biopsies were taken from the second part of the duodenum before starting parenteral nutrition, and after two weeks of parenteral nutrition. The ratio between the urine concentration of lactulose and mannitol after enteral administration of lactulose and mannitol was used to asses intestinal permeability.

Results: After two weeks of parenteral nutrition in the GT group intestinal permeability was unchanged, whereas permeability in the ST group increased significantly $(p<0.01)$. In addition, villous height was unaltered in the GT group whereas in the ST group a decrease was observed $(p<0.05)$.

Conclusions: These findings demonstrate a beneficial effect of glutamine addition in parenteral nutrition in preventing deterioration of gut integrity and mucosal architecture. 
Impairment of mucosal enzyme activities and deterioration of mucosal architecture are well established during prolonged total parenteral nutrition (TPN) (1,2). Deterioration of mucosal architecture has been associated with an increased permeability of the intestine (3), probably increasing the risk of bacteremia and endotoxaemia (4). It is postulated that these changes in intestinal function and structure are caused by the absence of the amino acid glutamine in commercially available amino acid solutions (5). Glutamine is not added to such solutions because of its instability during prolonged storage (6). The manufacturing of synthetic dipeptides such as L-alanine-L-glutamine and glycyl-L-glutamine, stable in solution and rapidly hydrolyzed in plasma after intravenous infusion, has made it possible to administer TPN containing glutamine (7). In animal studies beneficial effects on gut intestinal structure and function have been observed by addition of free glutamine as well as glutamine-dipeptide during TPN $(8,9)$. In addition, clinical trials with glutamine enriched TPN were performed, but they focused on clinical outcome (10) and muscle protein metabolism (10-12). These studies revealed that nitrogen balance, protein synthesis, and microbial colonization improve after surgery or bone marrow transplantation in patients receiving glutamine enriched TPN. In this study we report the effect of glutamine-peptide enriched TPN on mucosal architecture and intestinal permeability.

6.2 Patients and methods

\section{Patients}

Twenty patients admitted to the hospital for TPN, were randomly allocated to receive glutamine-dipeptide enriched TPN (GT) or standard TPN (ST). The groups were balanced for the presence of inflammatory bowel disease, and neoplastic disease, and were studied before surgery was performed. All investigators but the pharmacist were blinded to the randomization. Patients (table 1) received TPN for a period of at least 10 and maximally 14 days (mean $12 \pm 1$ day). During the study period a maximum of $500 \mathrm{ml}$ water or tea per day was allowed orally. The GT and ST solutions were isonitrogenous, isocaloric, and isovoluminous. Fat, glucose and amino acids were given in an "all in one" solution. The patients received $0.25 \pm 0.01 \mathrm{~g} \mathrm{~N}$ and $190 \pm$ $7 \mathrm{KJ} / \mathrm{kg}$ bodyweight daily. In the GT group $0.23 \pm 0.01 \mathrm{~g}$ glutamine $/ \mathrm{kg}$ bodyweight was given; non-protein energy ( $158 \pm 6 \mathrm{KJ} / \mathrm{kg}$ bodyweight per day) was derived in equal amounts from glucose and fat (20\% "Intralipid", Kabi Pharmacia). The GT group received TPN supplemented with the dipeptides glycyl-L-tyrosin and glycyl-Lglutamine. Compared with the ST formula the GT solution had a lower amount of total essential amino acids (table 2).

\section{Study design}

In the morning, after an overnight fast, patients underwent a duodenoscopy and intestinal biopsies were taken from the second part of the duodenum, distally from the papil of Vater. At the end of this procedure a solution containing $10 \mathrm{~g}$ lactulose, $0.5 \mathrm{~g}$ mannitol and $5 \mathrm{~g}$ xylose in $65 \mathrm{ml}$ water (osmolality $=1474 \mathrm{mosmol} / \mathrm{kg}$ ) was given directly into the duodenal bulb in order to investigate intestinal permeability. 
Venous blood samples were drawn for analysis of plasma amino acids (13), routine biochemical indices and plasma protein concentrations (prealbumin, retinol binding protein). Patients emptied their bladder before the duodenoscopy and urine was collected until six hours after infusion of the lactulose-mannitol-xylose solution and preserved with five $\mathrm{ml}$ thymol $10 \%$. Total urine volume was recorded and an aliquot was frozen at $-80^{\circ} \mathrm{C}$ until analysis. TPN was started at $6 \mathrm{pm}$. Blood sampling, duodenoscopy with biopsies, and permeability test were repeated on the last day of the study, during infusion of TPN. Twelve healthy volunteers without any evidence of gastrointestinal or systemic disease were evaluated to obtain control values for lactulose, mannitol, and xylose excretion in the urine. Control values for intestinal morphology were obtained from ten patients with dyspepsia complaints without histological abnormalities.

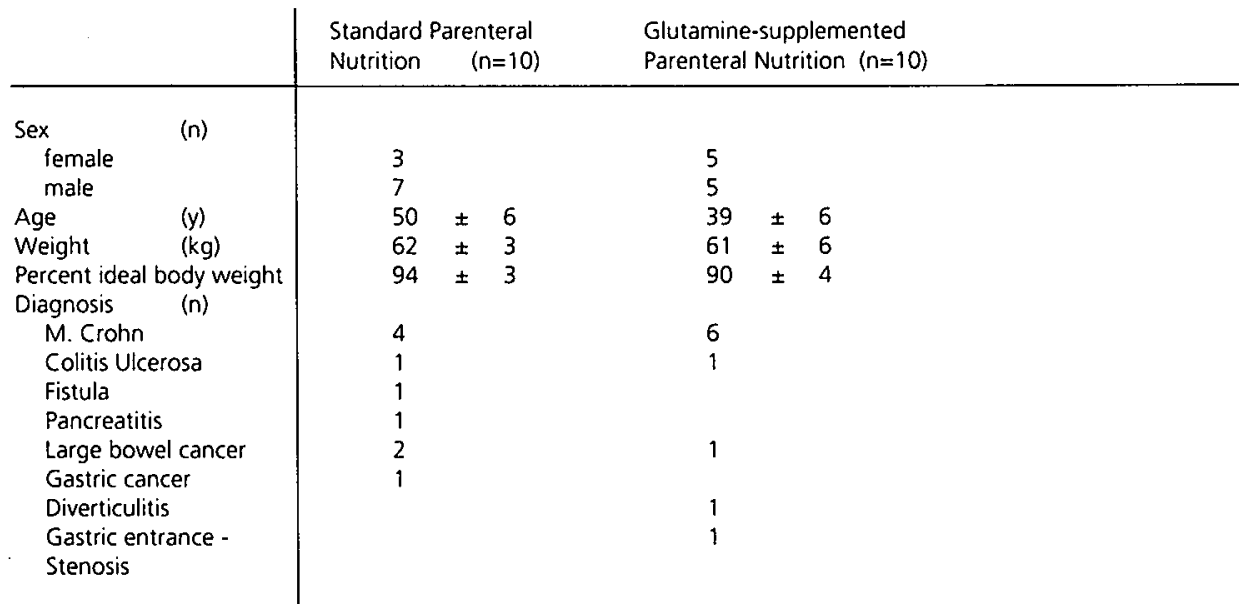

Table 1. Patient characteristics at study entry.

Data presented as means \pm SEM.

\begin{tabular}{l|cc} 
& $\begin{array}{c}\text { ST } \\
(\mathrm{g} / \mathrm{l})\end{array}$ & $\begin{array}{c}\mathrm{GT} \\
(\mathrm{g} /)\end{array}$ \\
\hline Fat & 48 & 48 \\
Glucose & 120 & 120 \\
Essential amino acids & 20.7 & 14.3 \\
Non-essential amino acids & 20.2 & 25.9 \\
$\quad$ including: & & $1.0 \star \dagger$ \\
$\quad$ Giycyl-L-tyrosine & - & $8.9 \neq \dagger$
\end{tabular}

Table 2. TPN solutions.

Composition expressed as grams per liter of "all in one" solutions ST and GT (Amino acids: Vamin 18 and Glamin, Kabi Pharmacia). * Corresponding to $0.7 \mathrm{~g} \mathrm{~L}$-tyrosine; $\ddagger$ corresponding to $5.9 \mathrm{~g} \mathrm{~L}$-glutamine; $\dagger$ corresponding to $3.3 \mathrm{~g}$ glycine. 


\section{Sample analysis}

Urinary lactulose and mannitol were determined simultaneously by application of gasliquid chromatography and excretion percentages and ratio were calculated as described by Shippee et al (14). Xylose concentrations in urine were determined enzymatically (15). Plasma amino acids were analyzed in plasma by HPLC (13). Histologic sections ( 3 to $4 \mu \mathrm{m}$ thick) of duodenal biopsies were made until a well oriented section, defined as a section with at least 3 adjoining well oriented villi was obtained. Villous height and crypt depth were measured using a video image system (JAVA). Stable means for villous height and crypt depth were obtained after measurement of at least ten well oriented villi and crypts. Intra-observer and inter-observer coefficients of variance for these measurements were respectively $3 \%$ and $7 \%$.

\section{Calculations and statistics}

Data are presented as means \pm SEM. Statistical analysis was performed using the Mann-Whitney $U$ test for comparison between the intervention groups and the Wilcoxon test for changes within both groups. The statistical procedures were performed with a SPSS-PC+ software program (16) on a MS-DOS personal computer. The study was approved by the Medical Ethical Committee of the University Hospital Maastricht and all patients gave their informed consent

\subsection{Results}

\section{Patients}

Patient characteristics are given in table 1. There were no adverse events of either TPN solution registered during the study period. In the ST group one patient was erroneously included with an artificial bladder made of ileum. This patient was excluded for evaluation of urinary sugars. In another patient in this group urine was accidently discarded during the second collection period.

\section{Intestinal permeability}

Intestinal permeability, measured by the ratio between urinary lactulose and mannitol was unaltered in the GT group, whereas permeability in all patients of the ST group increased $(p<0.01$, figure 1$)$. The significant change in permeability was not clearly attributed to either an alteration in excretion percentage of lactulose or of mannitol. Also urinary xylose excretion did not alter significantly (table 3). Lactulose/mannitol ratio was significantly higher in all patients compared to healthy controls.

\section{Intestinal morphology}

Intestinal villous height did not change in the GT group. In the ST group, however, a small decrease of intestinal villous height was observed. Crypt depth was not significantly different between groups and remained unaltered in the patient groups. Compared to the control values, mean villous height was lower in the GT group before and after TPN, whereas in the ST group villous height was decreased after two weeks of TPN (table 4). 


\section{Blood parameters}

In the GT group an increase of prealbumin $(0.15 \pm 0.03 \mathrm{~g} / \mathrm{l}$ vs $0.24 \pm 0.03 \mathrm{~g} /$, $p<0.01$ ), and plasma retinol binding protein ( $25 \pm 3 \mathrm{mg} / \mathrm{l}$ vs $43 \pm 5 \mathrm{mg} / \mathrm{l}, \mathrm{p}<0.001)$ was observed. In the ST group prealbumin concentrations were also increased $(0.19$ $\pm 0.02 \mathrm{~g} / \mathrm{l}$ vs $0.26 \pm 0.02 \mathrm{~g} / \mathrm{l}, \mathrm{p}<0.01)$, whereas retinol binding protein concentrations were unaltered ( $36 \pm 6 \mathrm{mg} / \mathrm{l}$ vs $44 \pm 6 \mathrm{mg} /$ ). Plasma glutamine concentrations rose significantly $(572 \pm 69 \mu \mathrm{mol} / \mathrm{l}$ vs $726 \pm 49 \mu \mathrm{mol} / \mathrm{l})$ in the GT group, and were higher compared to the ST group $(p<0.05)$, were plasma glutamine remained unchanged $(588 \pm 43 \mu \mathrm{mol} / /$ vs $614 \pm 33 \mu \mathrm{mol} / /)$.

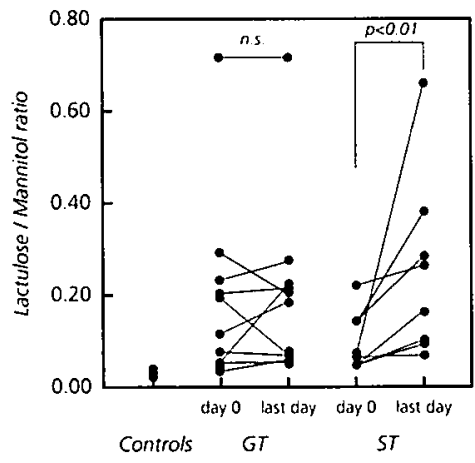

Figure 1. Intestinal permeability during TPN

Intestinal permeability in 12 healthy controls, 10 patients with glutamine enriched parenteral nutrition, and 8 patients with standard parenteral nutrition studied before start of parenteral nutrition and after 2 weeks of parenteral nutrition. $p<0.01$ day 0 versus last day in ST (Wilcoxon). $p<0.001$ controls versus ST and GT at day 0 and last day.

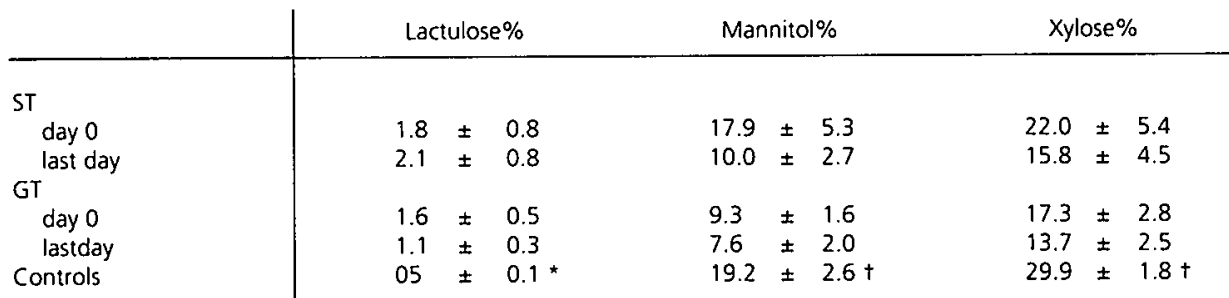

Table 3. Urinary excretion percentages of lactulose, mannitol and xylose.

Excretion percentages are percentages of enterally administered dose. Data presented as means $\pm S E M .{ }^{*} p<0.05$ versus standard TPN (ST) 0 and last day, and glutamine TPN (GT) 0 and last day. $\dagger p<0.05$ versus standard TPN, last day and glutamine TPN, day 0 and last day. 


\begin{tabular}{|c|c|c|c|c|}
\hline & \multicolumn{2}{|c|}{ Villous height $(\mu \mathrm{M})$} & \multicolumn{2}{|c|}{ Crypt depth $(\mu \mathrm{M})$} \\
\hline \multicolumn{5}{|l|}{ ST } \\
\hline day 0 & $476 \pm$ & 11 & $\$ 72$ & \pm 11 \\
\hline last day & $438 \pm$ & $\pm 14^{*}$ & 169 & \pm 10 \\
\hline \multicolumn{5}{|l|}{ GT } \\
\hline day 0 & $459 \pm$ & 13 & 168 & $\pm \quad 17$ \\
\hline lastday & $458 \pm$ & $\pm \quad 21$ & 169 & \pm 12 \\
\hline Controls & $509 \pm$ & $\pm 19 t$ & 178 & \pm 8 \\
\hline
\end{tabular}

Table 4. Intestinal morphology.

Villous height and crypth depth in duodenal mucosa $(\mu \mathrm{M})$. Data presented as means \pm SEM. Control values obtained from 10 patients with dyspepsia complaints without histological abnormalities. ${ }^{*} p<0.05$ versus day 0 , standard TPN. $\dagger p<0.05$ versus glutamine TPN, day 0 and last day, $p<0.01$ versus standard TPN last day.

6.4 Discussion

Supplementation of TPN with glutamine dipeptide prevented the increase in the lactulose/mannitol ratio as observed in all patients receiving glutamine free TPN. The excretion ratio of probes such as lactulose and mannitol has been demonstrated to yield reliable measures for intestinal permeability, even in the presence of variations in gastric emptying, intestinal transit time or absorption $(17,18)$. The unaltered lactulose/mannitol excretion ratio in the glutamine-peptide supplemented group therefore indicates that glutamine prevents an increase in intestinal permeability despite two weeks of gut starvation. This is relevant because an increased gut permeability is associated with decreased intestinal immunity and facilitation of bacterial translocation (5).

Rapidly dividing cells, such as gut mucosa cells and cells of the immune system, use glutamine as a fuel for oxidative metabolism and as precursor for DNA-synthesis (19-20). Although glutamine was originally thought to be a non-essential amino acid, the results of research over the last decade suggested a depletion of plasma and muscle glutamine in several conditions. Preservation of mucosal thickness, morphology, protein content, physiology and integrity due to glutamine enrichment of TPN have only been described in experimental studies $(8,9,22)$. In clinical studies the addition of glutamine or alanine-glutamine dipeptide resulted in a significant improvement of nitrogen balance after major surgery $(11,12)$. It was suggested that the addition of glutamine counteracts the decrease in muscle protein synthesis. However, $50-75 \%$ of the improvement of nitrogen balance during glutamine enriched TPN can be explained by the increase of free glutamine concentrations in muscle and other tissues (23). The effects of glutamine supplementation on overall net protein retention are therefore small. However, the modest beneficial effects of glutamine supplementation on villous height found in this study requires only minute quantities of protein retention, hardly large enough to be detected by overall body nitrogen balance. Importantly the effect on gut morphology coincides with impor- 
tant functional characteristics, i.e. preservation of mucosal integrity. These findings provide insight in the mechanisms underlying the beneficial effects of supplementation of TPN with glutamine on microbial colonization in patients undergoing bone marrow transplantation (10).

In conclusion this study suggests a beneficial effect of glutamine addition in TPN in preventing deterioration of gut integrity and mucosal architecture. 
1. Lo C.W., and W.A. Walker. Changes in the gastrointestinal tract during enteral or parenteral feeding. Nutrition Reviews 1989;47:193-198.

2. Guedon G., J. Schmitz, E. Lerebours, et al. Decreased brush border hydrolase activities without gross morphologic changes in human intestinal mucosa after prolonged total parenteral nutrition of adults. Gastroenterology 1986;90:373-378.

3. Menzies I.S., M.F. Laker, R. Pounder, et al. Abnorma intestinal permeability to sugars in villous atrophy. Lancet 1979:2:1107-1109.

4. Souba W.W., V.S. Klimbers, D.A. Plumley, et al. The role of glutamine in maintaining a healthy gut and supporting the metabolic response to injury and infection. Journal of Surgical Research 1990;48:383-391.

5. Wilmore D.W., R.J. Smith, S.T. O'Dwyer, D.O. Jacobs, T.R. Ziegler, and X.-D. Wang. The gut: a central organ after surgical stress. Surgery 1988; 104:917-923.

6. Khan K., G. Hardy, B. Mcelroy, and M. Elia. The stability of L-glutamine in total parenteral nutrition solutions. Clincial Nutrition 1991:10:193-198.

7. Adibi S.A., W. Fekl, P. Fürst, and M. Oehmke (ed). Dipeptides as new substrates in nutrition therapy. München Karger, 1987.

8. Tamada H., R. Nezu, I. Imamura, et al. The dipeptide alanyl-glutamine prevents intestinal mucosal atrophy in parenterally fed rats. Journal of Parenteral and Enteral Nutrition 1992;16:110-116.

9. O'Dwyer S.T., R.J. Smith, T.L. Hwang, and D.W. Wilmore. Maintenance of small bowel mucosa with glutamine-enriched parenteral nutrition. Journal of Parenteral and Enteral Nutrition 1989;13:579-585.

10. Ziegler T.R., L.S. Young. K. Benfell, et al. Clinical and metabolic efficacy of glutamine-supplemented parenteral nutrition after bone marrow transplantation. Annals of Internal Medicine 1992;116:821-828.

11. Stehle P.. J. Zander, N. Mertes, et al. Effect of parenteral glutamine peptide supplements on muscle glutamine loss and nitrogen balance after major surgery. Lancet 1989;1:231-233.

12. Hammarqvist F., J. Wernerman, R. All, A. von der Decken, and $E$. Vinnars. Addition of glutamine to total parenteral nutrition after elective abdominal surgery spares free glutamine in muscle, counteracts the fall in muscle protein synthesis, and improves nitrogen balance. Annals of Surgery 1989:209:455-461.

13. van Eijk H.M., M.A. van der Heijden, C.L. van Berlo, and P.B. Soeters. Fully automated liquid-chromatographic determination of amino acids. Clinical Chemistry 1988;34:2510-2513.
14. Shippee R.L., A.A. Johnson, W.G. Cioffi, J. Lasko, T.E. LeVoyer, and 8.S. Jordan. Simultaneous determination of lactulose and mannitol in urine of burn patients by gas-liquid chromatography. Clinical Chemistry 1992;38:343-345.

15. Eberts T., R. Sample, M. Glick, and H. Ellis. A simplified colorimetric micromethod for xylose in serum or urine with phloroglucinol. Clinical Chemistry 1979;25:1440-1443.

16. Norusis M.J. (ed) SPSS/PC+ V3.1 Base manual for the IBM PC/XT/AT and PS/2. SPSS Chicago, 1988.

17. Hollander $D$. The intestinal permeability barrier Scandinavian Journal of Gastroenterology 1992;27:721-726.

18. Epstein M.D. J.I. Tchervenkov, J.W. Alexander, J.R. Johnson, and J.W. Vester. Increased gut permeability following burn trauma. Archives of Surgery 1991;126:198-200.

19. Burke D.J., J.C. Alverdy, E. Aoys, and G.S. Moss. Glutamine-supplemented total parenteral nutrition improves gut immune function. Archives of Surgery 1989;124:1396-1399.

20. Windmueller H.G. Glutamine utilization by the small intestine. Advances in Enzymology 1982;53:201-237.

21. Newsholme E.A, and M. Parry-Billings. Properties of glutamine release from muscle and its importance for the immune system. Journal of Parenteral and Enteral Nutrition 1990;14:63S-67S.

22. Rombeau J.L. A review of the effects of glutamineenriched diets on experimentaliy induced enterocolitis. Journal of Parenteral and Enteral Nutrition 1990;14:1005-105S.

23. Walser M. Misinterpretation of nitrogen balances when glutamine stores fall or are replenished. American Journal of Clinical Nutrition 1991:53:13371338. 
2

3

4

5

6

Chapter 7

8

9

$F$ 
The role of parenteral glutamine

administration in gut immune function 


\section{Abstract}

Introduction: Total parenteral nutrition (TPN) is reported to be associated with atrophy of the intestinal mucosa, depletion of intestinal immune cells and increased gut permeability. In man addition of glutamine (GLN) to TPN solutions has been shown to preserve villous height and mucosal integrity by a mechanism which is not yet elucidated. The intestinal immune cells situated between the enterocytes (intra-epithelial lymphocytes = IEL) have been demonstrated in vitro to influence mucosal barrier function. In addition, in rats glutamine preserves the number of $\lg A$ producing plasma cells. To obtain insight in the underlying mechanism of the effect of GLN on gut barrier function we investigated the effect of glutamine supplementation to parenteral nutrition on the number of IgA producing plasma cells, intra-epithelial lymphocytes, Goblet cells and enterocyte proliferation in intestinal biopsies.

Patients and Methods: Twenty patients ran-domly received GLN enri-ched TPN (GT) or isonitrogenous stand-ard TPN (ST). Proliferative activity and number of immune cells were measured in intestinal biopsies obtained before and after 10 days of TPN.

Results: No change in enterocyte proliferative activity or in number of intestinal IgA plasma cells were observed in both TPN groups. Goblet cells increased in the ST group (per 100 enterocytes: $6.6 \pm 0.7$ preTPN, $8.9 \pm 0.8$ postTPN, $p<0.05$ ) whereas the change seen in the GT group did not reach significance $(6.1 \pm 0.7$ preTPN, $8.5 \pm 0.9$ postTPN). in the GT group IEL decrea-sed (per 100 enterocytes: $30 \pm 3$ preTPN, $22 \pm 3$ postTPN, $p<0.05$ ), whereas in the ST group no change in the number of IEL was observed $(23 \pm 2$ preTPN, $24 \pm 3$ postTPN).

Conclusions: TPN was not associated with changes in proliferative activity nor with depletion of gut immune cells. The observation that the number of IEL's in the GT group decrease whereas the number of these cells do not decrease in the ST group during TPN suggests that the immune system is less activated in the glutamine supplemented group. Some support for this hypothesis comes from the observation that there was a small increase in the number of Goblet cells in the ST group whereas the increase of these cells in the GT group was not significant. Because activation of intestinal immune cells may increase intestinal permeability, decreased intestinal immune cell activation could be a possible explanation for the preserving effect of glutamine on intestinal permeability. 
The gastrointestinal mucosa has an important function in preventing translocation of microbial products to the portal circulation (1). The association between diminished barrier function and increased translocation of bacteria and endotoxins has been reviewed by Alexander et al (2). Diminished barrier function is claimed to play a key role in the pathogenesis of multiple organ failure $(3,4)$. Clear evidence supporting this hypothesis in patients is still lacking. The intestinal barrier is composed of several elements: the mucous layer, the epithelium with the tightly interconnected enterocytes, and the gut associated lymphoid tissue (GALT) (4).

An important role in maintaining an intact gut barrier is ascribed to the amino acid glutamine. Enterocytes as well as immune cells use glutamine as an energy yielding substrate $(5,6)$. A lack of glutamine was proposed to lead to deterioration of the epithelial function (1). Standard total parenteral nutrition (TPN) does not contain glutamine, because it is unstable in solution during prolonged storage. TPN leads to impairment of the epithelial barrier which becomes apparent after two weeks (7). Supplementation of the TPN solution with glutamine as a stable glycyl-glutamine dipeptide preserved the epithelial barrier and intestinal morphology (7).

The mechanism by which glutamine protects the epithelial barrier is unknown. First, a beneficial effect of glutamine on proliferative activity of enterocytes $(8,9)$ may be an important factor. Stimulation of proliferation may result in preservation of villous height and barrier function. Second, there is evidence suggesting that glutamine may operate via GALT because in rat studies it was shown that glutamine supplementation in TPN prevents depletion of secretory $\lg A$ and preserves the number of IgA plasma cells and lymphocytes in the intestinal mucosa $(10,11)$. A third possibility might be that glutamine augments host defense by enhancing antioxidant protection via preservation of glutathione (GSH) stores (12). In this way immune activation due to oxidative stress in the gut can be prevented $(13,14)$ and the production of cytokines which may increase intestinal permeability (14) is diminished.

In the patient group under study we have reported that glutamine addition to total parenteral nutrition preserved mucosal morphology and barrier function (7). Subsequently we developed hypotheses which we could test by analysis of the biopsies taken in the proximal small bowel before and after a 10 day course of TPN with or without addition of glutamine-dipeptide. We tried to identify distinct questions that could be addressed within the framework of this clinical study: 1) Does glutamine supplementation affect the proliferative activity in the crypt area of the intestine? 2) Does glutamine supplementation increase the number of GALT cells? 3) Are there indications that glutamine decreases local inflammatory activity ? To asses the first question proliferative activity was measured by means of PCNA (proliferative cellular nuclear antigen) staining. The effect of glutamine on GALT was assessed by studing the number of IgA producing cells as a parameter of humoral immune function and the number of IEL as a parameter of cellular immunity. The number of Goblet cells was studied as an indicator of local inflammation (15). 


\section{Patients}

Patients (between 18 and 80 years) who did not tolerate enteral nutrition or were not allowed to be nourished enterally received total parenteral nutrition (TPN) and were randomly assigned to receive glutamine supplemented parenteral nutrition (GT) or standard parenteral nutrition (ST), after informed consent had been obtained. Patients with renal or liver failure, diabetes mellitus, ileus, congenital metabolic disorders, and patients who had received parenteral nutrition within 3 weeks prior to the study were excluded from the study. In addition, patients were excluded if their temperature was below 36.5 or above $38^{\circ} \mathrm{C}$, or if they suffered from intra-abdominal abscesses or respiratory or cardiac failure. The study was blinded to all patients and investigators except for the pharmacist. During TPN patients were allowed to drink a maximum of $500 \mathrm{ml}$ water or sugarfree tea per day. The study solutions contained identical amounts of calories and nitrogen. The GT group received the amino acid solution Glamin (Pharmacia, Erlangen, Germany) supplemented with the dipeptides glycyl-Ltyrosin and glycyl-L-glutamine. The ST group received the amino acid solution Vamin18 (Pharmacia, Erlangen, Germany). The Vamin-18 solution did not contain dipeptides.

\section{Investigative procedure}

Before and after the period of parenteral nutrition patients underwent a duodenoscopy after an overnight fast. Intestinal biopsies were taken from the second part of the duodenum at the level of the hepatopancreatic ampulla. At these time points venous blood was taken to measure hemoglobin, hematocrit, albumin, lymphocyte and leukocyte counts. Parenteral nutrition was administered during a period that lasting at least of 10 days and maximally 14 days. Biopsies were not obtained from healthy controls for ethical reasons. However, the data obtained in this study were comparable with the literature (16-20).

The study was approved by the Medical Ethical Committee of the University Hospital Maastricht.

\section{Intestinal histology}

Intestinal biopsies were immediately fixed either in ethanol (two specimens for determination of proliferative activity in the duodenal crypts) or in Bouin's solution (immunohistochemical staining of plasma cells, lymphocytes and Goblet cells in duodenal mucosa). Quantitative assessments were performed by one of the authors (RVDH) in coded sections prior to knowledge concerning the corresponding patients. Proliferating duodenal crypt cells were detected using immunostaining for proliferating cellular nuclear antigen (PCNA). Tissue sections were deparaffinized with xylol, washed with ethanol $100 \%$ and endogenous peroxidase activity blocked with $0.6 \%$ $\mathrm{H}_{2} \mathrm{O}_{2}$ in methanol for 15 minutes. Next, sections were incubated with target unmasking fluid (TUF, Monosan, The Netherlands) 10 minutes at $90^{\circ} \mathrm{C}$, washed with TRIS buffered saline (TBS, pH=7.6) and incubated with 1:300 diluted antibody to PCNA ( $P C 10$, Dako, The Netherlands) for 60 minutes at $37^{\circ} \mathrm{C}$ followed by washing in TBS and incubation with peroxidase labeled rabbit anti-mouse antibody 1:200 (P270, Dako, The Netherlands). Immunoreactivity was demonstrated using $\operatorname{DAB}(3,3$ 
diaminobenzidine D-5637, Sigma, St.Louis, MO) and sections were counterstained with hematoxylin-eosin. The PCNA labeling index was obtained by dividing the number of positive PCNA cells in crypts by the total number of enterocytes in the crypt multiplied with 100 (19). At least 10 well oriented longitudinal crypts were counted (corresponding to about 500 enterocytes).

For IgA and CD3 immunostaining, the same blocking and hydration procedure was used. Sections were incubated with an antibody to IgA (Rabbit anti-human IgA, A 408 Dako, The Netherlands), or an antibody to CD3 (Rabbit anti-human T-Cell CD3, A 452 Dako, The Netherlands) for 45 minutes at room temperature. After washing with TBS, peroxidase labeled swine anti-rabbit antibody (P217, Dako, The Netherlands) and DAB was applied. Plasma cells were counted in the lamina propria and expressed as the number of cells per high power field (11). At least 10 high power fields were counted. A correction was made for the surface of lamina propria using a transparent test grid overlay with a random dot design as described by Aherne (21). Quantitative measurement of CD3 positive cells in the epithelium (intra-epithelial lymphocytes = IEL) was obtained by counting lymphocytes present in relation with 1000 enterocytes (22). IEL presence was expressed as the number of lymphocytes counted per 100 enterocytes. Goblet cell percentage was assessed in the same way as IEL percentage (18).

\section{Calculations and statistics}

Data are presented as means \pm SEM. Levels of significance were set at $p<0.05$ unless stated otherwise. Group comparison for statistical significance was performed using the Mann-Whitney test between groups and with the Wilcoxon test within groups. Multiple regression analysis was used to assess whether the change in number of IEL during TPN was explained by intervention or due to differences at the beginning of the study. In this analysis the number of IEL after TPN was taken as dependent variable. The use of glutamine and the number of IEL before TPN were taken as independent variables. The difference in the number of cells before and after TPN necessary to obtain statistical differences was calculated for each different cell type considering a $90 \%$ power of achieving a significant result at the $5 \%$ level (23). The required difference was respectively for PCNA, IgA, IEL, and Goblet cells roughly $30 \%, 30 \%, 50 \%$, and $60 \%$ of the initial value. The statistical procedures were performed with a SPSS-PC+ software program (24).

7.3 Results

\section{Patients}

Twenty patients were included in the study. Patient characteristics are summarized in table 1 . Both groups had a similar proportion of patients with inflammatory bowel disease and neoplastic disease. The patients received $190 \pm 7 \mathrm{kJoule} / \mathrm{kg}$ body weight and $0.25 \pm 0.01 \mathrm{gram} \mathrm{N} / \mathrm{kg}$ bodyweight per day. The GT group received on average $0.23 \pm 0.01$ gram glutamine $/ \mathrm{kg}$ bodyweight per day. Patients received parenteral nutrition for a mean period of 12 days in both groups. No significant changes were observed in hemoglobin, hematocrit, albumin, leukocyte and lymphocyte counts in both groups (table 2). 


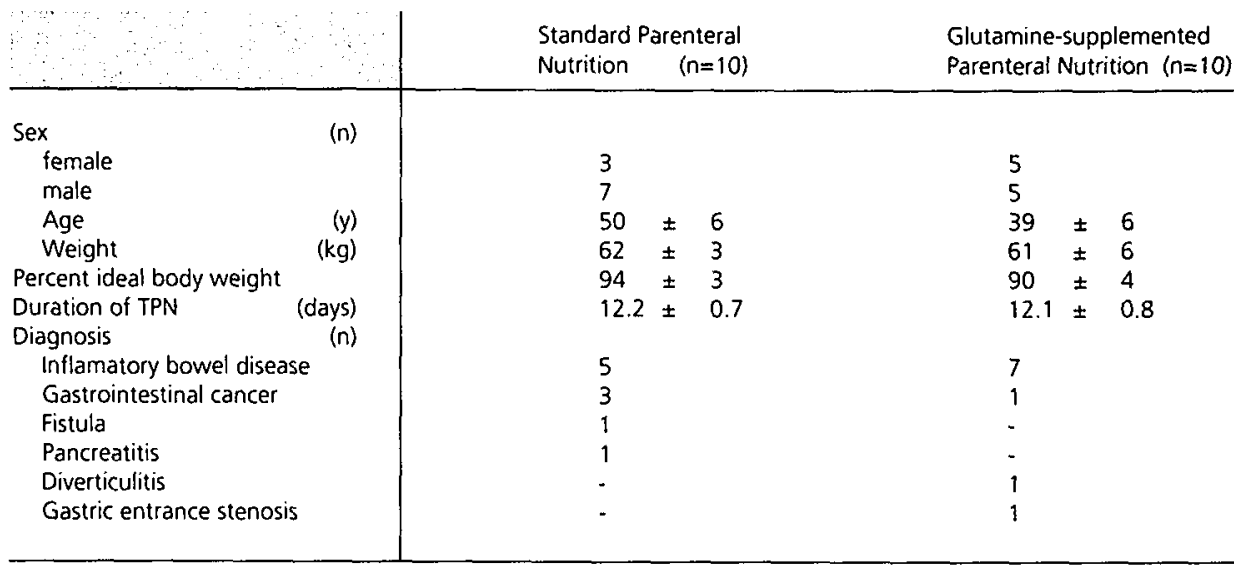

Table 1. Patients characteristics.

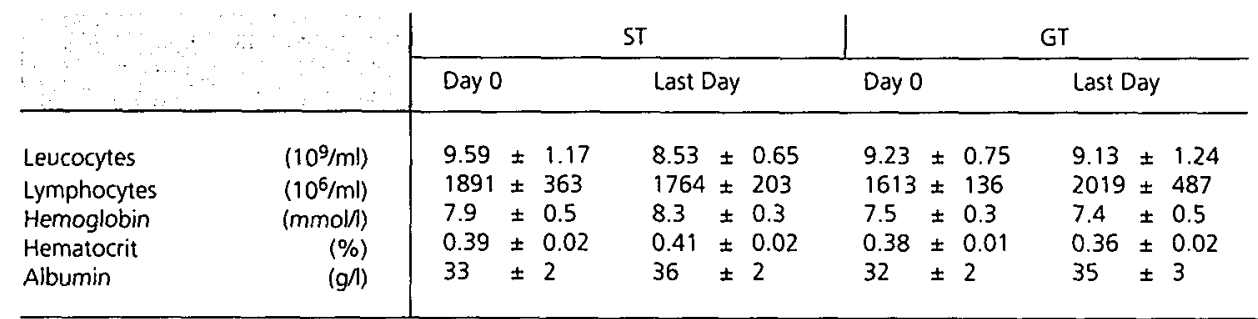

Table 2. Blood parameters in patients before and after two weeks of parenteral nutrition

\begin{tabular}{|c|c|c|c|c|c|c|c|c|c|c|}
\hline & $\because$ & IBD & $(n=$ & & $\mathrm{Ca}$ & $n=3$ & & $\operatorname{Re}($ & $=4$ ) & \\
\hline Iga & $\left(10^{9} / \mathrm{ml}\right)$ & 56 & \pm & 4 & 69 & \pm & 1 & 52 & \pm & 7 \\
\hline Goblet & (per 100 enterocytes) & 6 & \pm & 1 & 6 & \pm & 2 & 8 & \pm & 3 \\
\hline IEL & (per 100 enterocytes) & 27 & \pm & 2 & 22 & \pm & 8 & 28 & \pm & 6 \\
\hline PCNA & (LI) & 28 & \pm & 2 & 26 & \pm & 3 & 32 & \pm & 4 \\
\hline
\end{tabular}

Table 3. Number of IgA plasma cells, Goblet cells, intra-epithelial lymphocytes and labeling-index per diagnosis at day 0 .

$\mathrm{IBD}=$ inflammatory bowel disease, $\mathrm{Ca}=$ cancer, Re=remaining cases, HPF=high power field, LI=labeling index.

No statistical differences were found between patients with inflammatory bowel disease and the other patients (cancer and remaining cases together).

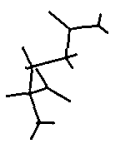




\section{Intestinal histology}

PCNA

The small number of patients in the different disease categories did not permit statistical analysis between all disease categories. Similar results were obtained for PCNA labeling index in patients with inflammatory bowel disease and the remaining categories (cancer and non-cancer together) (table 3). Comparison of the labeling index at the start of the study in the GT with the ST group showed that labeling index was slightly higher in the GT group compared to the ST group, although this was not significant $(p=0.09)$. During standard TPN no change in proliferative activity was observed. In addition, we were unable to show an effect of glutamine supplementation in parenteral nutrition on proliferative activity after two weeks of TPN (figure 1).

\section{IgA plasma cells}

There were no disease specific alterations in the number of IgA producing plasma cells in the lamina propria between the patients with inflammatory bowel disease and the remaining patients (table 3). The number of IgA plasma cells in the ST group was comparable to the number of IgA cells in the GT group at the start of the study. During a period of 10 days of standard TPN no change in the number of these cells in the lamina propria was observed (figure 2). Also, glutamine addition to parenteral nutrition did not have an effect on the number of IgA producing plasma cells.

\section{Intra-epithelial lymphocytes}

Counts of intra-epithelial cells (CD3 positive cells/100 enterocytes in villous epithelium) were similar between the patients with bowel inflammation and the remaining patients (table 3). At the start of the study the number of IEL's were lower in the ST group compared to the GT group ( $23 \pm 2$ vs $30 \pm 3, p<0.05$ ). During standard parenteral nutrition no change was observed in the number of IEL's. However, in the patient group supplemented with glutamine, a decrease of IEL's was observed $(p<0.05$, figure 3$)$. Multiple regression analysis showed that the number of IEL's after TPN was significantly influenced by the number of IEL's before start of the study $(p<0.01)$ and whether glutamine was given or not $(p<0.05)$. (IELafter=$11.7+8.03(\mathrm{G} \ln +/ \mathrm{G} \mid \mathrm{n}-)+0.85$ (IELbefore)). Therefore, the decrease in number of IEL in the GT group was independent of the difference in number of IEL at the start of the study.

\section{Goblet cells}

Patients with inflammation of the distal small bowel or large bowel did not show an increase in the number of Goblet cells in the proximal small bowel (table 3). The Goblet cell counts were comparable between the ST and GT group at the start of the study. During standard TPN an increase $(p<0.05)$ in the number of Goblet cells was observed, whereas in the glutamine supplemented group the increase in the number of Goblet cells did not become significant (figure 4). 

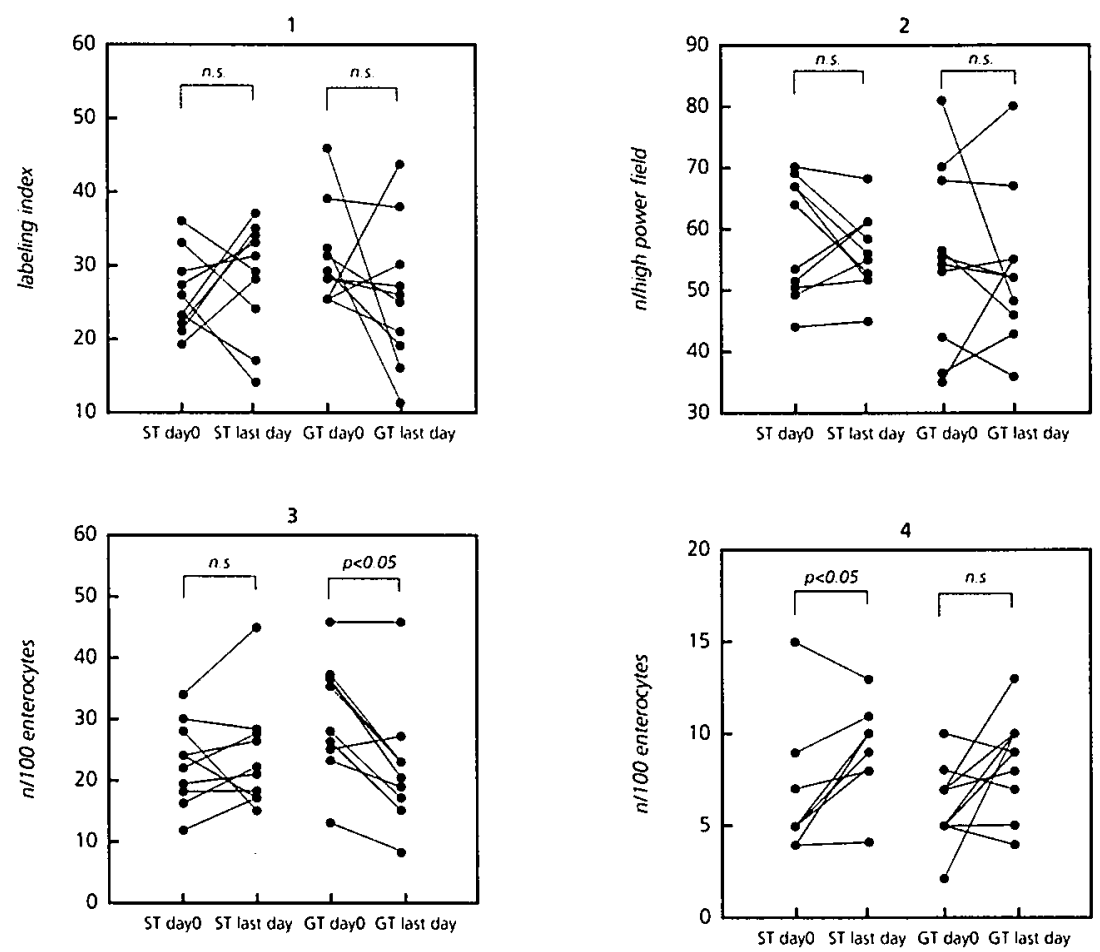

Figure 1. Proliferative activity in duodenal crypts.

The number of proliferating cells expressed as the PCNA labeling-index ((PCNA positive cells)/(PCNA positive + PCNA negative cells) $\times 100$ ) of both the ST and the GT group are given before and on the last day of parenteral nutrition. No change in PCNA labeling-index was observed during TPN with or without glutamine.

Figure 2. Number of plasma IgA cells in the lamina propria of duodenal mucosa.

The number of plasma cells staining for IgA of both the ST and GT gorup are given before and on the last day of parenteral nutrition. The number of IgA positive plasma cells are given per high power field. No change in the number of IgA plasma cells was observed.

Figure 3. Intra-epithelial lymphocytes in duodenal mucosa epithelium.

The number of IEL's of both the ST and GT group are given before and on the last day of parentera! nutrition. The number of IEL's per 100 enterocytes are given. No change in the number of intra-epithelial lymphocytes was observed after two weeks of TPN in the ST group. whereas the number of intra-epithelial lymphocytes decreased after two weeks of TPN in the GT group $(p<0.05)$.

Figure 4. The number of Goblet cells of both the ST and GT group are given before and on the last day of parenteral nutrition. The number of Goblet cells per 100 enterocytes are given. In the ST group the number of Goblet cells increased after two weeks of TPN $(p<0.05)$, whereas the number of Goblet cells did not change after two weeks of TPN in the GT group. 
Proliferation and immune cells

Since enterocyte proliferation can be stimulated by activated intestinal immune cells (25) we studied the relation between the number of immune cells and proliferation of enterocytes. The data show that an increased number of IEL's or Goblet cells was not significantly associated with increased proliferative activity (PCNA-IEL $r=0.36$ $p=0.15$, PCNA-Goblet $r=0.427, p=0.13$ ). On the contrary, the number of IgA plasma cells appeared to be negatively correlated to labeling-index $(r=-0.438, p=0.006)$.

\subsection{Discussion}

No change in intestinal proliferative activity was observed during a period of 10 days parenteral nutrition. In contrast, in rats fed parenterally, intestinal mucosa becomes hypoplastic and hypofunctional within 3 days (26). In patients, a small decrease of the duodenal villous height is observed after two weeks of TPN (7), whereas after 2-3 months changes are more pronounced (27). In this study we did not find an effect of glutamine supplementation in parenteral nutrition on enterocyte proliferation rate. This is in line with a study in rats in which it was observed that although glutamine supplemented TPN compared to standard TPN had a beneficial effect on villous height it did not have a consistent effect on cell birth rate (26). This suggests that glutamine supplemented TPN prolongs the life time of the existing cells in the gut, but does not promote the proliferation of enterocytes (26). The exact mechanism by which glutamine prolongs cell life is speculative. A possible mechanism could be augmentation of antioxidant protection by glutathion, thus increasing life time of enterocytes (12).

Depletion of gut associated immune cells during standard TPN was not demonstrated in this study in contrast to the observations in animal experiments (11). No changes in IgA plasma cells were observed in the ST and GT group. On the contrary, an increase of Goblet cells was observed. The studies in animals, however, substantially differ from the present study. The major difference is that patients are diseased and nutritionally depleted at the start of the study in contrast to the animals used in the experimental studies. The results of this study are therefore not necessarily in contradiction with the results of the animal experiments. It is hypothesized that as a result of increased permeability in diseased (28), nutritionally depleted (29), and TPN receiving patients (7), bacterial chemotactic peptides traverse the gut barrier and activate the gut associated immune cells. As a consequence of this a decrease in number of immune cells due to TPN may be counter balanced by the opposing sequestration of immune cells. In addition, increased colonization observed in patients receiving standard TPN (30) may activate immune cells (31). The depleting effect of TPN on the number of IgA cells and IEL's may thus be overwhelmed by immune activation. Some support for this hypothesis comes from the observation that there was a small increase in the number of of Goblet cells in the ST group. An increase in Goblet cells has been claimed to reflect local irritation of the intestine (15).

Glutamine addition to TPN did have a different effect on the number of immune cells in the gut compared to standard TPN during the two week period of TPN. A decrease 

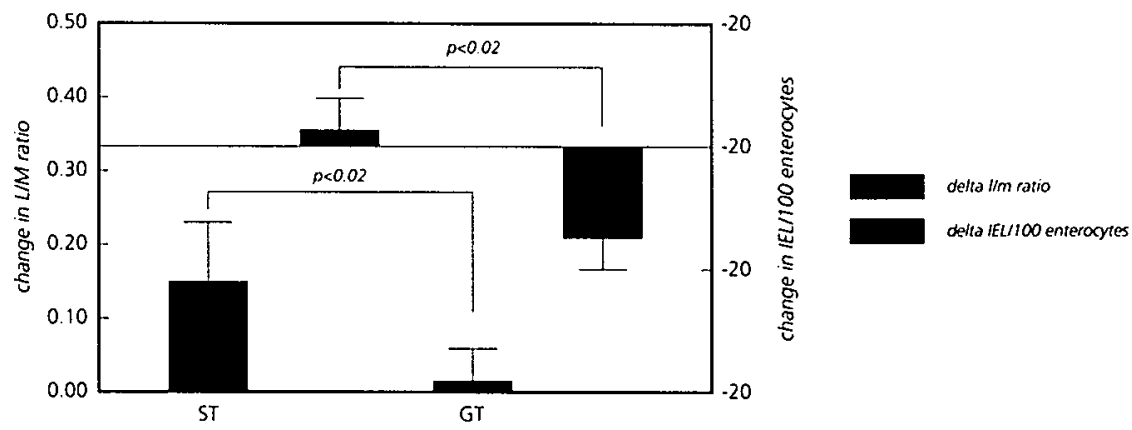

\footnotetext{
Figure 5. Relation between IEL and permeability in patients receiving TPN with or without glutamine.

On the left $Y$-axis and in black bars the absolute changes in permeability (measured with the lactulose/mannitol sugar test $=\mathrm{LM}$ ratio) in the two patient groups (7). On the right $Y$-axis and striped bars absolute changes in the number of IEL in these patients. An increase in permeability was associated with an unaltered number of IEL's, whereas no change in permeability was associated with a decrease in IEL's.
}

of IEL's was observed in the GT group in contrast to no change in the standard TPN group, and the number of Goblet cells increased significantly only in the standard TPN group. These observations suggest that in the glutamine supplemented group less immune activation in the gut occurs. It is interesting to relate a decreased immune activation in the gut to the protecting effect of glutamine on intestinal permeability and villous height $(7,32)$. One of the causes of increased permeability may be the loosening of tight junctions (33). Tight junctions connect adjacent epithelial cells in the zona occludens (34). In disease the zona occludens sealing function can be severely altered. Several factors may contribute to the opening of the tight junctions, but an important regulatory role appears to be reserved for the immune cells in the gut (13). Polymorphonuclear neutrophils have a dramatic effect on the resistance of the zona occludens, possibly by the production of oxygen radicals (35). The IEL's are thought to play a central role by the production of IFN- $\gamma(14)$. This opens tight junctions, but also activates the production of oxygen radicals by neutrophils and macrophages $(13,14)$. Increased permeability caused by immune activation will subsequently enhance immune activation due to increased translocation of bacterial products creating a vicious circle. In our study IEL and permeability were not directly correlated, but increased permeability in the standard TPN group was associated with an unaltered number of IEL, whereas unaltered permeability in the glutamine supplemented group was associated with a decrease of IEL's. Figure 5 depicts the relation between the changes in IEL and permeability (data from 7). The augmentation of antioxidant protection by glutamine (12) may decrease local immune activation. It is hypothesized that this prevents increased permeability caused by oxygen radicals produced by activated immune cells. The vicious circle may be interrupted in this way. 
In conclusion, in humans it was impossible to demonstrate a clearcut effect of TPN on the number of intestinal immune cells. The data indicate that TPN and the absence of enteral nutrition activates the intestinal immune system and that this is prevented by glutamine supplemented parenteral nutrition. This could be an explanation for the beneficial effect of glutamine on villous height and intestinal barrier function. 
1. Wilmore D.W., R.J. Smith, S.T. O'Dwyer, D.O. Jacobs, T.R. Ziegler, and X.-D. Wang. The gut: a central organ after surgical stress. Surgery 1988;104:917-923.

2. Alexander J.W., S.T. Boyce., G.F. Babcock, et al. The process of microbial translocation. Annals of Surgery $1990 ; 212: 496-512$

3. Carrico K., and J.L. Meakins. Multiple organ failure syndrome. Archives of Surgery 1986;121:196-208.

4. Wells C.L., M.A. Maddaus, and R.L. Simmons. Poposed mechanisms for the translocation of intestinal bacteria. Reviews of Infectious Diseases 1989:10:958-979.

5. Windmueller H.G., and A.E. Spaeth. Respiratory fuels and nitrogen metabolism in vivo in small intestine of fed rats. The Journal of Biological Chemistry 1980;255:107-113.

6. Newsholme E.A., B. Crabtree, and M.S. Ardawi Glutamine metabolism in lymphocytes: its biochemical, physiological and clinical importance. Quarterly Journal of Experimental Physiology 1985:76:473-489.

7. van der Hulst R.R., B.K. van Kreel, M.F. von Meyenfeldt, et al. Glutamine and the preservation of gut integrity. Lancet 1993:334:1363-1365.

8. Ferguson $\mathbf{A}$. The immune system and mucosal transformation-historical perspective. Digestion 1990;46S;255-261.

9. Scheppach W., C. Loges, P. Bartram, et al. Effect of free glutamine and alanyl-glutamine dipeptide on mucosal proliferation of the human ileum and colon. Gastroenterology 1994;107:429-434.

10. Burke D.J., J.C. Alverdy, E. Aoys, and G.S. Moss. Glutamine-supplemented total parenteral nutrition improves gut immune function. Archives of Surgery $1989 ; 124: 1396-1399$.

11. Alverdy J.A., E. Aoys, P. Weiss-Carrington, and D.A. Burke. The effect of glutamine-enriched TPN on gut immune cellularity, Journal of Surgical Research 1992:52:34-38

12. Harward T.R., D. Coe, W.W. Souba, N. Klingman, and J.M. Seeger. Glutamine preserves gut glutathione levels during intestinal ischemia/reperfusion. Journal of Surgical Research 1994:56:351-355.

13. Helton W.S. Editorial: The pathophysiologic significance of alterations in intestinal permeability induced by total parenteral nutrition and glutamine. Journal of Parenteral and Enteral Nutrition 1994;18:289-290.

14. Kaoutzani P., S.P. Colgan, K.L. Cepek, et al. Reconstitution of cultured intestinal epithelial monolayers with a mucosal-derived T lymphocyte cell line. The Journal of Clinical Investigation 1994:94:788796.
15. Keren D.F., H.L. Elliott, B.D. Brown, and J.H. Yardley. Atrophy of villi with hypertrophy and hyperplasia of Paneth cells in isolated (Thiry-Vella) ileal loops in rabbits. Gastroenterology 1975;68:83-87.

16. Arranz E., J. Bode, K. Kingstone, and A. Ferguson. Intestinal antibody of coeliac disease: association with $\gamma / \delta$ T cell receptor expression by intra-epithelial lymphocytes, and other indices of potential coeliac disease. Gut 1994:35:476-482.

17. Chandra R.K., and M. Wadhwa. Nutritional modulation of intestinal mucosal immunity. Immunological Investigations 1989;18:119-126.

18. Lev R., E. Thomas, F.F. Parl, and C.S. Pitchumoni. Pathological and histomorphometric study of the effects of alcohol on the human duodenum. Digestion 1980;20:207-213.

19. Sarraf C.E., C.S. McCormick, G.R. Brown, et al. Proliferating cell nuclear antigen immunolocalization in gastro-intestinal epithelia. Digestion 1991:50:8591.

20. Domagala W., K. Marlicz, D. Bielicki, and M. Osborn. Increased PCNAVcyclin index correlates with severity of duodenitis defined by histological criteria. Virchows Archives A Pathology. Anatomy and Histopathology 1993:422:345-349.

21. Aherne W.A., and M.S. Dunnil. Morphometry. Edward Arnold Publish Ltd. London, 1982

22. Mitchison H.C., H.A. Mardini, S. Gillespie, M. Laker, A Zaitoun, and C.O. Record. A pilot study of fluticasone propionate in untreated coeliac patients. Gut 1991;32:260-265.

23. Kirkwood B.K. (ed). Essentials of medical statistics. Oxford Blackwell scientific publications, 1988.

24. Norusis M.J. (ed). SPSS/PC+ V3.1 Base manual for the I8M PC/XT/AT and PS/2. SPSS Chicago, 1988.

25. Brandtzaeg P., T.S. Halstensen, K. Kett, et al. Immunobiology and immunopathology of human gut mucosa: humoral immunity and intra-epithelial lymphocytes. Gastroenterology 1989;97:1562-1584.

26. Platell C., R. McCauley, R. McCulloch, and J. Hall. The influence of parenteral glutamine and branched chain amino acids on total parenteral nutrition-induced atrophy of the gut. Journal of Parenteral and Enteral Nutrition 1993;17:348-354.

27. Pironi L., G.M. Paganelli, M. Miglioli, et al. Morphologic and cytoproliferative patterns of duodenal mucosa in two patients after long-term total parenteral nutrition: changes with oral refeeding and relation to intestinal resection. Journal of Parenteral and Enteral Nutrition 1994:18:351-354. 
28. Harris C.E., R.D. Griffiths, N. Freestone, D. Billington, S.T. Atherton, and R.R. Macmillan. Intestinal permeability in the critically ill. Intensive Care Medicine 1992; 18:38-41.

29. Maxton D.G. J.S. Mensies, B. Slavin, and R.P. Thompson. Small-intestinal function during enteral feeding and starvation in man. Clinical Science 1989;77:401-406

30. Ziegler T.R., L.S. Young, K. Benfell, et al. Clinical and metabolic efficacy of glutamine-supplemented parenteral nutrition after bone marrow transplantation. Annals of Internal Medicine 1992;116:821-828.

31. Crabbé P.A., H. Bazin, H. Eyssen, et al. The normal microbial flora as a major stimulus for proliferation of plasma cells synthesizing $\lg A$ in the gut. International Archives of Allergy 1968:34:362-375.

32. Li J., B. Langkamp-Henken, K. Suzuki, and L.H. Stahlgren. Glutamine prevents parenteral nutritioninduced increases in intestinal permeability. Journal of Parenteral and Enteral Nutrition 1994:18:303-307.

33. Travis S., and I. Menzies. Intestinal permeability: functional assessment and significance. Clinical Science 1992;82:471-488.

34. Madara J.L. Loosening tight junctions. The Journal of Clinical Investigation 1989;83:1089-1094.

35. von Ritter C., M.B. Grisham, M. Hollwarth, W. Inauen, and D.N. Granger. Neutrophil-derived oxidants mediate formyl-methionyl-leucyl-phenylalanine-induced increases in mucosal permeability in rats. Gastroenterology 1989;97:778-780. 
2

3

4

5

6

7

Chapter 8

9

$y^{2}$ 


\section{General discussion}




\subsection{General Discussion}

The amino acid glutamine has received much attention because it is an important substrate for cells of the immune system and the gut. In animal experiments it was shown that a lack of glutamine may lead to deterioration of immune and gut function (1). Although glutamine is traditionally a non-essential amino acid, mainly produced by muscle tissue, metabolic stress is associated with a decreased plasma glutamine concentration (2). The old observation that nutritional depletion is an important determinant of patient outcome after surgical or medical intervention (3) led us to formulate the following hypothesis. Nutritional depletion results in reduction of muscle mass and/or changes in intermediary glutamine metabolism, leading to diminished glutamine production capacity. This will result in diminished glutamine availability and thus deterioration of immune and gut function. Part of this hypothesis was investigated in this thesis: the effect of nutritional depletion on the gut and the role of glutamine.

In the first two studies we observed a decrease in plasma glutamine concentration in nutritionally depleted patients. We showed that glutamine is extracted by the proximal human gut at a high rate. In addition, this extraction is dependent on the plasma glutamine concentration. Nutritional depletion therefore is associated with diminished glutamine extraction by the gut.

In the subsequent studies we found that depletion was associated with decreased mucosa glutamine levels and morphological and functional changes in the intestinal mucosa. Compared to glutamine free parenteral nutrition, glutamine containing parenteral nutrition increased mucosa glutamine concentration and preserved intestinal morphology and function.

A problem in the interpretation of the data obtained in the studies described, is the heterogeneity of the patient groups. In the studies in which nutritional depletion was related to certain parameters in the gut mucosa, we therefore tried to find whether these parameters were influenced by the type of disease. Although disease in general influenced the parameters measured, specific effects of the type of disease were not observed. For instance, all patients had a higher intestinal permeability compared to controls but there was no difference in permeability between the different patient categories. In addition, the distribution of the disease categories, and disease activity were equal between the nutritionally depleted and non-depleted patients. This allowed us to conclude that the differences observed between the depleted and non-depleted patient groups were caused by the nutritional status. In the intervention studies, the distribution of disease categories, and disease activity were also comparable. Therefore, the observed differences were attributed to the type of intervention.

Another problem concerned the definition of nutritional depletion. Generally accepted parameters assessing nutritional depletion, such as protein concentrations in blood plasma have been shown to be influenced by the presence of disease (4). $A$ recent study performed in surgical patients showed that the percentage of ideal body weight (PIB) was an independent determinant of the postoperative complication risk (4). Therefore, we initially used PIB as the parameter for nutritional depletion. As the original hypothesis in this thesis was that the loss of muscle mass would result in decreased glutamine production capacity we used the bioimpedance tech- 
nique to obtain information regarding body composition as soon as this technique became available. Except for the first patients in whom we were not able to measure body composition, the percentage of ideal fat-free mass (PIFFM) was chosen to be the primary parameter for nutritional depletion. To avoid misinterpretations, most of the crucial results in this thesis are also related separately to PIB and PIFFM.

Bearing in mind these restrictions, the initial hypothesis that nutritional depletion results in diminished glutamine availability and consequently deterioration of gut function was confirmed in the studies described in this thesis.

\section{The future}

Although parts of the hypothesis have been solved, there remain parts that require further investigation. In addition, new questions have risen.

A question that remains to be answered is: what is the cause of reduced plasma glutamine levels observed in metabolic stress and nutritional depletion? Is it simply a reduction of muscle mass resulting in diminished glutamine production capacity or are there complex changes in intermediary metabolism preventing upregulation of glutamine production in situations where this is needed? To solve this question muscle glutamine metabolism has to be investigated in relation to muscle protein metabolism, and whole body glutamine metabolism. If indeed muscle mass appears to be a determinant of glutamine production capacity, simple bed-side methods assessing the amount of muscle mass in a patient have to be developed.

One of the conclusions in this thesis is that exogenous supply of glutamine has a beneficial effect on the human gut. The mechanism, however, by which glutamine has its effect on the gut remains largely unknown. Several potential mechanisms have been postulated. First, glutamine may have a stimulating effect on mucosal protein synthesis e.g. proteins necessary for the formation of tight junctions (5). In addition, glutamine may serve as a regulator of the spontaneous life span of proteins (6). Glutamine may have its effect through the immune cells in the gut (7). Intestinal bloodflow may be stimulated by glutamine (8). The production of glutathione, a radical scavenger, may be preserved by glutamine (9), and finally, glutamine could serve as a secretagogue, stimulating the elaboration of peptide hormones such as glucagon, exerting stimulatory effects on the mucosa. (10). Further research must give answers to the relative contributions of each of these and other mechanisms of action.

Another question which should be addressed in the near future is the route by which glutamine should be given. Obviously, a patient that can be fed enterally should not receive parenteral nutrition. Enteral nutrition can prevent gut starvation by itself. Glutamine enrichment of enteral nutrition which naturally contains a substantial amount of glutamine is therefore theoretically less likely to have the same effect compared to parenteral nutrition supplemented with glutamine. Nevertheless, some animal studies report beneficial effects of enrichment of enteral nutrition with glutamine $(11,12)$. It is important to notice that these studies were performed in severely stressed animals. It is possible that during severe stress a lack of glutamine develops in spite of the natural amount of glutamine present in enteral nutrition. From the studies in this thesis we conclude that the indication for the administration 
of glutamine supplemented parenteral nutrition seems to be the nutritionally depleted patient, who is metabolically stressed, and who is in need of parenteral nutrition. However, other patient groups may also benefit from the administration of glutamine. Clinical evidence for a beneficial effect of parenteral glutamine administration has been demonstrated in two studies in cancer patients who underwent bone marrow transplantation. In one study a decrease of clinical infections and hospital stay was observed in patients who received glutamine enriched parenteral nutrition (13). In another study in cancer patients hospital stay was reduced (14). Another study did not confirm these results, but this study was performed in a small group of patients (15). Another indication for glutamine administration could be in the patient with a short bowel syndrome. The administration of glutamine, growth hormone, and oral nutrition in patients with short bowel syndrome was shown to improve absorption of protein and carbohydrate $(16,17)$. Furthermore, $40 \%$ of the patients could discontinue their total parenteral nutrition. The results are very promising, although the contribution of the different aspects of the treatment regimen on outcome must be evaluated. In addition, these studies were uncontrolled necessitating further confirmation. Other possible treatment indications are specific intestinal diseases such as chemotherapy or radiotherapy induced enterocolitis. Animal experiments have demonstrated protective effects of glutamine administration in experimentally induced enterocolitis $(18,19)$. However, at this moment clinical data are not yet available.

A final question that remains to be settled is whether the relation between depletion, glutamine and the immune system is comparable to the relation depletion, glutamine and the gut. To answer this question simple and valid methods, which can measure an effect of nutritional depletion on immune function, must be developed. 
1. Payne-James J.J., and G.K. Grimble. The present status of glutamine. Current Opinion in Gastroenterology 1995;11:161-167.

2. Parry-Billings M., R.J. Baigrie, P.M. Lamont, P.J. Morris, and E.A. Newsholme. Effects of major and minor surgery on plasma glutamine and cytokine levels. Archives of Surgery 1992;127:1237-1240.

3. Studley H.O. Percentage of weight loss. A basic indicator fo surgical risk in patients with chronic peptic ulcer. Journal of the American Medical Association $1936 ; 106: 458-460$.

4. Meijerink W.J. Perioperative nutrition in gi cancer patients. Thesis. University of Limburg. The Netherlands, 1992.

5. Higashiguchi T., P-O. Hasselgren, K. Wagner, and J.E. Fischer. Effect of glutamine on protein synthesis in isolated intestinal eptihelial cells. Journal of Parenteral and Enteral Nutrition. 1993;17:307-314.

6. Robinson A.B, and L.R. Robinson. Distribution of glutamine and asparaginine residues and their near neighbors in peptides and proteins. Proceedings of the National Acadamy of Science USA 1991;88:88808884 .

7. Calder P.C. Glutamine and the immune system. Clinical Nutrition 1994;13:2-8.

8. Flynn W.J., F.R. Gosche, and N. Garrison. Intestinal blood flow is restored with glutamine or glucose suffusion after hemorrhage. Journal of Surgical Research 1992:52:499-504.

9. Harward T.R., D. Coe, W.W. Souba, N. Klingman, and J.M. Seeger. Glutamine preserves gut glutathione levels during intestinal ischemia/reperfusion. Journal of Surgical Research 1994;56:351-355.

10. Li S., M.S. Nussbaum, D.W. McFadden, et al. Addition of L-Glutamine to total parenteral nutrition and its effects on portal insulin and glucagon and the development of hepatic steatosis in rats. Journal of Surgical Research 1990;48:421-426.

11. Gianotti L., J.W. Alexander, R.F. Gennari, T. Pyles, and G.F. Babcock. Oral glutamine decreases bacterial translocation and improves survival in experimental gut-origin sepsis. Journal of Parenteral and Enteral Nutrition 1995:19:69-74.

12. Gennari R., J.W. Alexander, and T. Eaves-Pyles. Effect of different combinations of dietary additives on bac. terial translocation and survival in gut-derived sepsis. Journal of Parenteral and Enteral Nutrition 1995;19:319-325.

13. Ziegler T.R., L.S. Young. K. Benfell, et al. Clinical and metabolic efficacy of glutamine-supplemented parenteral nutrition after bone marrow transplantation. Annals of Internal Medicine 1992:116:821-828.
14. Schloerb P.R., and M. Amare. Total parenteral nutrition with glutamine in bone marrow transplantation and other clinical applications (a randomized, double blind study). Journal of Parenteral and Enteral Nutrition 1993:17:407-413.

15 van Zaanen H.C., H. van der Lelie, J.G. Timmer, P. Fürst, and H.P. Sauerwein. Parenteral glutamine dipeptide supplementation does not ameliorate chemotherapy-induced toxicity. Cancer 1994; 74:2879-2884.

16. Byrne T.A., T.B. Morrissey, T.V. Nattakom, T.R. Ziegler, and D.W. Wilmore. Growth hormone, glutamine, and a modified diet enhance nutrient absorption in patients with severe short bowel syndrome. Journal of Parenteral and Enteral Nutrition 1995;19:296-302.

17. Byrne T.A., R.L. Persinger, L.S. Young, T.R. Ziegler, and D.W. Wilmore. A new treatment for patients with short-bowel syndrome: growth hormone, glutamine. and a modified diet. Annals of Surgery 1995;222:243255.

18. Klimberg V.S., W.W. Souba, D.J. Dolson et al. Prophylactic glutamine protects the intestinal mucosa from radiation injury. Cancer 1990;66:62-68.

19. Rombeau J.L. A review of the effects of glutamineenriched diets on experimentally induced enterocolitis. Journal of Parenteral and Enteral Nutrition 1990;145:100S-105S. 
2

3

4

5

6

7

8

Chapter 9 


\section{Summary and conclusions}


During catabolic illness the plasma concentration of the amino acid glutamine decreases. Glutamine is a preferential fuel for rapidly dividing cells such as the cells of the immune system and the enterocytes. On the one hand there is an increased mobilization of glutamine most likely to satisfy increased demands by the immune system and fibrocytes involved in wound healing. On the other hand nutritional depletion may have resulted in decreased muscle mass. Because muscle is the main glutamine producing tissue, this will result in a decreased glutamine production capacity. In addition, these patients often receive glutamine-free parenteral nutrition, which may in turn accelerate glutamine depletion. A decreased supply of glutamine may result in a breakdown of the intestinal barrier and/or diminished immune functioning. In this thesis the effect of nutritional depletion on the gut, and the role of glutamine is investigated.

In the first study in this thesis (chapter 2) the extraction of glutamine by the gut was studied. This study was the first in man to investigate the isolated extraction of glutamine by parts of the gut. Extraction of glutamine largely takes place in the proximal part of the small intestine and seems to be dependent on the plasma concentration. Although in this study changes during the pre and postoperative state in glutamine extraction were not studied, decreased plasma levels may be the reason why intestinal glutamine extraction is diminished after surgery. In addition, plasma glutamine concentrations were lower in nutritionally depleted patients compared to non-depleted patients, resulting in diminished gut utilization of glutamine during nutritional depletion. The intestinal degradation of glutamine to citrulline and arginine, an important regulator of immune function, may have important consequences for the immune system. The presence of cancer has long been suggested to play an important role in the development of glutamine depletion as malignant cells consume glutamine at a high rate. We could however, not demonstrate an increased extraction of glutamine by cancer containing colon compared to non-cancer containing colon.

In chapter 3 the effect of nutritional depletion on mucosal amino acid concentrations was studied. Nutritional depletion was associated with a decreased alanine and glutamine concentration in the mucosa. This was explained by a decrease in plasma glutamine level which results in decreased extraction of glutamine (chapter 2).

In the subsequent study (chapter 4) the effect of nutritional depletion and thus diminished glutamine extraction on gut function and histology was studied. Intestinal permeability was assessed using dual sugar probes. In all patients permeability was increased compared to healthy controls. h, nutritional depletion aggravated the degree of permeability. In addition, nutritional depletion resulted in decreased villous height. Nutritional depletion did not have an effect the number of immune cells in the gut.

From these studies it was concluded that nutritional depletion results in diminished glutamine uptake and subsequently leads to a deterioration of intestinal function and morphology. The next studies were therefore designed to test whether the administration of exogenous parenteral glutamine(peptide) would preserve intestinal glutamine concentration, gut function and gut morphology. In chapter 5 the effect of standard parenteral nutrition and glutamine enriched parenteral nutrition on gut 
amino acid concentration was compared. Parenteral nutrition did not result in a decrease of mucosa glutamine in spite of the lack of glutamine in the solution. Parenteral nutrition supplemented with glutamine increased glutamine concentration in the mucosa. This effect was obtained only in depleted patients receiving glutamine enriched parenteral nutrition. From this study it was concluded that parenteral nutrition enriched with glutamine increases mucosal glutamine content mainly in depleted patients, and as a consequence that only depleted patients may benefit from glutamine supplementation.

In chapter 6 the effect of glutamine supplementation in parenteral nutrition on gut morphology and integrity was studied. Compared to standard parenteral nutrition, glutamine supplementation had a beneficial effect on gut permeability and morphology.

To assess whether glutamine has an effect on immune function in the gut, mucosal immune cells were quantified in the last study (chapter 7). From this study it was suggested that glutamine prevents immune activation in the gut. A connection between changes in intra-epithelial lymphocytes and gut permeability was suggested, confirming in vitro studies in which it was shown that the intra-epithelial lymphocytes play an important role in the regulation of gut permeability.

In general the main conclusions from the studies in this thesis are:

1) Nutritional depletion is associated with diminished plasma and mucosa glutamine concentration.

2) Diminished plasma glutamine concentration results in diminished extraction of glutamine by the gut.

3) Nutritional depletion is associated with morphological and functional changes of the gut.

4) The administration of glutamine in parenteral nutrition increases glutamine concentration in the gut probably by increasing plasma glutamine concentration.

5) The administration of glutamine in parenteral nutrition preserves gut permeability and morphology.

6) The administration of glutamine in parenteral nutrition is suggested to decrease immune activation in the gut.

7) Tentatively, permeability is associated with the presence of intra-epithelial lymphocytes, and IgA producing plasma cells in the gut. 


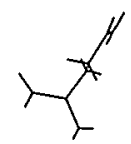


Metabole stress, zoals die optreedt na chirurgie, leidt bij patiënten tot een daling van de plasma-concentratie van het aminozuur glutamine. Glutamine is een belangrijke brandstof voor snel delende cellen, zoals de cellen van het immuunapparaat en van de darm. Tijdens metabole stress neemt de netto produktie van glutamine toe door het spierweefsel, het belangrijkste glutamine producerende orgaan. Men veronderstelt dat tijdens metabole stress een verhoogde glutamine produktie nodig is om aan het toegenomen gebruik van glutamine door het immuunsysteem tegemoet te komen. Men denkt dat patiënten die in een goede voedingstoestand verkeren over het algemeen voldoende glutamine produktie capaciteit hebben, terwijl de glutamine produktie tekort schiet bij patiënten die in een "slechte voedingstoestand" verkeren. Deze laatste groep patiënten wordt depleet genoemd. Depletie heeft de oude term "ondervoeding" vervangen omdat het gewichtsverlies niet alleen door een verminderde voedselinname veroorzaakt wordt, zoals de term ondervoeding suggereert, maar ook door de metabole veranderingen die optreden bij ziekte. Enerzijds leidt depletie tot een afname van de hoeveelheid spiermassa, hetgeen zou kunnen resulteren in een verminderde glutamine produktie-capaciteit. Anderzijds kunnen de veranderingen in het intermediair metabolisme, die geassocieerd zijn met depletie, resulteren in een verminderde glutamine produktie. Een factor die bovendien een rol speelt bij het ontwikkelen van een glutamine tekort bij deplete patiënten is het gegeven dat deze patiënten vaak gevoed worden middels parenterale voeding, die geen glutamine bevat. Een combinatie van metabole stress, depletie, en/of parenterale voeding kan dus een glutamine tekort veroorzaken. Doordat in deze situatie de cellen van het immuunapparaat en de darm te weinig glutamine tot hun beschikking hebben kunnen de darmbarrière functie en/of immuun functie verstoord raken. In dit proefschrift zijn de gevolgen van depletie voor de darm en de rol, die glutamine hierbij speelt, onderzocht.

In de eerste studie in dit proefschrift (hoofdstuk 2) werd de extractie van glutamine door de darm bestudeerd. Voor het eerst werd bij de mens de glutamine extractie in geïsoleerde delen van de darm onderzocht. Ondanks het feit dat het technisch niet mogelijk was de bloed-doorstroming te meten, leverde de studie een aantal belangrijke bevindingen op. Glutamine extractie vindt voornamelijk plaats in de proximale dunne darm en is afhankelijk van de plasma glutamine concentratie. Deze bevinding verklaart waarom de glutamine opname door de darm direkt postoperatief afgenomen is: de plasma glutamine concentratie is dan immers verlaagd. Uit de studie bleek voorts dat de plasma glutamine concentratie in deplete patiënten lager is dan in niet deplete patiënten. Hiermee werd aangetoond dat de opname van glutamine door de darm bij deplete patiënten afgenomen moet zijn. Verder bleek dat glutamine in de darm gemetaboliseerd wordt tot citrulline en arginine, een belangrijke regulator van de immuunfunctie. Het glutamine metabolisme in de darm kan daarom belangrijke consequenties voor het immuunsysteem hebben. Eén van de oorzaken van een glutamine tekort is toegeschreven aan het aanwezig zijn van kanker. Kankercellen zouden ten behoeve van hun snelle deling veel glutamine als brandstof gebruiken. De glutamine extractie door tumor bevattende darm bleek in onze studie echter niet hoger dan die van niet tumor bevattende darm, waarbij wij aannamen dat de bloed-doorstroming door tumor bevattende darm niet veel hoger 
is dan die van niet tumor bevattende darm.

In hoofdstuk 3 werd het effect van depletie op de aminozuur concentratie in de darmmucosa bestudeerd. Depletie bleek geassocieerd te zijn met een afname van de alanine en glutamine concentraties in de mucosa. Dit werd verklaard door een afname van de plasma glutamine concentratie welke resulteert in een verminderde extractie van glutamine (hoofdstuk 2).

In de daaropvolgende studie (hoofdstuk 4) werd het effect van depletie en daarmee verminderde glutamine extractie op de darmfunctie en histologie in de darm onderzocht. Intestinale permeabiliteit werd bestudeerd met behulp van de lactulose/mannitol test. Bij alle patiënten was de permeabiliteit vergeleken met een controle groep verhoogd. Depletie resulteerde in een verdere toename van de intestinale permeabiliteit. Ook werd een afname van villushoogte gezien tijdens depletie. Er werd geen effect van depletie op aantal immuuncellen in de darm gevonden.

Uit deze eerste hoofdstukken werd geconcludeerd dat depletie resulteert in een verminderde opname van glutamine door de darm. Dit tekort aan glutamine in de darm leidt vervolgens tot verstoring van de darmbarrière functie en van de mucosa morfologie. De volgende studies waren erop gericht te onderzoeken of het toedienen van parenterale voeding verrijkt met glutamine(-peptide) een gunstig effect heeft op de intestinale glutamine concentratie, darmfunctie en morfologie. In hoofdstuk 5 werd het effect van parenterale voeding met of zonder glutamine op de concentraties van aminozuren in de darmmucosa bestudeerd. Standaard parenterale voeding leidde niet tot een afname van de mucosa glutamine concentratie, ondanks het ontbreken van glutamine in deze oplossing. Parenterale voeding, met glutamine gesuppleerd, leidde tot een verhoging van de glutamine concentratie in de mucosa. Dit effect werd alleen waargenomen in de deplete patiëntengroep. Geconcludeerd werd dat bij deplete patiënten, tijdens de toediening van parenterale voeding verrijkt met glutamine, de mucosa glutamine concentratie sterker stijgt dan bij de toediening van standaard parenterale voeding. Een gunstig effect van glutamine suppletie mag daarom alleen in een deplete patiëntengroep verwacht worden.

In hoofdstuk 6 werd het effect van parenterale voeding, met of zonder glutamine toevoeging, op de darmmorfologie en permeabiliteit onderzocht. Het bleek dat parenterale voeding gesuppleerd met glutamine een gunstig effect heeft op de darmmorfologie en permeabiliteit vergeleken met standaard parenterale voeding.

Het effect van glutamine op de intestinale immuunfunctie werd in het laatste hoofdstuk bestudeerd. Door het tellen van de immuuncellen in de darm werd een indruk over immuunactivatie verkregen bij patiënten die al dan niet glutamine in de parenterale voeding toegediend kregen (hoofdstuk 7). Er werden aanwijzingen gevonden, dat glutamine immuunactivatie in de darm kan voorkómen. Ook bestonden er aanwijzingen, dat er een verband bestaat tussen het aantal intra-epitheliale lymfocyten en intestinale permeabiliteit. Dit is een bevestiging van in vitro studies, waaruit blijkt dat intra-epitheliale lymfocyten een belangrijke rol spelen bij de regulatie van intestinale permeabiliteit. 
De algemene conclusies van dit proefschrift zijn:

1) Depletie is geassocieerd met een verminderde plasma en mucosa glutamine concentratie.

2) Daling van de glutamine concentratie in het plasma leidt tot verminderde glutamine extractie door de darm.

3) Depletie is geassocieerd met morfologische en functionele veranderingen in de darm.

4) Parenterale voeding gesuppleerd met glutamine, verhoogt de glutamine concentratie in de darm, middels verhoging van de plasma glutamine concentratie bij deplete patiënten.

5) Parenterale voeding met glutamine voorkomt een toename van de intestinale permeabiliteit en een verlies van de normale mucosa architectuur.

6) Er bestaan aanwijzingen dat de toediening van parenterale voeding met glutamine immuun activatie in de darm vermindert.

7) Intestinale permeabiliteit lijkt gerelateerd aan het aanwezig zijn van intraepitheliale lymfocyten, en IgA producerende plasma cellen in de darm. 



\section{Dankwoord}

Dokter, zegt $U$ eens eerlijk, zei hij met een stem waarin een mengsel van hoop en onzekerheid te horen was, heb ik er zelf wat aan? Ondanks het feit dat ik als geen ander het belang van onderzoek, zeker dit onderzoek, inzie, heb ik er toch moeite mee. Niet omdat het onderzoek zo belastend is, want belastend is het. Nee, niet daarom. Mogelijk speelt het een ondergeschikte rol, maar het is zeker niet de belangrijkste reden. Ik denk dat het komt omdat ik moeite heb iets te vragen zonder er direct iets voor terug te kunnen doen. Het gevoel met lege handen op een verjaardagspartijtje te komen, omdat je toevallig een vriend bezoekt en vergeten was dat hij net jarig is geweest. Niet direct, zei ik, maar $U$ helpt er wel andere patiënten mee in de toekomst. $U$ doet zoveel voor mij, zei hij, laat ik het maar doen. Wat doen wij dan voor $U$ dacht ik, zonder het te zeggen. Jazeker, wij behandelen $U$, Uw kwaal, en dat doen we zo goed als we kunnen, maar daarvoor bent $U$ verzekerd. Daarvoor hoeft $U$ niets terug te doen, het is ons vak, onze plicht, zoals de AH verplicht is zijn schappen op tijd te vullen. Of zou het Uw plicht zijn te participeren in wetenschappelijk onderzoek? Net zoals wij verplicht zijn wetenschappelijk onderzoek uit te voeren? Maar waarom laat ik $U$ dan kiezen? Daarmee schep ik, terwijl ik het weet, een neurotische relatie. Weet $U$ het zeker, fluisterde ik, daarmee hopend mijn schuldgevoel af te kunnen kopen. Ja, zei hij waar moet ik ondertekenen? Ik wees hem waar hij moest ondertekenen en groette hem. Ik hoop dat ik niet gelogen heb. Ik hoop dat hij en alle andere patiënten en vrijwilligers die de data in dit proefschrift hebben voortgebracht inderdaad toekomstige patiënten zullen helpen. Mijn dank aan hen.

Het feit dat ik je steeds vaker begrijp (denk ik), betekent dat ik 1 hoop van je geleerd heb. Peter Soeters, je hebt me, tijdens de uitvoering van het onderzoek en het opschrijven van de resultaten, door je overzicht geinspireerd en door je stimulerend vermogen geactiveerd. Bedankt.

Als je weer $1 \mathrm{~s}$ tijdens 1 van onze besprekingen met allerlei nieuwe plannen uit de kast kwam, wist ik soms niet waar ik moest beginnen. Ik werd er echter ook enorm door gemotiveerd. Vanaf het begin heb je me met je enthousiasme in positieve zin "besmet". Maarten von Meyenfeldt, bedankt.

Margriet Rouflart, ik wil je bedanken voor de manier waarop jij mij geleerd hebt klinisch onderzoek te verrichten. Niets aan het toeval overlaten. Veel belangrijker nog dan onderzoek is voor jou de kliniek, de patiënt. Voor de vele kennis en kunde die je me op het klinisch vlak hebt bijgebr8 ben ik je erg dankbaar. Janine Hoefnagels, jouw enthousiasme en opgewektheid waren altijd aanstekelijk. Ik wil je bedanken voor de berekeningen van het ideaalgewicht en de energetische behoefte van de patiënten. Janine en Margriet bedankt voor 4 jaar prettige samenwerking. $1 \mathrm{k} \mathrm{mis} \mathrm{het}$ $f-$ hapje na de voedingsvisite.

Naast Janine ben ik Sandra en Marja van de afdeling diëtetiek erkentelijk voor de overname van de taken van Janine bij haar afwezigheid. Nel bedankt voor de uitleg die je me herhaalde malen hebt gegeven over de "body composition" metingen. Jeroen Meijerink bedankt voor de voorzet die jij gegeven hebt voor het onderzoek in dit proefschrift beschreven. 
Jolanda Elbers, Monique Schellinx, Annemiek Kok, Tertu Haring, Sylvia Heeneman en Britta Gerdts. velijk bedankt voor de tijd die jullie tijdens je studie hebben vrijgemaakt om allerlei hand en span diensten voor mij te verrichten.

Mick Deutz, met de eerste protocollen en abstracts ben ik heel wat keren bij je terug moeten komen met weer 1 nieuwe versie van 1 stuk. Ondanks het feit dat ik dat in het begin niet zo geweldig vond realiseer ik me dat ik hier veel van geleerd heb. Je kritische houding ten aanzien van vele aspecten van research waren altijd heel zinvol. Ook heb jij mij geholpen bij de interpretatie van de aminozuurdata. Hans van Eijk en Dennis Rooyakkers bedankt voor de aminozuuranalyses en de uitleg en assistentie bij de glucose en ammonia analyses. Ivo de Blaauw en Carlo Welters bedankt voor de glucoses en ammonias die jullie voor mij gedraaid hebben. Mieke Janssen en Gabrie ten Have bedankt voor de verwerking van de biopten voor de aminozuuranalyses.

Wim Buurman, jij hebt mij adviezen gegeven ten aanzien van de bestudering van immuuncellen in de darm. Het is jammer dat ik niet al die adviezen heb kunnen gebruiken, omdat ik niet meer voldoende materiaal ter beschikking had. Jouw kritische houding ten aanzien van de gevonden resultaten dwongen mij op zijn tijd te relativeren.

De vakgroep Algemene Heelkunde in Maastricht en, in het bijzonder, Prof.dr. G. Kootstra wil ik bedanken voor de mogelijkheid dat ik 4 jaar als researchassistent heb kunnen participeren in het voedingsteam. Ook dank aan de chirurgen en assistenten chirurgie die tijdens darmoperaties bloed "gesampled" hebben. Mijn waardering gaat uit naar de afdeling klinische chemie voor alle plasma, urine, en biopt bepalingen. Dit werd mogelijk door de intensieve samenwerking met Bernard van Kreel. Ook wil ik noemen: Loe, Simon, Marian, Serva en natuurlijk Mia. Dank gaat ook uit naar de afdeling pathologie. Zij boden mij de mogelijkheid histologische coupes te bekijken. In het bijzonder wil ik Jan-Willem Arends, Ton Tiebosch, en Eric Thunissen bedanken voor hun begeleiding hierbij. Margriet en Anniek wil ik bedanken voor het snijden van de coupes, en de hulp bij het kleuren van de coupes. Sjaak en Jan bedankt voor het inbedden en maken van paraffine blokjes van de darmbiopten. Frank Kubben bedankt voor je advies ten aanzien van de "proliferatie" kleuringen.

De afdeling klinische farmacologie wil ik bedanken voor het produceren van de parenterale voedingen. Speciaal wil ik noemen: Lidia Bongaers-Molenbroek en Marie Jose Kamm-Vrancken. Eugène Hardy bedankt voor de trial administratie en randomisatie en de nuttige bijdragen bij de protocol besprekingen.

De afdeling gatroenterologie ben ik dank verschuldigd vanwege het verrichten van de duodenoscopieën. Reinhold Stockbrügger, Robert-Jan Brummer, Maurice Russel, Wim Hameeteman, Bart van Hoek, Peter Houben en Roel Zeijen, bedankt. Ook dank aan de endoscopie afdeling voor de assistentie en de tijd die jullie altijd wisten vrij te maken. Maya, Liselotte, Ria, Daisy, Ber10, Lucie, Monique, Liesbeth, Andy, en Harry bedankt.

Bij de afdeling farmacologe mocht ik geregeld gebruik maken van de apparatuur om weer 1s de lengte van villi en crypten te meten. Jo de Mey en Gregorio Fazzi bedankt voor deze mogelijkheid en de uitleg hierbij. 
Het personeel van de afdelingen waar de studie patiënten gelegen hebben wil ik $\checkmark$ elijk bedanken. Met name het personeel van A5, B5, A4 en B4 bedankt voor jullie medewerking. Even 1s erkentelijk ben ik de medewerkers van de prikdienst voor de bloedafnames.

De firma Pharmacia bedankt voor de hulp bij het opzetten van protocollen, monitoring, analyse en verslaglegging van de studie. Tatjana Romanyk, Rob Bakx, Rob Bot, Bauke Buwalda velijk bedankt. Der Firma Pharmacia möchte ich herzlich danken für die Hilfe bei den Protokollvorbereitungen, dem Monitoring der Studie, der Analyse und der Beschreibung der Studie. Karl Daiß, Eva Biesel, Linda Jodozi, Lars Ekman und Klaus Langer: vielen dank! Ook voor de sponsoring van dit proefschrift wil ik de firma Pharmacia-Upjohn bedanken. Ook de overige sponsors bedankt: de Dr.Ir. van der Laar Stichting, Nutricia, ABBOT, Bard, Yakult en Glaxo-Welcome.

Arnold Ke * bedankt voor de statistische adviezen en hulp.

Ik wil de leden van de beoordelingscommissie, Hans Sauerwein, Hugo Heymans, Kenneth Fearon, Jan-Willem Arends en voorzitter Reinhold Stockbrügger, bedanken voor hun beoordeling van het manuscript.

Guus Vrencken, jij hebt er iets moois van gemaakt. Bedankt!

E* en Wilma bedankt voor jullie hulp bij de laatste loodjes die leiden tot de promotie. Karel, Bernadette, Wilma en Monique, de vele lunches die ik met jullie heb doorgebr8 tijdens de voedingsteamperiode waren erg voedzaam. Karel en Bernadette veel succes met het voortzetten van het onderzoek.

Jacqueline, Albert en Frank, bedankt voor jullie begrip, steun en het geregel.

Mijn vader en moeder wil ik bedanken voor de steun en het vertrouwen die zij altijd in mij gehad hebben. Bedankt ook voor de mogelijkheden die jullie me gegeven hebben.

Vrienden en familieleden waardeer ik voor de steun tijdens mijn remodelingsfase. Het spijt me dat ik jullie de laatste tijd wat verwaarloosd heb. Ik hoop dat er nu weer wat meer tijd voor jullie komt.

M.a.w. ieder1 bedankt!! 


\section{Curriculum vitae}

年 


\section{Curriculum vitae}

René Remmelt Willie Johan van der Hulst was born on June 3th, 1966 in Heerlen, The Netherlands. He graduated in 1984 from the "Rombouts-college" in Brunssum. He continued his study at the Medical Faculty of the University of Limburg. After receiving his doctoral degree in 1988 (cum laude), he received his medical degree in 1990 (cum laude). During his study he worked as a research assistant at the department of Human Genetics and as a paramedic on the emergency assistant team in Heerlen. From November 1990 he was a research fellow and member of the nutritional support team at the Academic Hospital Maastricht in the metabolic and nutrition research group of Prof. Dr. P.B. Soeters. For his work in chapter 6 he received the Schoemaker award 1994. From February 1995 he is in training as a surgical resident in the Academic Hospital Maastricht (Chairman Prof. Dr. G. Kootstra). 
De publicatie van dit proefschrift werd financieel mogelijk gemaakt door PharmaciaUpjohn. De studies in hoofdstuk 5, 6, en 7 werden eveneens gesponsord door Pharmacia-Upjohn. Overige financiele bijdrages waren afkomstig van de Dr.Ir.van der Laar stichting, Nutricia, ABBOT, Bard, Yakult en Glaxo-Welcome. 